\title{
The Design of an Optical Switch Based on Dinuclear Ruthenium Pentaammine Dicyanamide Complexes
}

\author{
by
}

Diane S. Jodoin, B.Sc.

A thesis submitted to the Faculty of Graduate and Postdoctoral Affairs in partial fulfillment of the requirements for the degree of

Master of Science

in

Chemistry

Carleton University

Ottawa, Ontario

(C) 2015, Diane S. Jodoin 


\begin{abstract}
A novel photochromic polymer (SP-PS) with a polystyrene (PS) backbone linked to spiropyran (SP) by alkyl chain was synthesized (4\% yield). Ultraviolet irradiation of SP-PS induces photoisomerization from SP to merocyanin (MC); back-reaction occurs thermally or by visible irradiation. SP-PS was characterized by ${ }^{1} \mathrm{H}-\mathrm{NMR}$ spectroscopy, differential scanning calorimetry and gel permeation chromatography. The $T_{g}$ and $M_{n}$ were determined to be $118.41{ }^{\circ} \mathrm{C}$ and $63,980 \mathrm{~g} / \mathrm{mol} \pm 1.731 \%(Đ=1.24)$, respectively. $\Phi_{365 \mathrm{~nm}}$ for SP-MC photoisomerization was 0.80 after $5 \mathrm{~s}$ (toluene). When SP-PS is combined with $\left[\left\{\mathrm{Ru}\left(\mathrm{NH}_{3}\right)_{5}\right\}_{2}(\mu\right.$-dicyd $\left.)\right]\left[\mathrm{BPh}_{4}\right]_{4}, \quad\left(\right.$ dicyd $^{2-}=$ dicyanamido benzene dianion), a near-infrared photoswitchable material results.

Interaction between $\mathrm{MC}$ and $\left[\left\{\mathrm{Ru}\left(\mathrm{NH}_{3}\right)_{5}\right\}_{2}(\mu\right.$-dicyd) $]\left[\mathrm{BPh}_{4}\right]_{4}$ was observed through comparison of MC-SP photoisomerization rates. Thin films of $\left[\left\{\mathrm{Ru}_{(\mathrm{NH}}\right)_{5}\right\}_{2}(\mu-$ dicyd)][$\left[\mathrm{BPh}_{4}\right]_{4}$ in polystyrene displayed unique photochemistry; $30 \mathrm{~s}$ of $523 \mathrm{~nm}$ irradiation by light-emitting diode reduced ligand-to-metal charge transfer band absorbance by $70 \%$ with $82 \%$ recovery after $46 \mathrm{~h}$. The mechanism of this effect remains to be determined.
\end{abstract}




\section{Acknowledgements}

First and foremost, I would like to thank Dr. Robert J. Crutchley for his wisdom, time and patience. You have been my mentor throughout my journey to becoming a scientist and have always been able to inspire me to strive for innovation in times where I thought it was not possible. I deeply grateful for your guidance and, without a doubt, I could not have done it without you.

I would like to thank NSERC and Carleton University for financial support.

To Keith Bourque and Tony O’Neill, thank you for sharing your knowledge and helping me throughout my time at Carleton. To Susa, Tanya, and Peter, thank you for your patience with me even when I come to the store at 4:25 PM; I appreciate the time you have spent helping me over the years. To Jim Logan, thank you for knowing everything every time I ask you anything! I can't express enough gratitude for your help even though I say it's the last time I will need it every time.

I am thankful for all members of the Crutchley lab (past and present), Fatemeh Habibagahi, Mahbub Choudhuri, Alex Daniels, Ben Jones and Carmen Harb. You have all made my journey a little bit more interesting (maybe too interesting sometimes) and I think I probably would have just gone insane without you. Fatemeh may argue that at times I was insane, but, it takes one to know one! Thank you, Fatemeh, for letting me be crazy and even joining me in it.

Thank you to my adoptive lab mates, Monica Gill and Sam Shields. Thanks for having an open lab door and an open ear. To Sam Shields, my lab partner-in-crime, I couldn't have done this without you. You make me a better person and chemist! 
To my friends who will probably never look at this and regret it every time they ask me what I do everyday, thank you for supporting me and helping me relieve some stress!

To my family, Mom, Dad, Camille and Aunt Ruth, you have inspired me and helped me every step of the way. I am so lucky to have a family that supports me unconditionally and believes in me when I fail to believe in myself. Thank you. 


\section{Table of Contents}

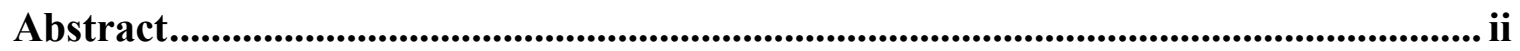

Acknowledgements .............................................................................................................................. iii

Table of Contents ..............................................................................................................

List of Tables ................................................................................................................................. viii

List of Figures............................................................................................................................... ix

List of Schemes....................................................................................................................... xiii

List of Abbreviations .............................................................................................................. xiv

List of Appendices.................................................................................................................. $\mathbf{x v}$

1 Chapter: Introduction ....................................................................................... 1

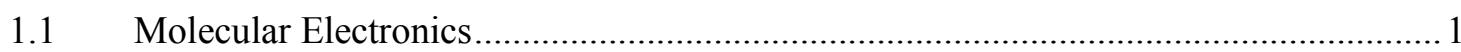

1.1.1 Charge Transfer in Ruthenium Dicyanamide Complexes...................................... 2

1.2 Polymers Based on Stimuli-Responsive Materials.................................................. 6

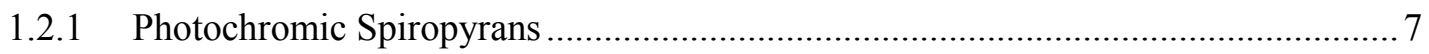

1.2.2 Photodynamic Materials Based on Spiropyran ................................................. 9

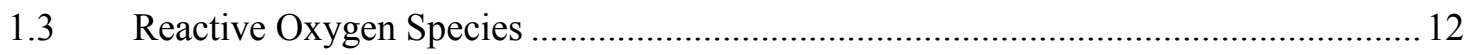

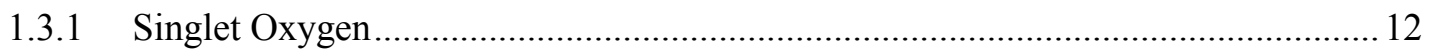

1.3.2 Properties of Singlet Molecular Oxygen .......................................................... 12

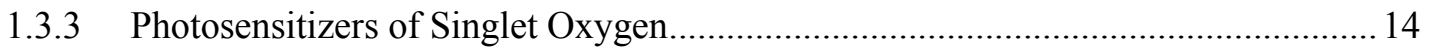

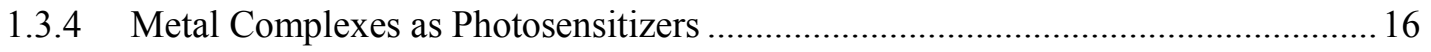

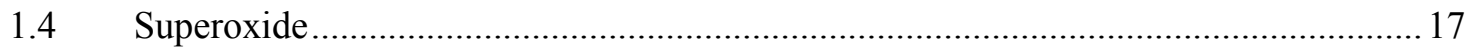

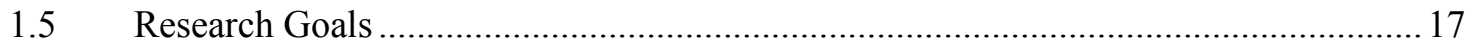

2 Chapter: Experimental.................................................................................................. 19

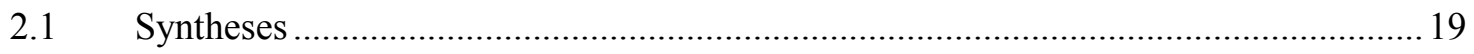




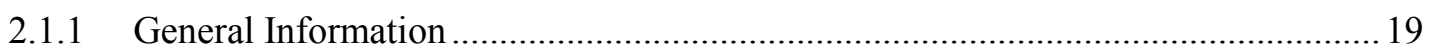

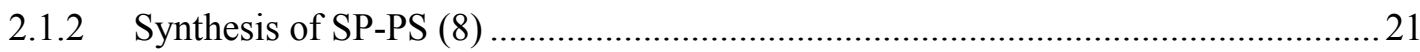

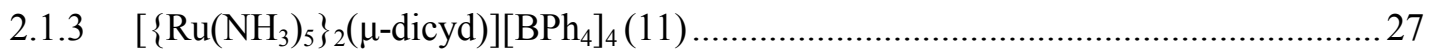

2.1.3.1 Alternative Complexes Used in Various Studies ..........................................2 27

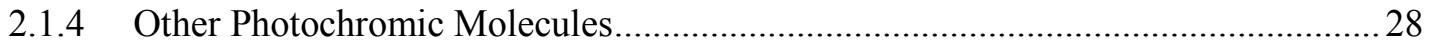

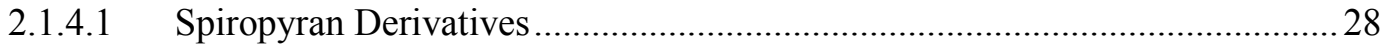

2.1.4.2 Donor-Acceptor Stenhouse Adduct (DASA) ...............................................29

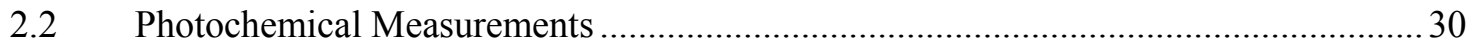

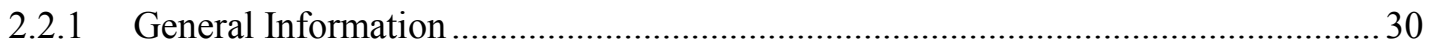

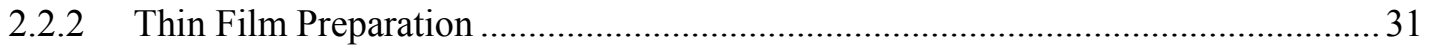

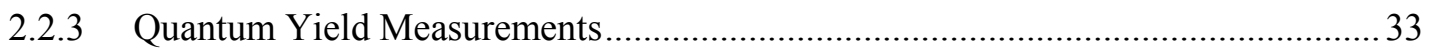

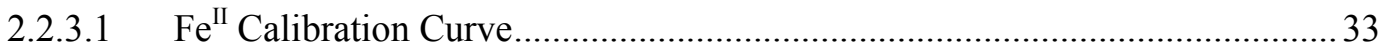

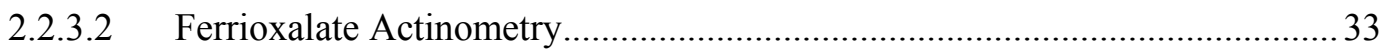

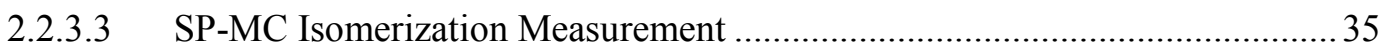

3 Chapter: Results and Discussion ................................................................................ 37

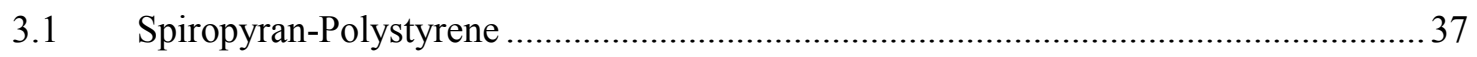

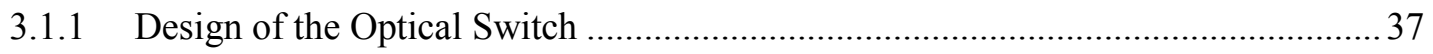

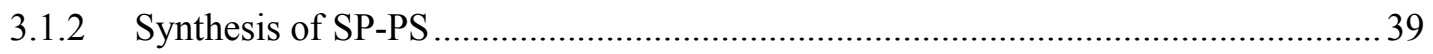

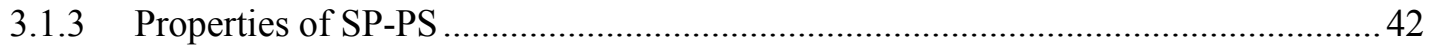

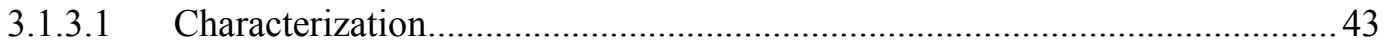

3.1.3.2 Quantum Yield of SP-PS Isomerization.................................................... 48

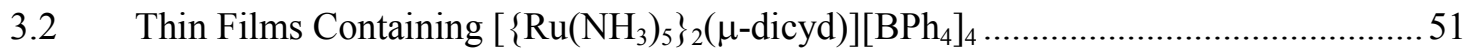

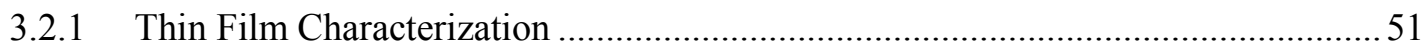

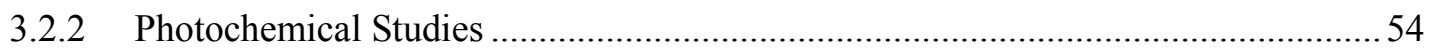

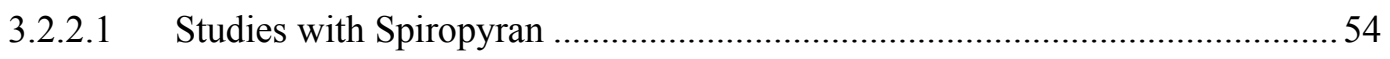




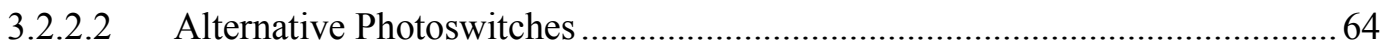

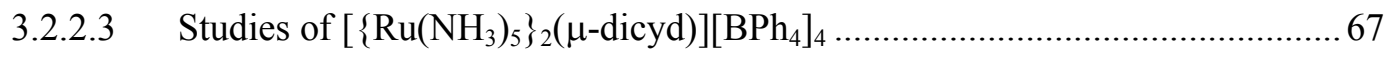

4 Chapter: Conclusions and Future Work .................................................................. 79

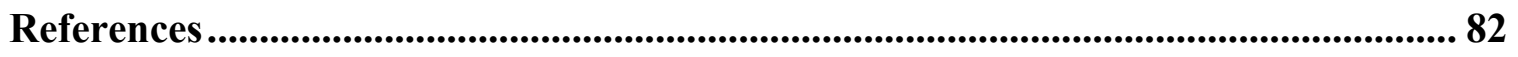

Appendices .............................................................................................................................. 85 


\section{List of Tables}

Table 1. Reduction potential of $\mathrm{O}_{2}(1 \mathrm{~atm})$ vs the normal hydrogen electrode in various solvents collected using cyclic voltammetry at $0.1 \mathrm{~V} / \mathrm{s}^{28}$

Table 2. Molar extinction coefficient of the LMCT band at peak wavelength of

$\left[\left\{\mathrm{Ru}\left(\mathrm{NH}_{3}\right)_{4}(\mathrm{py})\right\}_{2}(\mu\right.$-dicyd $\left.)\right]\left[\mathrm{PF}_{6}\right]_{4}$ in various solvents ${ }^{11}$ 65

Table 3. Change in the LMCT band $(1123 \mathrm{~nm})$ of 11 after irradiation by LED 72

Table 4. Additional LED information (*the royal blue LED was a Luxeon Rebel LED) 96

Table 5. T-test results of films undergoing optical reversibility 97

Table 6. T-test results of films undergoing thermal reversibility 97 


\section{List of Figures}

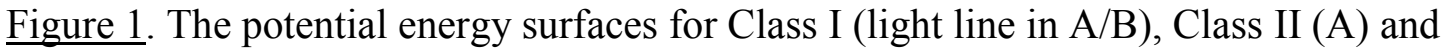
Class III (B) complexes, where $H$ is the coupling between metal centres, $\Delta \mathrm{G}_{\text {th }}$ is the energy barrier to thermal electron transfer, $\mathrm{E}_{\mathrm{IT}}$ is the energy of the intervalence charge transfer and $\Delta \mathrm{G}_{\mathrm{r}}$ ' is the free energy of resonance exchange per complex in the mixed valence system. ${ }^{6}$ (Reprinted with permission from J. Am. Chem. Soc., 1998, 120(50), 13096-13103. C2014 American Chemical Society.)......................................................... 3

Figure 2. Electron transfer between donor $(\mathrm{Ru}(\mathrm{II}))$ and acceptor $(\mathrm{Ru}(\mathrm{III}))$ metal centres through a bridging ligand (dicyd ${ }^{2-}$ ) in mixed-valence complexes by electron transfer (A)

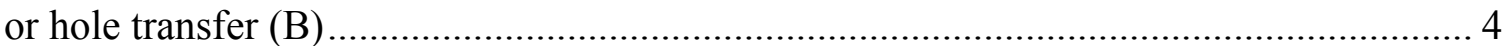

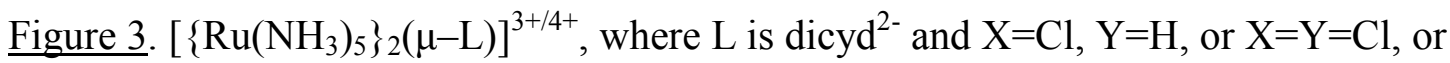

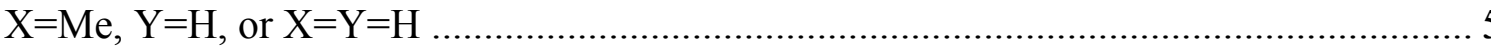

Figure 4. LMCT band intensity dependence on solvent donor number in $\left[\left\{\mathrm{Ru}\left(\mathrm{NH}_{3}\right)_{5}\right\}_{2}(\mu-\right.$ dicyd) $]\left[\mathrm{PF}_{6}\right]_{4} \cdot{ }^{6}$ (Reprinted with permission from J. Am. Chem. Soc., 1998, 120(50), 13096-13103. (C)2014 American Chemical Society.) ....................................................... 6

Figure 5. General structure of spiropyran or spiro[2H-1-benzopyran-2,2'-indoline] (BIPS)

Figure 6. Ring opening of SP to form the MC isomer in 6- $\mathrm{NO}_{2} \mathrm{BIPS}$, where $v_{1}$ is $365 \mathrm{~nm}$ and $v_{2}$ is $590 \mathrm{~nm}$

Figure 7. UV-Vis absorption spectrum of spiropyran (SP) and merocyanin (MC) (Figure duplicated with permission) ${ }^{13}$ 
Figure 8. Electron configurations of the ground and lowest excited energy states of

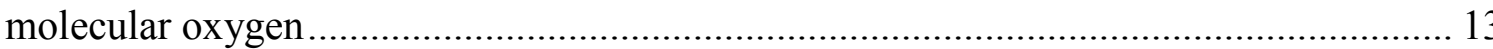

$\underline{\text { Figure 9. }}$ Transitions in molecular oxygen, blue lines representing absorption and red lines representing radiative energy release $\mathrm{e}^{21}$ 14

Figure 10. Hypothesized interaction of ammine ligands and SP 18

Figure 11. Instrumental setup for the quantum yield measurement: A) LED, B) standard star board LED mount, C) heat sink, D) DC power supply, E) buck puck DC driver, F) mounting apparatus for LED light source, G) neutral density filter (not used in this experiment), H) cuvette holder, I) quartz cuvette containing solution to be analyzed, J) detector and K) spectrophotometer light source. (Figure duplicated with permission) ${ }^{37} .35$ Figure 12. Structure of the monomer in SP-PS, mSP-PS 38 Figure 13. ${ }^{1} \mathrm{H}-\mathrm{NMR}$ spectrum of $\mathrm{mSP}-\mathrm{PS}(7)$ at $400 \mathrm{MHz}$ in $\mathrm{CDCl}_{3}$ between 8.0 and 5.1

ppm 43

Figure 14. ${ }^{1} \mathrm{H}-\mathrm{NMR}$ spectrum of SP-PS (8) at $400 \mathrm{MHz}$ in $\mathrm{CDCl}_{3}$

Figure 15. The detector response after separation of SP-PS by GPC as a function of elution time 47

Figure 16. DSC curve for SP-PS showing an inflection by at $118.41{ }^{\circ} \mathrm{C}$ 48

Figure 17. The quantum yield of SP-PS as a function of length of irradiation at $365 \mathrm{~nm} 50$ Figure 18. SEM images of a film of 11 and commercial polystyrene $\left(M_{w} 280,000\right)$ viewed through an edge in the center of the film (A) and the surface of the film at a shallow angle (B) 52

Figure 19. Film of SP-PS and 11 irradiated with an LED at $365 \mathrm{~nm}$ for $10 \mathrm{~s}(\mathrm{~A})$ and subsequently irradiated at $590 \mathrm{~nm}$ for five 1-minute increments (B) under argon 56 
Figure 20. Thin film of polystyrene and 11 irradiated with an LED at $365 \mathrm{~nm}$ for $10 \mathrm{~s}$ (A) and subsequently 5x60 s of visible light at $590 \mathrm{~nm}$ (B) all under argon with Next Day signifiying thermal relaxation in ambient atmosphere for one night.

Figure 21. Thin film of SP-PS and 11 (4.5:1 molar equivalents of monomer in SP-PS to 11) irradiated at $365 \mathrm{~nm}$ for $10 \mathrm{~s} \mathrm{(A)}$ and thermal relaxation of the film over time in ambient atmosphere (B) 60 Figure 22. The recovery of the LMCT band of 11 as a function of thermal relaxation time for a thin film of SP-PS and 11 in ambient atmosphere 61 Figure 23. Thin film of commercial polystyrene $(\mathrm{Mw} 280,000)$ and 11 after irradiation at $365 \mathrm{~nm}$ for $5 \mathrm{~s}(\mathrm{~A})$ and the thermal relaxation (R) of the film over time (B) in ambient atmosphere 62 Figure 24. The percentage change in absorbance of merocyanin at $590 \mathrm{~nm}$ due to (A) irradiation by an LED at $590 \mathrm{~nm}$ or (B) thermal relaxation, after irradiation at $365 \mathrm{~nm}$ for $5 \mathrm{~s}$ of films composed of commercial polystyrene $\left(\mathrm{M}_{\mathrm{w}} 280,000\right)$ and $6-\mathrm{NO}_{2} \mathrm{BIPS}$ with (blue) or without (red) complex 11. Smooth lines are fitted curves, while the data points are the data collected experimentally. 64

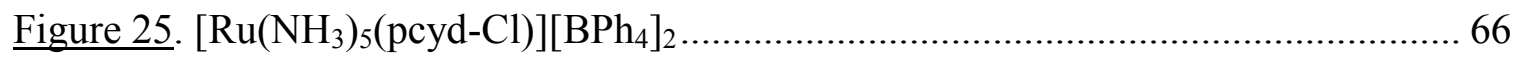

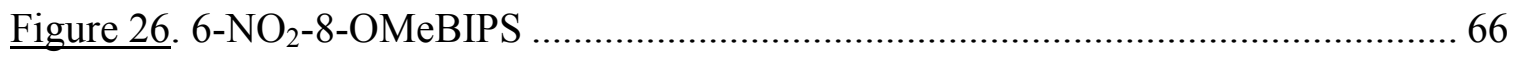

Figure 27. Thin film of 11 in polystyrene $\left(\mathrm{M}_{\mathrm{w}} 280,000\right)$ after $30 \mathrm{~s}$ of irradiation at 447.5 $\mathrm{nm}$ in ambient atmosphere (A) and thermal relaxation (B) 69 Figure 28. Thin film of 11 in polystyrene $\left(\mathrm{M}_{\mathrm{w}} 280,000\right)$ after $30 \mathrm{~s}$ of irradiation at $523 \mathrm{~nm}$ in ambient atmosphere (A) and thermal relaxation (B) 70 
Figure 29. Thin film of 11 in polystyrene $\left(M_{w} 280,000\right)$ after $30 \mathrm{~s}$ of irradiation at $590 \mathrm{~nm}$ in ambient atmosphere (A) and thermal relaxation (B) 71

Figure 30. Thin film of 11 in polystyrene $\left(\mathrm{M}_{\mathrm{w}} 2,500\right)$ after $30 \mathrm{~s}$ of irradiation at $523 \mathrm{~nm}$ in ambient atmosphere (A) and thermal relaxation (B) 73

Figure 31. Thin film of 11 in polystyrene $\left(M_{w} 280,000\right)$ after $30 \mathrm{~s}$ of irradiation at $523 \mathrm{~nm}$ under argon (A) and exposure to oxygen after relaxation under argon for 24 hours (B) .75 Figure 32. Hyposthesized mechanisms for the photoactivity and reversibility of $\left[\left\{\mathrm{Ru}\left(\mathrm{NH}_{3}\right)_{5}\right\}_{2}(\mu\right.$-dicyd) $]\left[\mathrm{BPh}_{4}\right]_{4}$ (where $\mathrm{C}$ is the complex, $\mathrm{C}^{*}$ is the complex excited state

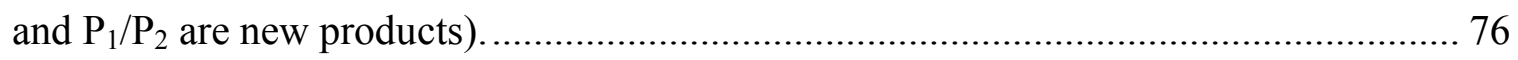

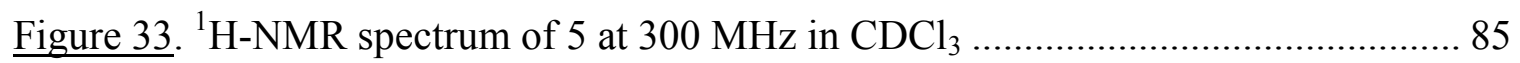

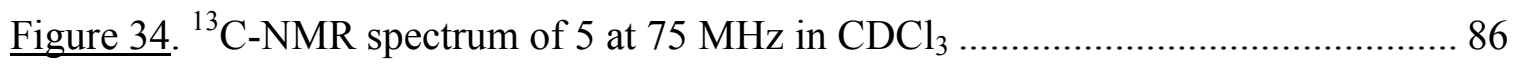

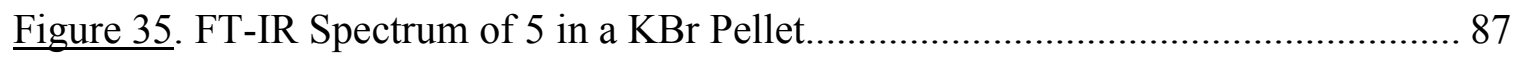

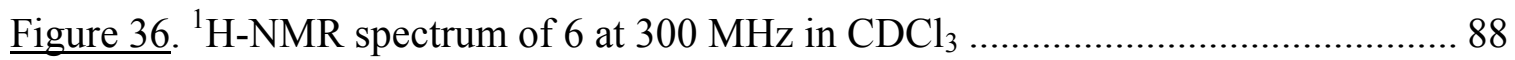

Figure 37. ${ }^{13} \mathrm{C}-\mathrm{NMR}$ spectrum of 6 in $\mathrm{CDCl}_{3}$ at $75 \mathrm{MHz}$, Carbons denoted by * are 18 ,

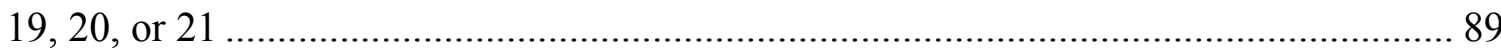

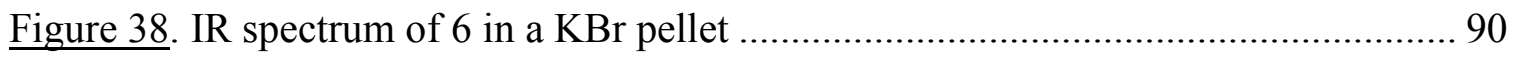

Figure 39. ${ }^{1} \mathrm{H}-\mathrm{NMR}$ spectrum of mSP-PS (7) at $400 \mathrm{MHz}$ in $\mathrm{CDCl}_{3}$......................... 91 Figure 40. ${ }^{1} \mathrm{H}-\mathrm{NMR}$ spectrum of mSP-PS (7) at $400 \mathrm{MHz}$ in $\mathrm{CDCl}_{3}$ between 8.0 and 5.1

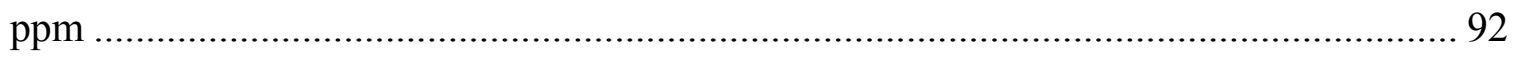

Figure 41. ${ }^{13} \mathrm{C}-\mathrm{NMR}$ spectrum of $\mathrm{mSP}-\mathrm{PS}(7)$ at $100 \mathrm{MHz}$ in $\mathrm{CDCl}_{3}$ (all peaks were not

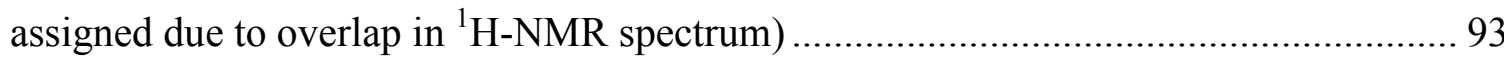

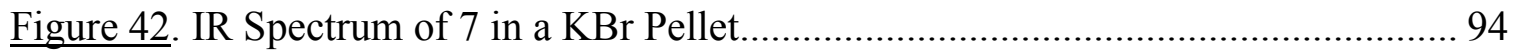

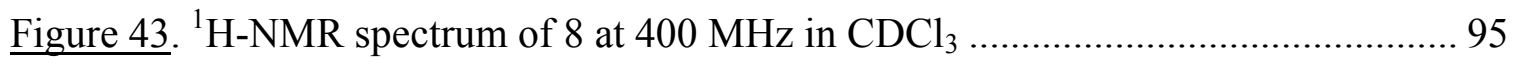




\section{List of Schemes}

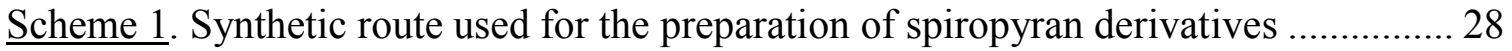

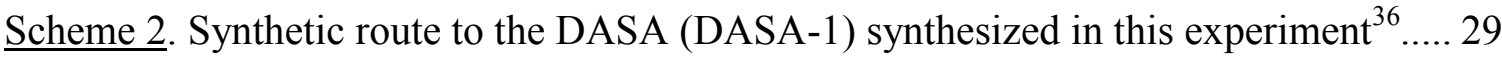

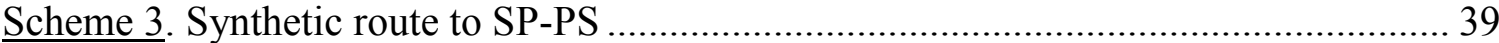

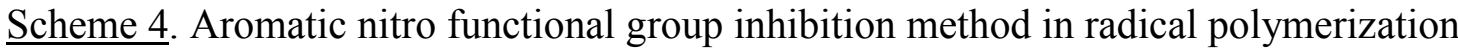

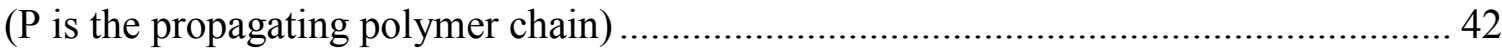

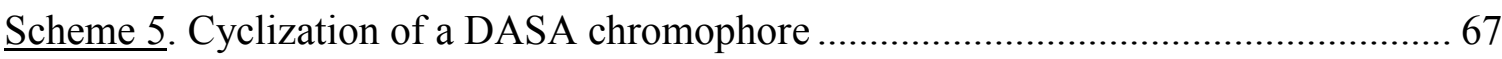




\section{List of Abbreviations}

\begin{tabular}{|c|c|}
\hline Abbreviation & Formal Term \\
\hline AIBN & $\begin{array}{c}\text { 2,2'-azobis(2- } \\
\text { methylpropionitrile) }\end{array}$ \\
\hline bipy & 2,2'-bipyridine \\
\hline DASA & $\begin{array}{c}\text { Donor-acceptor Stenhouse } \\
\text { adduct }\end{array}$ \\
\hline $\operatorname{dicyd}^{2-}$ & $\begin{array}{l}\text { 1,4-dicyanamidobenzene } \\
\text { dianion }\end{array}$ \\
\hline DMF & $N, N$-dimethylformamide \\
\hline $\mathrm{DSC}$ & $\begin{array}{l}\text { Differential scanning } \\
\text { calorimetry }\end{array}$ \\
\hline GPC & $\begin{array}{l}\text { Gel permeation } \\
\text { chromatography }\end{array}$ \\
\hline HOMO & $\begin{array}{c}\text { Highest occupied molecular } \\
\text { orbital }\end{array}$ \\
\hline LED & Light emitting diode \\
\hline LMCT & $\begin{array}{c}\text { Ligand-to-metal charge } \\
\text { transfer }\end{array}$ \\
\hline LUMO & $\begin{array}{l}\text { Lowest unoccupied molecular } \\
\text { orbital }\end{array}$ \\
\hline $\mathrm{MC}$ & Merocyanin \\
\hline MMCT & Metal-to-metal charge transfer \\
\hline py & Pyridine \\
\hline SEM & Scanning electron microscopy \\
\hline SP & Spiropyran \\
\hline SP-PS & Spiropyran-polystyrene \\
\hline TBAI & Tetrabutylammonium iodide \\
\hline THF & Tetrahydrofuran \\
\hline
\end{tabular}




\section{List of Appendices}

Appendix A - Spectroscopic Characterization of Novel Intermediates in the Synthesis of

SP-PS 85

Appendix B - Additional LED Information...................................... 96

Appendix C - Statistical Analysis of Films........................................97 


\section{Chapter: Introduction}

\subsection{Molecular Electronics}

The research and development of molecular devices is a rapidly advancing and expanding field as it addresses the needs of contemporary society: increasing data storage and decreasing device size. The development of molecular devices has taken a 'bottomup' approach - with the molecule as a starting point - instead of the 'top-down' approach traditionally observed - starting large and miniaturizing. Molecular devices are a combination of molecules each possessing their own properties and, when assembled, are able to carry out a specific function. Molecular machines are a type of molecular device that respond to an external stimulus by a nuclear or electronic rearrangement. A photon, a chemical reagent or reduction/oxidation imparts the energy required by these molecular machines. Analogous to large-scale machines, control over their performance is necessary and on the molecular level, this can typically be achieved photochemically. Molecular devices and machines research has the power to advance technology from micro- to nano-scale while removing the limitations of electronics and imparting the advantages of photonics. ${ }^{1}$

Applications of long-range electron transfer within the field of molecular electronics are widespread. Studying the movement of the electron within a multinuclear system (such as dinuclear metal complexes connected by a bridging ligand) is simplified versus an intermolecular electron transfer and can provide crucial information about the electron transfer process as well as the linker that is able to act as a molecular wire. ${ }^{2}$ 


\subsubsection{Charge Transfer in Ruthenium Dicyanamide Complexes}

Ruthenium dicyanamide complexes are studied in the following research due to their well-developed synthetic pathways, cost, and, most importantly, their spectroscopic properties (that allow for their potential application in molecular devices). In dinuclear ruthenium complexes, two transitions in the visible and NIR spectrum are of great importance: the metal-to-metal charge transfer band (MMCT) and the ligand-to-metal charge transfer band (LMCT). The MMCT band in dinuclear systems is due to electron transfer between two metal centres across a bridging ligand. When the MMCT is not observed in a dinuclear complex, it is due to an intense LMCT band concealing the MMCT. $^{3}$ This is the case in the following research on dinuclear ruthenium pentaammine dicyanamide complexes; the nature of the LMCT band will be discussed in terms of mixed-valence complexes $([\mathrm{Ru}(\mathrm{III})-\mathrm{Ru}(\mathrm{II})])$ and non-mixed valence $([\mathrm{Ru}(\mathrm{III})-\mathrm{Ru}(\mathrm{III})])$ complexes as the results are the same.

Robin and Day have categorized mixed-valence complexes according to the extent of the coupling between metal centres. ${ }^{4}$ The potential energy surfaces below show the coupling between metal centres $\left(\mathrm{H}_{\mathrm{ad}}\right)$ as a function of Class. In Class I mixed-valence complexes, there is no coupling between metal centres and the properties of the individual mononuclear complexes are typically present. Conversely, in Class III complexes, properties of mononuclear complexes are not observable as complete delocalization of electrons occurs. In Class II complexes, there is weak coupling between metal centres. Since the Robin and Day classification system was reported, Class II-III complexes have been identified as having localized electrons but delocalized solvent effects. $^{5}$ 


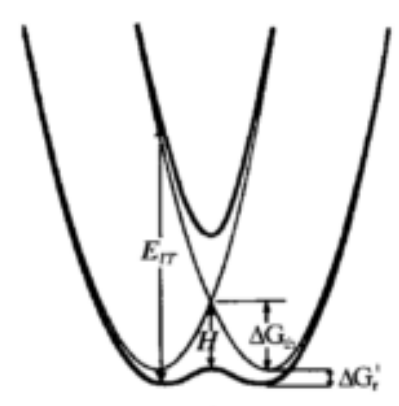

A

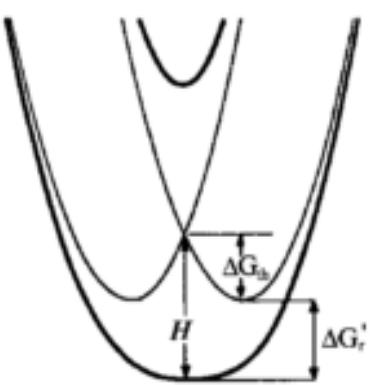

B

Figure 1. The potential energy surfaces for Class I (light line in A/B), Class II (A) and Class III (B) complexes, where $\mathrm{H}$ is the coupling between metal centres, $\Delta \mathrm{G}_{\mathrm{th}}$ is the energy barrier to thermal electron transfer, $\mathrm{E}_{\mathrm{IT}}$ is the energy of the intervalence charge transfer and $\Delta \mathrm{G}_{\mathrm{r}}{ }^{\prime}$ is the free energy of resonance exchange per complex in the mixed valence system. ${ }^{6}$ (Reprinted with permission from J. Am. Chem. Soc., 1998, 120(50), 13096-13103. (C2014 American Chemical Society.)

In multinuclear complexes, electron transfer between metal centres may occur through overlap of metal orbitals ${ }^{7}$ or through coupling of the metal orbitals to a bridging ligand (superexchange). ${ }^{8}$ Superexchange is most clearly demonstrated in mixed-valence complexes and may proceed through the $\pi$-HOMO (highest occupied molecular orbital) or through the $\pi$-LUMO (lowest unoccupied molecular orbital) of the bridging ligand and are referred to as 'hole transfer' and 'electron transfer', respectively (shown in the figure below). ${ }^{9}$ The extent of overlap between the $\mathrm{d} \pi$ orbitals of the metal centre and $\mathrm{p} \pi$ orbitals of the bridging ligand determines the method and the extent through which the MMCT occurs. MMCT is referred to as IVCT or intervalence charge transfer in mixed-valence complexes. 

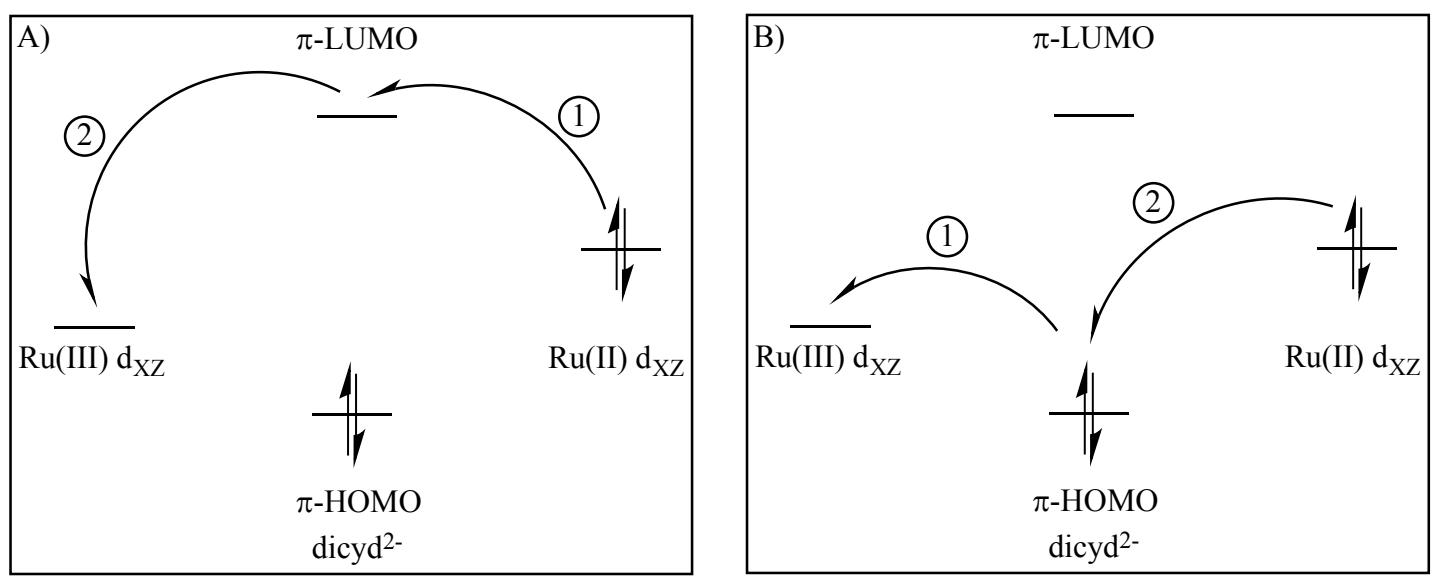

Figure 2. Electron transfer between donor $(\mathrm{Ru}(\mathrm{II}))$ and acceptor $(\mathrm{Ru}(\mathrm{III}))$ metal centres through a bridging ligand $\left(\right.$ dicyd $\left.^{2-}\right)$ in mixed-valence complexes by electron transfer (A) or hole transfer (B)

For symmetric mixed-valence complexes, Hush theory ${ }^{10}$ states:

$$
\begin{array}{ll}
E_{o p}=\chi_{i}+\chi_{o}+\Delta E & \text { Equation 1-1 }
\end{array}
$$

where $E_{o p}$ is the energy of the intervalence charge transfer, $\chi_{i}$ is the inner-sphere reorganizational energy, $\chi_{\mathrm{o}}$ is outer-sphere reorganization energy and $\Delta \mathrm{E}$ is any energy required for excitation to a ligand-field or spin-orbit excited states. Inner-sphere refers to any intramolecular rearrangements while outer-sphere is solvent-oriented rearrangements. The metal-metal coupling in several families of dinuclear ruthenium ammine dicyanamide complexes have been shown to be highly sensitive to outer-sphere and inner-sphere perturbations, most notably complexes of the type $\left[\left\{\mathrm{Ru}\left(\mathrm{NH}_{3}\right)_{5}\right\}_{2}(\mu-\mathrm{L})\right]^{3+/ 4+}$, where $\mathrm{L}$ is a substituted or unsubstituted dicyanamide ligand (shown below). ${ }^{6}$ This is beneficial, as it allows for tailoring of the electronic properties of the complexes to be incorporated into molecular devices or machines. 


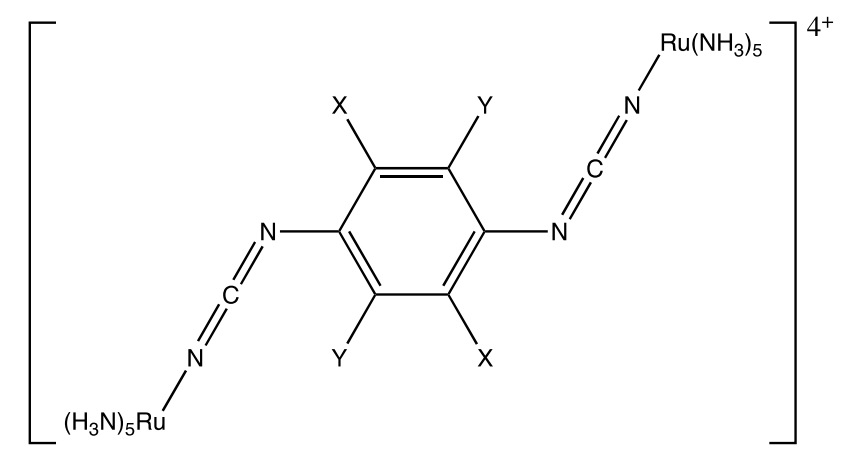

$\underline{\text { Figure 3. }} .\left[\left\{\mathrm{Ru}\left(\mathrm{NH}_{3}\right)_{5}\right\}_{2}(\mu-\mathrm{L})\right]^{3+/ 4+}$, where $\mathrm{L}$ is dicyd ${ }^{2-}$ and $\mathrm{X}=\mathrm{Cl}, \mathrm{Y}=\mathrm{H}$, or $\mathrm{X}=\mathrm{Y}=\mathrm{Cl}$, or $\mathrm{X}=\mathrm{Me}, \mathrm{Y}=\mathrm{H}$, or $\mathrm{X}=\mathrm{Y}=\mathrm{H}$

The organic bridging ligand to be used in this study is dicyanamide, dicyd ${ }^{2-}$, shown below. The dicyd family of ligands are $\pi$ donors and have the correct symmetry and energy to interact with ruthenium $\mathrm{d} \pi$ orbitals to produce a conjugated $\pi$ system through the hole transfer mechanism. The energy of the $\pi$ orbitals in dicyd is easily tuned by altering the substituents on the phenyl ring. Adding electron withdrawing substituents on the phenyl ring of dicyd reduces the coupling between ruthenium and dicyd - resulting in a lower extinction coefficient of the LMCT band. ${ }^{11}$ The dinuclear ruthenium pentaammine complexes are further affected by inner-sphere perturbations with regards to changes in the coordination sphere. Replacement of an ammine with a pyridine or bipyridine ligand (reducing the $\sigma$-donor ability of the ligand) stabilizes the ruthenium $\mathrm{d} \pi$ orbitals and increases coupling between the ruthenium $\mathrm{d} \pi$ orbitals and dicyd $\pi$-HOMO orbitals. $^{6}$

Outer-sphere perturbations have a significant effect on metal-metal coupling. The intensity of the LMCT band in complexes of the type $\left[\left\{\mathrm{Ru}\left(\mathrm{NH}_{3}\right)_{5}\right\}_{2}(\mu-\mathrm{L})\right]^{3+/ 4+}$ have the largest dependence on solvent interactions in comparison to triammine and tetraammine complexes. ${ }^{6}$ Solvents with electron donor ability (measured by Gutmann Donor 
Numbers $^{12}$ ) create a hydrogen bond with the ammines of the complex and electron density is donated from the nitrogen ammine to the ruthenium metal centre. This raises the energy of the metal centre, reducing the orbital overlap with the cyanamide ligand and therefore reducing the extent of coupling between metal centres. Ultimately, a decrease in the intensity of the LMCT band is observed. The electron transfer in these families of complexes occurs via the hole transfer mechanism. ${ }^{6}$ For this reason, the coupling between metal centres can be measured through the ligand-to-metal charge transfer (LMCT) band in Ru(III)-Ru(III) systems.

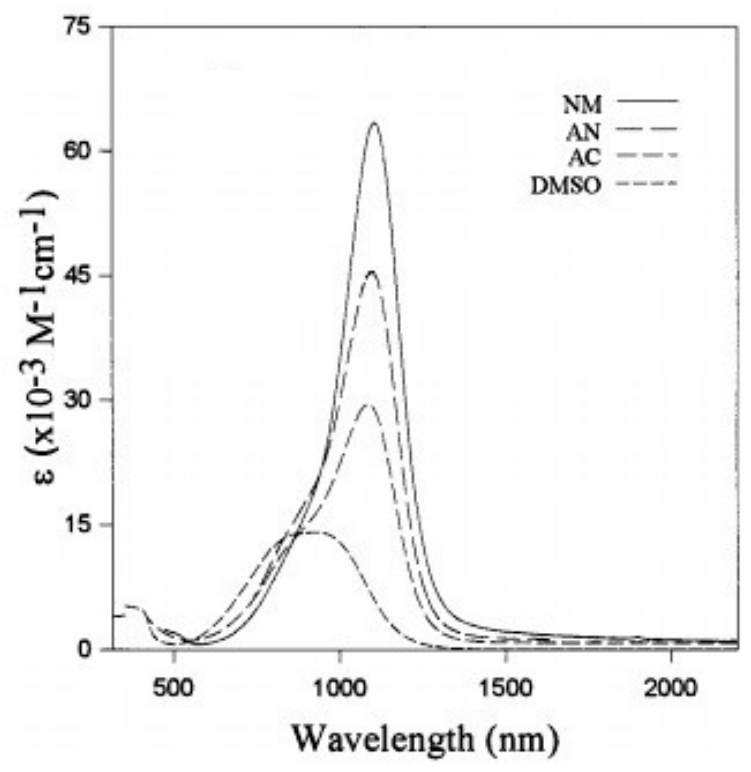

Figure 4. LMCT band intensity dependence on solvent donor number in $\left[\left\{\mathrm{Ru}\left(\mathrm{NH}_{3}\right)_{5}\right\}_{2}(\mu-\right.$ dicyd) $]\left[\mathrm{PF}_{6}\right]_{4}{ }^{6}$ (Reprinted with permission from J. Am. Chem. Soc., 1998, 120(50), 13096-13103. (C2014 American Chemical Society.)

\subsection{Polymers Based on Stimuli-Responsive Materials}

Light as an external energy source over other input sources in stimuli-responsive materials has several benefits: it is temporally, spatially and energetically precise, there is no contamination by chemical reagents and light may be delivered in a closed system. ${ }^{13}$ 
In this work, a light-responsive polymer will be synthesized based on the spiropyran family of photochromes. Photochromic molecules isomerize reversibly upon exposure to specific wavelengths of light and alternate between two or more (stable or metastable) states possessing different molecular properties. Photochromic molecules have been used extensively in recent history as the major components in optical data processing. ${ }^{14}$

\subsubsection{Photochromic Spiropyrans}

Spiropyrans are a class of organic molecules whose photochromism was discovered in 1952 by Fischer and Hirshberg. ${ }^{15}$ They reported derivatives of spirans demonstrating equilibrium between colourless and coloured forms affected by temperature or ultraviolet irradiation. Since this discovery, spiropyrans have been researched extensively and many derivatives have been synthesized as small molecules, ligands, polymer pendant groups/backbones, surface supports and nanomaterials for a wide range of applications. ${ }^{16}$

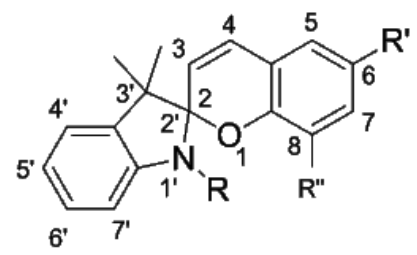

Figure 5. General structure of spiropyran or spiro[2H-1-benzopyran-2,2'-indoline] (BIPS)

Spiropyrans consist of perpendicular indoline and chromene moieties bound together by a spirocarbon. The chromene moiety is common to all derivatives of spiropyrans. ${ }^{17}$ The backbone structure of spiropyran is shown above; from herein spiropyran (SP) and merocyanin (MC) will refer to the closed and open form isomers of 
the molecule spiro[2H-1-benzopyran-2,2'-indoline] (BIPS). Exposure of SP to various stimuli - most commonly radiation at wavelengths shorter than $400 \mathrm{~nm}$ - results in heterolytic cleavage at the $\mathrm{C}-\mathrm{O}$ junction and the formation of the conjugated, zwitterionic, planar MC.
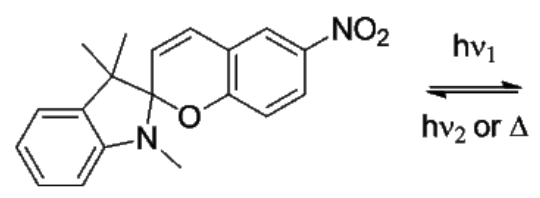

spiropyran

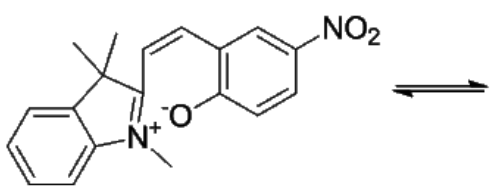

cisoid merocyanin
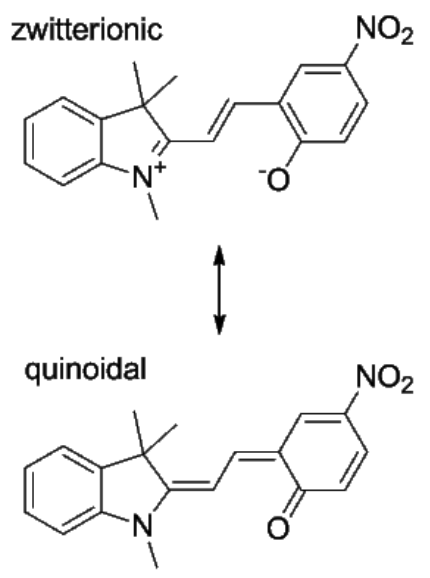

transoid merocyanin

Figure 6. Ring opening of SP to form the MC isomer in 6-NO $\mathrm{NO}_{2} \mathrm{BIPS}$, where $v_{1}$ is $365 \mathrm{~nm}$ and $v_{2}$ is $590 \mathrm{~nm}$

The ring-opening process is also possible through NIR irradiation in a two-photon absorption mechanism. This photoisomerization is reversible by thermal relaxation or by radiation at wavelengths between 550 and $600 \mathrm{~nm}$. Upon ring-opening, MC isomerizes from cisoid to transoid and exist in an equilibrium between quinionic and dipolar forms. Other stimuli known to induce the isomerization include $\mathrm{pH}$, mechanical force, reduction/oxidation, presence of metal ions and medium polarity. ${ }^{13}$

In the UV-Vis spectrum, SP has two major absorption peaks, one at $270-300 \mathrm{~nm}$ and another at approximately $325-350 \mathrm{~nm}$. The former representing a $\pi-\pi^{*}$ transition and the latter due to absorptions in the chromene portion. Upon isomerization, the extended 
conjugation of MC results a shift in absorption into the visible range at between 550-600 $\mathrm{nm}$. The exact peak maximum is dependent on the substitution pattern of the SP derivative. In the spectrum of $\mathrm{MC}$, the quinoidal resonance form - preferred over the dipolar form in non-polar solvents - causes a red shift in the peak maximum due to stabilization of the MC excited state. ${ }^{13}$ Likewise, aggregation of MC may occur due to interaction between dipoles and $\pi$-stacking on adjacent $\mathrm{MC}$ isomers. When the stacking occurs in a parallel fashion with parallel molecules (J-aggregates) a bathochromic shift occurs. Alternatively, H-aggregates, where the stacking occurs in an antiparallel fashion, result in blue shift of the MC peak maximum. ${ }^{18}$

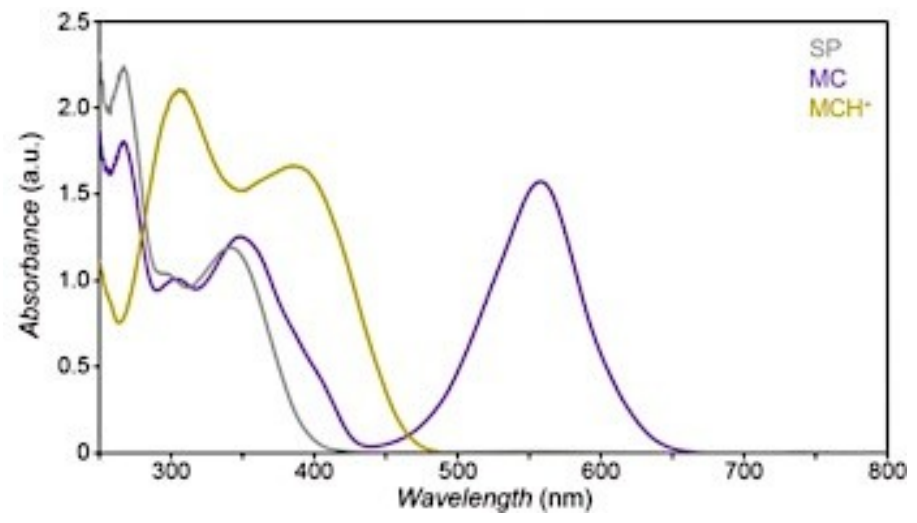

Figure 7. UV-Vis absorption spectrum of spiropyran (SP) and merocyanin (MC) (Figure duplicated with permission) ${ }^{13}$

\subsubsection{Photodynamic Materials Based on Spiropyran}

Spiropyran derivatives are ideal chromophores for incorporation into photodynamic materials due to the major difference in properties between SP and MC. The differences between SP and MC include size (SP has a smaller volume than MC), dipole (4.3 D (SP) vs 17.7 D (MC)), colour (MC absorbs in the visible range and SP does not) and emission properties (MC has a strong emission band at approximately $650 \mathrm{~nm}$ 
while SP doesn't exhibit any strong emission bands). ${ }^{13}$ These differences lead to many useful applications in SP-based polymers: reversible photo-modulated wettability, polymer solubility control, metal ion sensing, indicators of mechanical stress, photoactuation and photoswitches for conductive polymers. ${ }^{16}$

It is possible to take advantage of the isomerization-induced change in properties of BIPS-derived materials due to the reversible, quantitative and rapid isomerization between SP and MC. Furthermore, the position of the SP-MC equilibrium is tunable as it is sensitive to several factors. It is greatly dependent on the BIPS substitution pattern, the characteristics of the medium (viscosity, solvent polarity) and temperature. ${ }^{17}$ Many substitution patterns on BIPS exist, with the most common SP used being $6-\mathrm{NO}_{2} \mathrm{BIPS}$ $\left(\mathrm{R}^{\prime}=\mathrm{NO}_{2}\right.$ and $\mathrm{R}$ ' $=\mathrm{H}$, see Figure 6). For example, substitution of a nitro group para to the phenoxide group ultimately stabilizes the MC isomer of $6-\mathrm{NO}_{2} \mathrm{BIPS}$ by stabilizing the negative charge on the phenoxide. Conversely, placement of an electron-donating group in the para and ortho positions to the phenoxide would increase the electron density on the phenoxide and destabilize the MC isomer. With regards to medium viscosity, solid SP does not exhibit photochromism but SP in solution does (solution could be solvent, gel, polymer etc.). ${ }^{17}$ More polar solvents stabilize MC while less polar solvents favour SP and aggregation of $\mathrm{MC}$ isomers. Finally, an increase in temperature induces the ring-opening reaction. It is important to restate that various stimuli, in addition to temperature and light, induce the ring-opening, such as $\mathrm{pH}$, electric potential and mechanical force. ${ }^{13}$

For the many reasons outlined above, SPs are excellent candidates for incorporation into efficient and useful photodynamic materials. To fulfill their potential 
as photodynamic materials, however, they must be immobilized onto a solid support. Immobilization reduces aggregation of MC isomers that leads to irreversible/impeded recovery of SP and also reduces photodegradation. SP has two mechanisms for photodegradation: interaction of the triplet excited state of SP with oxygen leads to the formation of singlet oxygen that causes oxidation (minor contributor to photodegradation) and a bimolecular pathway dependent upon SP (major contributor). Immobilization of SP greatly reduces the bimolecular photodegradation pathway. It also prevents leaching and therefore phase separation that can occur due to isomerization. Additionally, immobilization onto the solid support can impart the properties of the support, which can prove beneficial with regards to solubility, biocompatibility and processing. $^{13}$

SPs were the primary choice of photochromes in this work for many reasons. The most notable among them is the change in dipole upon isomerization from SP to $\mathrm{MC}-$ this change increases the electron donating ability of the molecule and, when combined with the dinuclear ruthenium dicyanamide complex, will drastically change the outersphere. It is also important to note that this isomerization occurs at wavelengths of light low enough in energy to avoid significant decomposition of the dinuclear ruthenium dicyanamide complex. Lastly, SPs are synthetically accessible photochromes with many available derivatives whose properties have been widely studied; therefore, it is possible to easily tune the nature of the SP. 


\subsection{Reactive Oxygen Species}

A brief introduction to the reactive oxygen species singlet oxygen and superoxide follows to facilitate later discussion of experimental results.

\subsubsection{Singlet Oxygen}

In 1928, Mulliken assigned an absorption line observed in the spectrum of atmospheric oxygen to a low energy singlet excited state and correctly predicted the existence of an intermediate singlet state, thereby discovering what we refer to as 'singlet oxygen' - the first excited state of molecular oxygen. ${ }^{19}$ While the presence of this intermediate singlet excited state was confirmed swiftly after Mulliken's predictions, ${ }^{20}$ the debate over the role of singlet molecular oxygen in many oxygenation reactions continued for another 35 years. ${ }^{21}$ In 1963, Kasha and Khan studied the reaction between hydrogen peroxide and sodium hypochlorite in solution and were able to confirm the production of singlet oxygen by spectrograph, thus ceasing any debate. ${ }^{22}$ Since this time, studies on the properties and applications of singlet molecular oxygen have expanded dramatically.

\subsubsection{Properties of Singlet Molecular Oxygen}

In the ground state $\left({ }^{3} \Sigma_{\mathrm{g}}{ }^{-}\right)$, molecular oxygen is in the triplet spin state containing two unpaired electrons in the lowest energy antibonding orbitals. The lowest energy excited states at 95 and $158 \mathrm{~kJ} / \mathrm{mol},{ }^{1} \Delta_{\mathrm{g}}$ and ${ }^{1} \Sigma_{\mathrm{g}}{ }^{+}$, respectively, differ by the configuration of the electrons in the lowest energy antibonding orbitals, as shown below. ${ }^{23}$ While the higher energy singlet state, ${ }^{1} \Sigma_{\mathrm{g}}{ }^{+}$, is fairly inert (unreactive in solution), the lower energy 
singlet state, ${ }^{1} \Delta_{\mathrm{g}}$ (will be referred to as singlet oxygen herein), exhibits chemistry greatly varying from the ground state. ${ }^{24}$

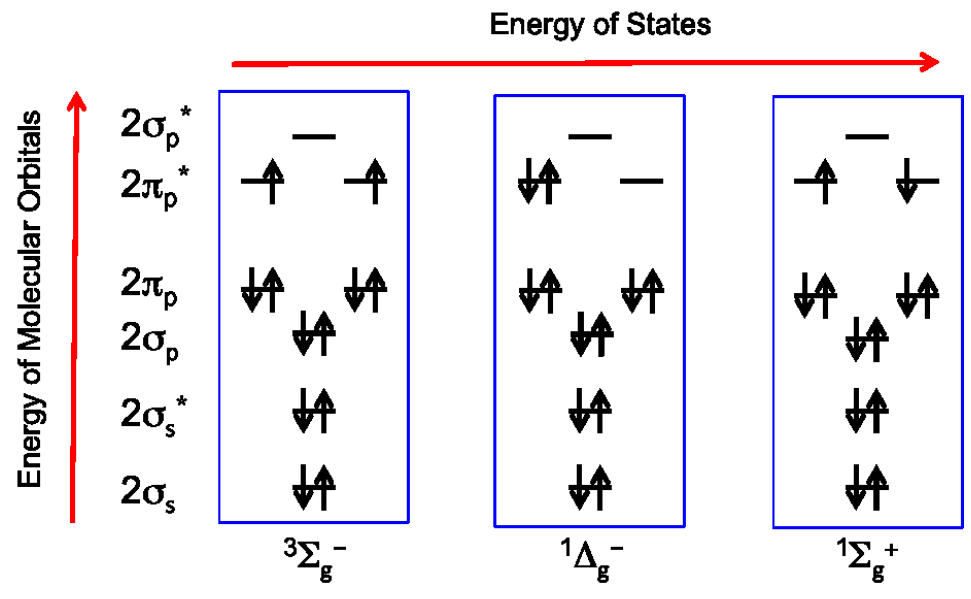

Figure 8. Electron configurations of the ground and lowest excited energy states of molecular oxygen

The transition between the triplet ground state of molecular oxygen and the first excited state is spin forbidden, giving a long lifetime in gas and solution phase at $45 \mathrm{~min}$ and $10^{-6}-10^{-3} \mathrm{~s}$, respectively. The metastability of the ${ }^{1} \Delta_{\mathrm{g}}$ state allows for the presence of singlet state molecular oxygen to be monitored spectroscopically by the appearance of a band at $1268 \mathrm{~nm}$ in absorption and emission spectra. The transition between excited singlet states of molecular oxygen is spin allowed and therefore greatly reduces the lifetime of the ${ }^{1} \Sigma_{\mathrm{g}}{ }^{+}$state (in comparison to ${ }^{1} \Delta_{\mathrm{g}}$ ) to $7-12 \mathrm{~s}$ and $10^{-11}-10^{-9} \mathrm{~s}$ in gas and solution phase, respectively. ${ }^{23}$ 


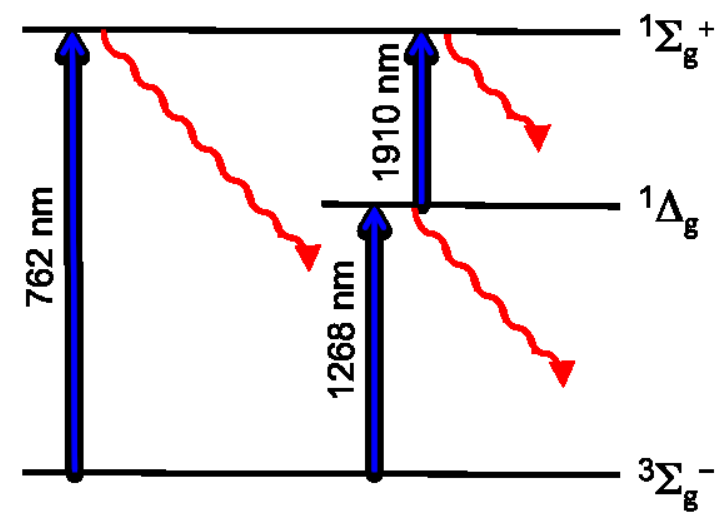

Figure 9. Transitions in molecular oxygen, blue lines representing absorption and red lines representing radiative energy release ${ }^{21}$

\subsubsection{Photosensitizers of Singlet Oxygen}

Photosensitizers are molecules that when excited by irradiation at specific wavelengths in the presence of molecular oxygen produce singlet oxygen. The photosensitized production of singlet oxygen arises from a broad range of molecules; for example, porphyrins are known to be excellent photosensitizers. ${ }^{23}$

Photosensitization of oxygen may occur via singlet or triplet mechanisms, the latter being more typical. ${ }^{25}$ In the triplet mechanism of photosensitization, the triplet excited state of the photosensitizer is generated by irradiation of the singlet ground state $\left(P\left(S_{0}\right)\right)$ and subsequent intersystem crossing to the triplet excited state. The triplet excited state of the photosensitizer, $\left(P\left(T_{1}\right)\right)$, having a longer lifetime, has greater probability for interaction with molecular oxygen $\left({ }^{3} \Sigma_{\mathrm{g}}{ }^{-}\right)$,

$$
P\left(S_{0}\right) \stackrel{h v}{\rightarrow} P\left(S_{n}\right) \stackrel{k_{v r}}{\rightarrow} P\left(S_{1}\right) \stackrel{k_{i s c}}{\rightarrow} P\left(T_{1}\right)
$$

Equation 1-2

The triplet excited state photosensitizer may then transfer energy to ground state molecular oxygen generating singlet oxygen (2),

$$
P\left(T_{1}\right)+O_{2}\left({ }^{3} \Sigma_{g}^{-}\right) \stackrel{k_{e n}}{\longrightarrow} P\left(S_{0}\right)+O_{2}\left({ }^{1} \Delta_{g}\right)
$$

Equation 1-3 
Alternatively, $P\left(T_{1}\right)$ may react by an intermediate substrate that is excited by proton abstraction or electron transfer and in turn reacts and creates a reactive oxygen species. The quantum yield of singlet oxygen production, $\Phi_{O_{2}}$, describes the efficiency of a photosensitizer with regards to singlet oxygen formation. It may be determined using the following equation,

$$
\boldsymbol{\Phi}_{O_{2}}=\boldsymbol{\Phi}_{P\left(T_{1}\right)} \cdot \boldsymbol{\Phi}_{\text {en }}
$$

Equation 1-4

where $\Phi_{P\left(T_{1}\right)}$ is the quantum yield of the formation of triplet photosensitizer and $\Phi_{e n}$ is the efficiency of singlet oxygen production by $P\left(T_{1}\right)$. The yield of the triplet state photosensitizer is affected by competing reactions of the excited singlet state photosensitizer including fluorescence (Equation 1-5) and internal conversion (Equation 1-6) leading to the following equation for the quantum yield of $P\left(T_{1}\right)$ formation,

$$
\begin{aligned}
& P\left(S_{1}\right) \stackrel{k_{F}}{\rightarrow} P\left(S_{0}\right)+h v_{F} \\
& P\left(S_{1}\right) \stackrel{k_{I C}}{\rightarrow} P\left(S_{0}\right) \\
& \Phi_{P\left(T_{1}\right)}=\frac{k_{I S C}}{k_{I S C}+k_{F}+k_{I C}}
\end{aligned}
$$

Equation 1-5

Equation 1-6

Equation 1-7

Competing oxygen quenching mechanisms may also occur - electron transfer leading to the formation of the superoxide radical (Equation 1-8) or physical deactivation (Equation 1-9) of the triplet excited state. Other possible quenching mechanisms of $P\left(T_{l}\right)$ not involving oxygen include phosphorescence (Equation 1-10) and non-radiative deactivation (Equation 1-11). Consideration of these competing mechanisms leads to Equation 1-12 for the efficiency of singlet oxygen formation,

$$
\begin{aligned}
& P\left(T_{1}\right)+O_{2}\left({ }^{3} \Sigma_{g}^{-}\right) \stackrel{k_{e t}}{\rightarrow} P^{+}+O_{2}^{-} \\
& P\left(T_{1}\right)+O_{2}\left({ }^{3} \Sigma_{g}^{-}\right) \stackrel{k_{d}}{\rightarrow} P\left(S_{0}\right)+O_{2}\left({ }^{3} \Sigma_{g}^{-}\right) \\
& P\left(T_{1}\right) \stackrel{k_{P}}{\rightarrow} P\left(S_{0}\right)+h v_{P}
\end{aligned}
$$

Equation 1-10 


$$
\begin{aligned}
& P\left(T_{1}\right) \stackrel{k_{n r}}{\longrightarrow} P\left(S_{0}\right) \\
& \Phi_{e n}=\frac{k_{e n}\left[o_{2}\right]}{\left(k_{e t}+k_{d}+k_{e n}\right)\left[O_{2}\right]+k_{p}+k_{n r}}
\end{aligned}
$$

Once singlet oxygen is formed there are two methods through which quenching may occur. Physical quenching (Equation 1-13) does not cause product formation and chemical quenching (Equation 1-14) yields a new product and consumes oxygen. Chemical quenching by singlet oxygen is possible as singlet oxygen is approximately $1 \mathrm{~V}$ more oxidizing than molecular oxygen. Singlet oxygen reacts with electron rich compounds such as alkenes, amines and anions. ${ }^{23}$

$$
\begin{aligned}
& { }^{1} O_{2}+A \rightarrow{ }^{3} O_{2}+A \\
& { }^{1} O_{2}+A \rightarrow{ }^{3} O_{2}+B
\end{aligned}
$$

Equation 1-13

Equation 1-14

\subsubsection{Metal Complexes as Photosensitizers}

There are several requirements to be an efficient photosensitizer of singlet oxygen: photostability, high absorption in UV-Vis spectrum, a triplet excited state of sufficient energy to excite molecular oxygen (greater than $95 \mathrm{~kJ} / \mathrm{mol}$ ), a large quantum yield of excited state formation (greater than 0.4 ) and a long lifetime of emission (greater than $1 \mu \mathrm{s}) .^{23}$ There are many types of molecules that act as photosensitizers, ranging from organic dyes to transition metal complexes. Ruthenium(II) complexes are a very well studied class of singlet oxygen photosensitizers due to their synthetic accessibility and spectroscopic properties. ${ }^{26}\left[\mathrm{Ru}(\text { bipy })_{3}\right]^{2+}$ (bipy is $2,2^{\text {' }}$-bipyridine) is the benchmark $\mathrm{Ru}(\mathrm{II})$ singlet oxygen photosensitizer with a quantum yield of singlet oxygen formation of 0.86 in methanol saturated with 1 atm of oxygen. ${ }^{23}$ Since the discovery of $\left[\mathrm{Ru}(\mathrm{bipy})_{3}\right]^{2+}$ as an 
efficient photosensitizer, many other $\mathrm{Ru}(\mathrm{II})$ complexes have been observed with quantum yields of singlet oxygen formation of $1 .^{27}$

\subsection{Superoxide}

Superoxide, $\mathrm{O}_{2}^{-}$, is the product of a one-electron reduction of molecular oxygen. It is a paramagnetic free radical species. The formation of superoxide is biologically important and also has a role in fuel cell systems. The reduction of molecular oxygen (shown below) to superoxide is highly dependent on the solvent and electrode used. The reduction potential of superoxide in various solvents is shown below; the potential becomes less negative as the polarity of the solvent increases. In protic solvents (such as water) superoxide is not stable and forms peroxide, according to Equation 1-14. ${ }^{28}$

$$
\mathrm{O}_{2}(\mathrm{~g}, \mathbf{1 a t m})+\mathrm{e}^{-} \rightarrow \mathrm{O}_{2}^{-}
$$

Equation 1-15

Table 1. Reduction potential of $\mathrm{O}_{2}(1 \mathrm{~atm})$ vs the normal hydrogen electrode in various solvents collected using cyclic voltammetry at $0.1 \mathrm{~V} / \mathrm{s}^{28}$

\begin{tabular}{c|cc}
\hline Solvent & $C_{\mathrm{O}_{2}}(\mathrm{mM})$ & $\begin{array}{c}\Delta \mathrm{E}^{\circ} \mathrm{vs} . \\
\mathrm{NHE}(\mathrm{V})\end{array}$ \\
\hline $\mathrm{H}_{2} \mathrm{O}$ & 1.0 & -0.16 \\
$\mathrm{DMSO}$ & 2.1 & -0.54 \\
Pyridine & 4.9 & -0.62 \\
Acetonitrile & 8.1 & -0.63 \\
\hline
\end{tabular}

$$
2 \mathrm{O}_{2}^{-}+2 \mathrm{H}_{2} \mathrm{O} \rightarrow \mathrm{H}_{2} \mathrm{O}_{2}+\mathrm{O}_{2}+2 \mathrm{OH}^{-}
$$

Equation 1-16

\subsection{Research Goals}

SP was recently used in a bulk optode sensor in which protons and chloride ions diffused into a polymeric membrane upon isomerization of SP to MC. This diffusion was 
triggered by the increase in basicity from SP to MC and the diffusion of chloride ions was monitored by spectral changes associated with interaction between the protons and MC. ${ }^{29}$ Our aim is similar in that our goal is the creation of a dynamic optical molecular switch incorporating SP. To achieve this goal, a novel photodynamic polymer containing a SP pendant group chemically bound to a polystyrene backbone via an alkyl linker will first be synthesized. The novel polymer will be exposed to $\left[\left\{\mathrm{Ru}\left(\mathrm{NH}_{3}\right)_{5}\right\}_{2}(\mu\right.$-dicyd) $]\left[\mathrm{BPh}_{4}\right]_{4}$ in a thin film and the LMCT band in the absorption spectrum of the complex will be monitored as the SP photoisomerizes between SP and MC. An interaction between the SP and the complex similar to the interaction of a high donor solvent with the complex is hypothesized.

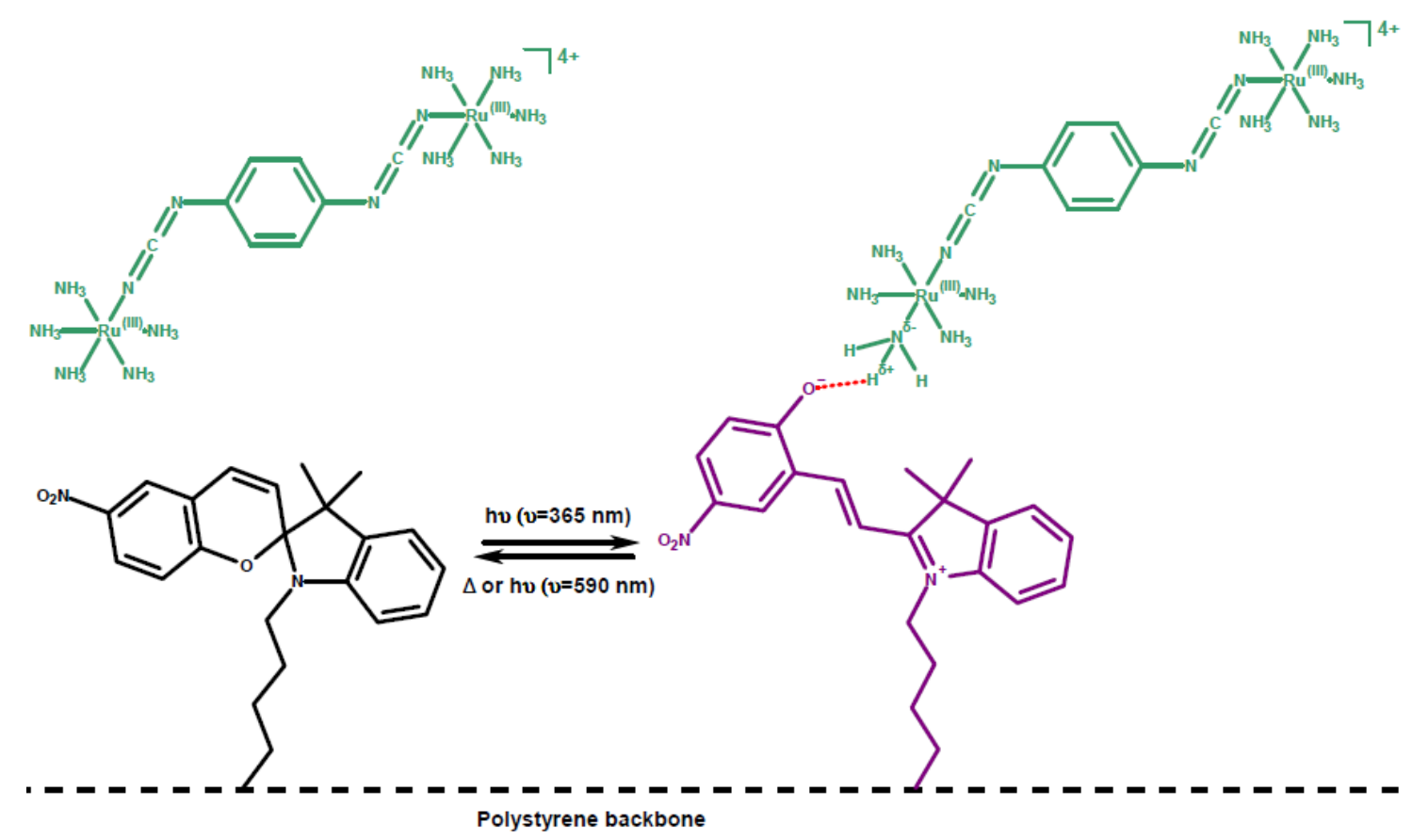

Figure 10. Hypothesized interaction of ammine ligands and SP 


\section{Chapter: Experimental}

\subsection{Syntheses}

\subsubsection{General Information}

All starting materials were purchased from Sigma-Aldrich as reagent grade and used as received unless otherwise noted. Magnesium sulfate and sodium hydroxide were obtained from Bioshop, ammonium chloride was obtained from BDH Chemicals and tetrabutylammonium iodide (TBAI) was obtained from Fisher Scientific. Anhydrous potassium acetate was synthesized by dissolving $10 \mathrm{~g}$ of potassium hydroxide and $10 \mathrm{ml}$ of glacial acetic acid in $10 \mathrm{ml}$ of distilled water, removing the solvent, crystallizing from ethanol and acetone and drying for 24 hours at $110{ }^{\circ} \mathrm{C}$ under vacuum. All column chromatography was performed using 200-400 mesh silica gel with a pore size of $60 \AA$ and Celite 545 was used. Thin layer chromatography (TLC) was performed on glassbacked Extra Hard Layer (60 Å) TLC plates obtained from Silicycle. The sephadex used was Sephadex CM-25 purchased from Sigma-Aldrich. Ultra High-Purity Grade argon from Praxair was used to perform experiments in an inert atmosphere.

All solvents are reagent grade from Caledon Labs unless otherwise noted. Anhydrous ethanol was obtained from commercial alcohols. Dry tetrahydrofuran (THF) was distilled from benzophenone and sodium metal. Dry benzene was distilled from calcium hydride onto $3 \AA$ molecular sieves. Acetonitrile was distilled from calcium hydride. $N, N$-dimethylformamide (DMF) was dried by incubation in $3 \AA$ molecular sieves under argon.

NMR spectra were acquired using a Bruker Avance 300 or Bruker Avance III 400

spectrometer at 300 or $400 \mathrm{MHz}$ for ${ }^{1} \mathrm{H}$ and 75 or $100 \mathrm{MHz}$ for ${ }^{13} \mathrm{C}$, respectively, at room 
temperature in $\mathrm{d}_{3}$-chloroform or $\mathrm{d}_{6}$-DMSO from CDN Isotopes. Chemical shifts are reported relative to tetramethylsilane (TMS) $(\delta=0.00 \mathrm{ppm})$ and are listed in parts per million (ppm, $\delta$ ). Coupling constants $(J)$ are listed in $\mathrm{Hz}$ and the splitting abbreviations are as follows: br (broad), s (singlet), d (doublet), t (triplet), q (quartet) and m (multiplet). IR Spectra were obtained using a Varian Scimitar 1000 FTIR spectrometer in a $\mathrm{KBr}$ pellet or as thin films on sodium chloride plates. Melting point determination was performed using an Electrothermal Mel-Temp 1001D manual melting point apparatus.

Gel permeation chromatography (GPC) was performed using an Agilent GPC system connected to a Wyatt Heleos II multi-angle laser light scattering detector, a Viscostar viscometer and an Optilab T-rex refractometer. The sample was filtered through a $0.45 \mu \mathrm{m}$ syringe filter before insertion into the GPC system and the mobile phase used was THF at $1 \mathrm{ml} / \mathrm{min}$. The refractive index increment used to calculate the molecular weight was that of polystyrene $(0.185 \mathrm{ml} / \mathrm{g})$. Differential scanning calorimetry (DSC) was performed using the differential scanning calorimeter Q1000 V9.9 from TA instruments. The thermal history of the polymer was eliminated by placing the polymer in a closed sample heating pan and performing the following heating program: $-95{ }^{\circ} \mathrm{C}$ to $150{ }^{\circ} \mathrm{C}$ at $10{ }^{\circ} \mathrm{C} / \mathrm{min}, 150{ }^{\circ} \mathrm{C}$ for $3 \mathrm{~min}$, cooling from $150{ }^{\circ} \mathrm{C}$ to $-95{ }^{\circ} \mathrm{C}$ and $-95^{\circ} \mathrm{C}$ for 3 min. The glass transition temperature $\left(\mathrm{T}_{\mathrm{g}}\right)$ was obtained from the inflection point on the thermogram during the second heating cycle of the sample. GPC and DSC were performed at the University of Ottawa by Shanshan Ren of Dr. Marc Dubé's lab. 


\subsubsection{Synthesis of SP-PS (8)}

4-(4'-chlorobutyl)styrene (2). 2 was prepared by a modification of the method described by Spanka et al. ${ }^{30}$ Magnesium turnings $(3.797 \mathrm{~g}, 0.156 \mathrm{~mol}, 1.1 \mathrm{eq})$ and iodine (1 crystal, catalytic quantity) were added to a $500 \mathrm{ml}$ 2-neck round-bottom flask fitted with a condenser, a septum and a stir bar. The magnesium turnings were gently heated under argon using a heating mantle. Dry diethyl ether $(190 \mathrm{ml})$ was added to the flask and 4vinylbenzylchloride $(20 \mathrm{ml}, 0.138 \mathrm{~mol}, 1.0 \mathrm{eq})$ was added with a pressure equalizing dropping funnel at a rate allowing a gentle reflux to be maintained. The insoluble material was allowed to settle. Dry THF $(190 \mathrm{ml})$, 1-bromo-3-chloropropane $(20 \mathrm{ml}$, $0.202 \mathrm{~mol}, 1.5 \mathrm{eq})$ and dilithium tetrachlorocuprate (II) solution (0.1 M in THF, $1.5 \mathrm{ml}$, $0.001 \mathrm{eq}$ ) were added by syringe with stirring to another $500 \mathrm{ml}$ 2-neck round bottomed flask fitted with a septum under argon and was cooled to $0{ }^{\circ} \mathrm{C}$ using an ice-bath. The Grignard reagent was added to the solution containing 1-bromo-3-chloropropane by canula over 30 minutes using pressure while avoiding the addition of the insoluble material. The mixture was allowed to warm to room temperature and was stirred for 20 hours under argon. The mixture was then quenched by the slow addition of water $(50 \mathrm{ml})$ and saturated ammonium chloride $(50 \mathrm{ml})$. The layers were separated and the aqueous layer was washed with diethyl ether $(3 \times 30 \mathrm{ml})$. The washings were added to the organic layer and the mixture was washed with saturated ammonium chloride $(3 \times 75 \mathrm{ml})$, brine $(3 \times 75 \mathrm{ml})$ and dried using magnesium sulfate. The solvent was removed under reduced pressure to give the crude product as a yellow oil $(38.10 \mathrm{~g})$. The crude product was purified using silica gel column chromatography (hexanes, $R_{\mathrm{f}}=0.35$ ) to give pure $\mathbf{2}$ as a colourless oil (3.79 g, $19.5 \mathrm{mmol}, 42 \%) .{ }^{1} \mathrm{H}-\mathrm{NMR}\left(300 \mathrm{MHz}, \mathrm{CDCl}_{3}\right) \delta$ 7.37-7.34 (m, 
2H), 7.17-7.15 (m, 2H), 6.76-6.67 (dd, $J=17.7,10.8 \mathrm{~Hz}, 1 \mathrm{H}), 5.76-5.70(\mathrm{dd}, J=17.7$, $0.9 \mathrm{~Hz}, 1 \mathrm{H}), 5.24-5.20(\mathrm{dd}, J=10.8,0.9 \mathrm{~Hz}, 1 \mathrm{H}), 3.58-3.55(\mathrm{~m}, 2 \mathrm{H}), 2.68-2.63(\mathrm{~m}, 2 \mathrm{H})$, 1.88-1.73 (m, 4H). ${ }^{1} H$-NMR spectroscopy and all other spectroscopic data was in agreement with literature. ${ }^{30}$

4-(4'-Acetoxybutyl)styrene (3). 3 was prepared using a modification of the method described by Spanka et al. ${ }^{30}$ In a single neck round-bottom flask fitted with a stir bar, $\mathbf{2}$ (3.79 g, 19.5 mmol, 1 eq) was dissolved in dry DMF (39 ml) under argon. Anhydrous potassium acetate $(3.05 \mathrm{~g}, 31.1 \mathrm{mmol}, 1.6 \mathrm{eq})$ and TBAI $(103.3 \mathrm{mg}, 0.28 \mathrm{mmol}, 0.014$ eq) were added to the clear solution. The round-bottom flask was fitted with a condenser and the mixture was allowed to stir under argon at $60{ }^{\circ} \mathrm{C}$ until no starting material was observed by TLC analysis (approximately 168 hours). Solvent was removed from the opaque white solution under reduced pressure and a mixture of ethyl acetate/2 $\mathrm{M} \mathrm{HCl}$ $(1: 1,160 \mathrm{ml})$ was added slowly. The layers were separated and the aqueous phase was washed with ethyl acetate $(2 \times 30 \mathrm{ml})$. The washings were added to the organic layer and the solution was washed with water $(3 \times 50 \mathrm{ml})$, brine $(1 \times 50 \mathrm{ml})$ and dried using magnesium sulfate. The solvent was removed under reduced pressure to give a light yellow oil as pure 3 (3.97 g, $18.2 \mathrm{mmol}, 93 \%)$. ${ }^{1} \mathrm{H}-\mathrm{NMR}\left(300 \mathrm{MHz}, \mathrm{CDCl}_{3}\right) \delta$ 7.37-7.34 (m, 2H), 7.17-7.14 (m, 2H), 6.76-6.67 (dd, J = 17.7, $11.1 \mathrm{~Hz}, 1 \mathrm{H}), 5.76-5.69(\mathrm{dd}, J=$ 17.7, $0.6 \mathrm{~Hz}, 1 \mathrm{H}), 5.23-5.20$ (dd, $J=11.1,0.6 \mathrm{~Hz}, 1 \mathrm{H}), 4.10-4.08$ (m, 2H), 2.68-2.63 (m, 2H), $2.06(\mathrm{~s}, 3 \mathrm{H}), 1.71-1.67(\mathrm{~m}, 4 \mathrm{H}) .{ }^{1} H-N M R$ spectroscopy and all other spectroscopic data was in agreement with literature. ${ }^{30}$ 
4-(4'-Hydroxybutyl)styrene (4). 4 was prepared by a modification of the method decribed by Spanka et al. ${ }^{30}$ In a single neck round-bottom flask, 3 (3.79 g, $18.2 \mathrm{mmol}$, 1.00 eq) was dissolved in methanol $(60 \mathrm{ml})$ and aqueous sodium hydroxide solution (25 $\mathrm{ml}, 4 \mathrm{M}, 0.1 \mathrm{~mol}, 5.5 \mathrm{eq})$ was added to the solution under argon. The clear yellow solution became turbid and was allowed to stir for 2.5 hours at room temperature. Distilled water $(60 \mathrm{ml})$ was added to the solution and it became white immediately. The organic phase was removed under reduced pressure and the remaining aqueous phase was extracted using diethyl ether $(3 \times 30 \mathrm{ml})$. The diethyl ether extracts were then washed using distilled water $(3 \times 30 \mathrm{ml})$, brine $(1 \times 30 \mathrm{ml})$ and dried using magnesium sulfate. The solvent was removed under reduced pressure to give a light yellow oil of pure 4 (3.13 g, $17.8 \mathrm{mmol}, 98 \%) .{ }^{1} \mathrm{H}-\mathrm{NMR}\left(300 \mathrm{MHz}, \mathrm{CDCl}_{3}\right) \delta$ 7.36-7.34 (m, 2H), 7.18-7.15 (m, 2H), 6.76-6.67 (dd, $J=17.7,10.8 \mathrm{~Hz}, 1 \mathrm{H}), 5.75-5.69(\mathrm{dd}, J=17.7,0.9 \mathrm{~Hz}, 1 \mathrm{H}), 5.23-5.19$ (dd, $J=10.8,0.9 \mathrm{~Hz}, 1 \mathrm{H}), 3.71-3.65(\mathrm{~m}, 2 \mathrm{H}), 2.68-2.63(\mathrm{~m}, 2 \mathrm{H}), 1.75-1.57(\mathrm{~m}, 4 \mathrm{H}), 1.26-$ $1.23(\mathrm{~m}, 1 \mathrm{H}) .{ }^{1} H-N M R$ spectroscopy and all other spectroscopic data was in agreement with literature. ${ }^{30}$

4-(4'-iodobutyl)styrene (5). The following procedure for the preparation of 5 was adapted from Spino and Barriault. ${ }^{31}$ Triphenylphosphine $(9.311 \mathrm{~g}, 35.5 \mathrm{mmol}, 2 \mathrm{eq})$, imidazole (2.417 mg, $35.5 \mathrm{mmol}, 2 \mathrm{eq})$ and iodine (9.0102 g, $35.5 \mathrm{mmol}, 2 \mathrm{eq})$ were added successively to a solution of $4(3.13 \mathrm{~g}, 17.8 \mathrm{mmol}, 1 \mathrm{eq})$ in diethyl ether/acetonitrile $(4: 1,107 \mathrm{ml})$ in a single neck round-bottom flask and the mixture was allowed to stir for 60 minutes under argon. The dark purple mixture was diluted with diethyl ether $(50 \mathrm{ml})$, filtered over Celite and the Celite was washed with diethyl ether 
(40 ml). The filtrate solution was then washed with saturated sodium bicarbonate solution $(2 \times 100 \mathrm{ml})$, brine $(1 \times 100 \mathrm{ml})$ and dried using magnesium sulfate. The solvent was removed under reduced pressure and the mixture was triturated with hexanes to give yellow oil as crude 5 (4.91 g, $17.2 \mathrm{mmol})$. The crude product was then purified using silica gel column chromatography (hexanes, $\mathrm{R}_{\mathrm{f}}=0.48$ ) to give pure 5 as a colourless, clear oil (3.14 g, $11.0 \mathrm{mmol}, 62 \%) .{ }^{1} \mathrm{H}-\mathrm{NMR}\left(300 \mathrm{MHz}, \mathrm{CDCl}_{3}\right) \delta$ 7.35-7.33 (m, 2H), 7.15$7.12(\mathrm{~m}, 2 \mathrm{H}), 6.74-6.65(\mathrm{dd}, J=17.7,10.8 \mathrm{~Hz}, 1 \mathrm{H}), 5.74-5.68(\mathrm{dd}, J=17.7,0.9 \mathrm{~Hz}, 1 \mathrm{H})$, 5.22-5.18 (dd, $J=10.8,0.9 \mathrm{~Hz}, 1 \mathrm{H}), 3.22-3.17(\mathrm{~m}, 2 \mathrm{H}), 2.65-2.60(\mathrm{~m}, 2 \mathrm{H}), 1.90-1.81(\mathrm{~m}$, 2H), 1.78-1.73 (m, 2H); ${ }^{13} \mathrm{C}-\mathrm{NMR}\left(75 \mathrm{MHz}, \mathrm{CDCl}_{3}\right) \delta 141.51,136.60,135.37,128.55$, 126.25, 113.07, 34.47, 32.89, 32.10, 6.70; IR (NaCl plate, $\left.\mathrm{cm}^{-1}\right)$ 3047, 2934, 1906, 1815, $1629,1455,1167,843 \mathrm{~cm}^{-1}$.

\section{2,3,3-trimethyl-1-[4-(4-vinylphenyl)butyl]indol-1-ium $\quad$ iodide $\quad$ (6). 2,3,3-} trimethylindolenine (1.76 ml, $11.0 \mathrm{mmol}, 1 \mathrm{eq})$ was added to 5 (3.13 g, $11.0 \mathrm{mmol}, 1 \mathrm{eq})$ in dry acetonitrile $(9 \mathrm{ml})$ in a $50 \mathrm{ml}$ round-bottom flask fitted with a condenser under argon. The dark red solution was allowed to reflux until no starting material was detectable by NMR spectroscopy (ca. 96 hours). The now dark purple solution was allowed to cool to room temperature and the solvent was removed under reduced pressure. The purple oily crude mixture containing $\mathbf{6}$ was then dissolved in a minimum of acetonitrile, precipitated into diethyl ether and filtered on a glass frit to obtain pure light pink solid 6 (4.72 g, $10.6 \mathrm{mmol}, 96 \%)$. MP 113.3-114.5 ${ }^{\circ} \mathrm{C} ;{ }^{1} \mathrm{H}$ NMR (300 MHz, $\mathrm{CDCl}_{3}$ ) $\delta 7.66-7.43(\mathrm{~m}, 5 \mathrm{H}), 7.40-7.30(\mathrm{~m}, 3 \mathrm{H}), 7.20-7.09(\mathrm{~m}, 2 \mathrm{H}), 6.69$ (dd, $J=17.6,10.9$ $\mathrm{Hz}, 1 \mathrm{H}), 5.72(\mathrm{~d}, J=17.6 \mathrm{~Hz}, 1 \mathrm{H}), 5.22(\mathrm{~d}, J=10.8 \mathrm{~Hz}, 1 \mathrm{H}), 4.71(\mathrm{t}, J=7.6 \mathrm{~Hz}, 2 \mathrm{H})$, 
$3.08(\mathrm{~s}, 3 \mathrm{H}), 2.73(\mathrm{t}, J=7.0 \mathrm{~Hz}, 2 \mathrm{H}), 2.03-1.78(\mathrm{~m}, 5 \mathrm{H}), 1.63(\mathrm{~s}, 7 \mathrm{H}) ;{ }^{13} \mathrm{C}$ NMR $(75$ $\mathrm{MHz}, \mathrm{CDCl} 3) \delta 195.64,141.57,140.94,140.33,136.44,135.70,130.14,129.56,128.65$, $126.43,123.28,115.37,113.42,77.47,77.25,77.04,76.62,54.63,50.04,34.55,27.91$, 27.05, 23.21, 17.15; IR ( $\mathrm{NaCl}$ plate, $\left.\mathrm{cm}^{-1}\right)$ 3010, 2931, 1919, 1817, 1701, 1626, 1459, 729.

\section{3,3'-dimethyl-6-nitro-1'-(4-(4-vinylphenyl)butyl)spiro[chromene-2,2'-indoline]}

(mSP-PS) (7). 2-hydroxy-5-nitrobenzaldehyde (1.772 g, $10.6 \mathrm{mmol}, 1 \mathrm{eq})$ was added to a solution of $6(4.72 \mathrm{~g}, 10.6 \mathrm{mmol}, 1 \mathrm{eq})$ in anhydrous ethanol $(40 \mathrm{ml})$ in a $100 \mathrm{ml}$ roundbottom flask fitted with a condenser under argon. Piperidine $(1.0 \mathrm{ml}, 10.6 \mathrm{mmol}, 1 \mathrm{eq})$ was added to the dark purple solution and the solution was allowed to reflux until the mixture became dark red with fine precipitate visible (ca. 5 hours). The mixture was cooled to room temperature and then to $4{ }^{\circ} \mathrm{C}$ overnight. Fine red precipitate was removed from the mixture by suction filtration and was washed with cold methanol $(10 \mathrm{ml})$. The precipitate was dissolved in a minimum volume of ethyl acetate and was triturated with hexanes to remove the piperidine salt. The solution of crude $\mathbf{7}$ in ethyl acetate (diluted to $200 \mathrm{ml}$ ) was washed with a dilute aqueous solution of sodium chloride $(4 \times 100 \mathrm{ml})$, distilled water $(4 \times 100 \mathrm{ml})$ and dried using magnesium sulfate. The solvent was removed under reduced pressure to give solid, dark red 7 (2.08 g, 4.60 mmol, 43\%). MP 78.5-84.5 ${ }^{\circ} \mathrm{C} ;{ }^{1} \mathrm{H}$ NMR (400 MHz, $\mathrm{CDCl}_{3}$ ) $\delta$ 8.01-7.97 (m, 2H), 7.30-7.28 (m, 2H), 7.19-7.15 (dt, $J$ $=7.6,0.8 \mathrm{~Hz}, 1 \mathrm{H}), 7.08-7.06(\mathrm{~m}, 3 \mathrm{H}), 6.87-6.84(\mathrm{~m}, 2 \mathrm{H}), 6.71-6.65(\mathrm{~m}, 2 \mathrm{H}), 6.54-6.52$ (d, $J=7.6 \mathrm{~Hz}, 1 \mathrm{H}), 5.81-5.79(\mathrm{~d}, J=10.4 \mathrm{~Hz}, 1 \mathrm{H}), 5.72-5.68(\mathrm{~d}, J=17.2 \mathrm{~Hz}, 1 \mathrm{H}), 5.21-$ $5.18(\mathrm{~d}, J=11.6 \mathrm{~Hz}, 1 \mathrm{H}), 3.19-3.13(\mathrm{~m}, 2 \mathrm{H}), 2.60-2.561(\mathrm{t}, J=13.6 \mathrm{~Hz}, 2 \mathrm{H}), 1.69-$ 
$1.525(\mathrm{~m}, 6 \mathrm{H}), 1.27(\mathrm{~s}, 3 \mathrm{H}), 1.16(\mathrm{~s}, 3 \mathrm{H}) ;{ }^{13} \mathrm{C} \mathrm{NMR}(100 \mathrm{MHz}, \mathrm{CDCl} 3) \delta 159.61,147.08$, $141.76,140.88,136.58,135.92,135.29,128.49,128.07,127.72,126.17,125.87,122.67$, $122.00,121.67,119.32,118.42,115.50,113.03,106.68,77.31,77.20,77.00,76.70$ 76.68, 52.63, 43.60, 35.31, 28.90, 28.40, 26.01, 19.83; IR (KBr, $\left.\mathrm{cm}^{-1}\right)$ 2931, 1907, 1806, $1651,1610,1518,1481,1336,1274,1090,807,746$.

(SP-PS) (8). 7 (0.49887 g, $1.07 \mathrm{mmol}, 1$ eq.) was added to a $25 \mathrm{ml}$ flame-dried roundbottom flask fitted with a condenser, flushed with argon and dissolved in freshly distilled and degassed benzene (6 ml). 2,2'-Azobis(2-methylpropionitrile) (AIBN) $(0.2 \mathrm{M}$ in toluene, $0.5 \mathrm{ml}, 0.01 \mathrm{eq}$ ) was added to the solution and the mixture was heated to reflux for 21 hours under argon. The flask was removed from heat and cooled in an ice bath and then exposed to the atmosphere. The solvent was removed in vacuo and dissolved in a minimum of benzene $(1 \mathrm{ml})$. The solution was added dropwise to a stirring solution of methanol $(50 \mathrm{ml})$ and then filtered on a fine glass frit. This was repeated three times or until no monomer was visible by NMR spectroscopy. The crude product was then stirred in hexanes $(10 \mathrm{ml})$ and filtered to yield pure 8 as a pale purple-grey solid $(21 \mathrm{mg}, 4 \%)$. $\operatorname{Tg} 118.14{ }^{\circ} \mathrm{C}$; Mn 63,980 (D=1.24); ${ }^{1} \mathrm{H}$ NMR (300 MHz, $\left.\mathrm{CDCl}_{3}\right) \delta 7.96$ (br s, $\left.2 \mathrm{H}\right), 7.12-$ 6.52 (br m, 12H), 5.79 (br s, 1H), 3.14 (br s, 2H), 2.51 (br s, 2H), 1.60 (br s, 8H), 1.26 (br s, 3H), (1.15 (br s, 3H). 


\subsection{3 $\left[\left\{\mathrm{Ru}\left(\mathrm{NH}_{3}\right)_{5}\right\}_{2}(\mu-\right.$ dicyd $\left.)\right]\left[\mathrm{BPh}_{4}\right]_{4}(11)$}

The author is thankful to Dr. Robert J. Crutchley and previous members of the Crutchley group for the synthesis of the crude complex, $\left[\left\{\mathrm{Ru}\left(\mathrm{NH}_{3}\right)_{5}\right\}_{2}(\mu\right.$-dicyd) $][\mathrm{Br}]_{4}(\mathbf{9})$. The synthesis is described below.

$\left[\left\{\mathbf{R u}\left(\mathbf{N H}_{3}\right)_{5}\right\}_{2}(\mu\right.$-dicyd) $]\left[\mathbf{P F}_{6}\right]_{4}(\mathbf{1 0}) .\left[\left\{\mathrm{Ru}\left(\mathrm{NH}_{3}\right)_{5}\right\}_{2}(\mu\right.$-dicyd) $][\mathrm{Br}]_{4}$ was prepared by $\mathrm{Dr}$. Robert J. Crutchley according to the method described by Naklicki et al. ${ }^{32}$ Crude 9 (710 mg) was purified by Sephadex column using 1.0 M aqueous sodium chloride solution as eluent and collecting the first vibrant green band. Crude 9 was further purified previously

described. ${ }^{32}$ Solid black crystalline 10 was obtained $(170 \mathrm{mg}, 0.150 \mathrm{mmol}) .10$ was used without spectroscopic characterization.

$\left[\left\{\mathbf{R u}\left(\mathbf{N H}_{3}\right)_{5}\right\}_{2}(\mu\right.$-dicyd) $]\left[\mathbf{B P h}_{4}\right]_{4}(\mathbf{1 1}) .11$ was prepared by the dissolution of $\mathbf{1 0}(170 \mathrm{mg}$, $0.150 \mathrm{mmol}, 1$ eq.) in a minimum of acetone and precipitation with excess TBAB. The bromide salt was then filtered and dissolved in a minimum of distilled water. 11 was then precipitated from solution by the addition of excess $\mathrm{NaBPh}_{4}$. The precipitate was collected on a glass frit, washed with ice-cold water and diethyl ether and dried under vacuum overnight to give solid, light brown 11 (249 mg, $0.136 \mathrm{mmol}, 91 \%) .{ }^{1} \mathrm{H}$ NMR (300 MHz, DMSO- $\left.d_{6}\right) \delta 53.21(\mathrm{br} \mathrm{s}, 24 \mathrm{H}), 7.17(\mathrm{~m}, 32 \mathrm{H}), 6.94-6.89(\mathrm{~m}, 32 \mathrm{H}), 6.80-6.76$ $(\mathrm{m}, 16 \mathrm{H}),-9.16(\mathrm{br} \mathrm{s}, 4 \mathrm{H})$. Note that the trans ammines were outside the scan width.

\subsubsection{Alternative Complexes Used in Various Studies}

The author is thankful to previous members of the Crutchley group for the synthesis of $\left[\left\{\mathbf{R u}\left(\mathbf{N H}_{3}\right)_{4}(\mathbf{p y})\right\}_{2}(\mu-d i c y d)\right]\left[\mathrm{PF}_{6}\right]_{4}$ and $\left[\mathbf{R u}\left(\mathbf{N H}_{3}\right)_{5}(\mathbf{p c y d}-\mathrm{Cl})\right]\left[\mathrm{ClO}_{4}\right]_{2}$. The 
counterion was changed to $\mathrm{BPh}_{4}{ }^{-}$following the procedure listed above for 11 . The complexes were used without spectroscopic characterization.

\subsubsection{Other Photochromic Molecules}

\subsubsection{Spiropyran Derivatives}

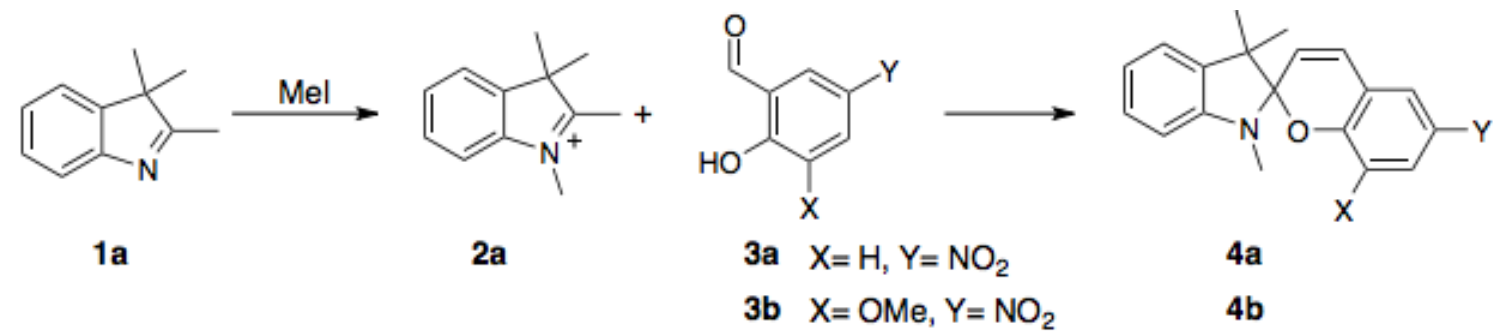

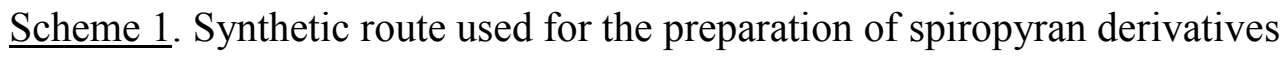

1,2,3,3-tetramethyl-3H-Indolium iodide (2A). $2 \mathrm{~A}$ was prepared by the method described by Ueno et al. ${ }^{33}$ Solid purple $\mathbf{2 A}$ was prepared $(2.71 \mathrm{~g}, 8.98 \mathrm{mmol}, 90 \%) .{ }^{1} \mathrm{H}$ NMR (400 MHz, $\left.\mathrm{CDCl}_{3}\right) \delta$ 7.67-7.54 (m, 4H), $4.30(\mathrm{~s}, 3 \mathrm{H}), 3.15(\mathrm{~s}, 3 \mathrm{H}), 1.71(\mathrm{~s}, 6 \mathrm{H})$. ${ }^{1} H$-NMR spectroscopy and all other spectroscopic data was in agreement with literature. $^{33}$

6-nitro-1',3,3'-trimethylspiro-[2H-1-benzopyran-2,2'-indoline] $\quad$ (4A). $4 \mathrm{~A} \quad$ was prepared using commercial $\mathbf{3 A}$ by the method described by Li et al. ${ }^{34}$ Solid light brown 4A was prepared (1.59 g, $4.3 \mathrm{mmol}, 86 \%) .{ }^{1} \mathrm{H}$ NMR (300 MHz, $\left.\mathrm{CDCl}_{3}\right) \delta 8.04-8.00(\mathrm{~m}$, 2H), $7.24-7.18(\mathrm{dt}, J=7.8,1.5 \mathrm{~Hz}, 1 \mathrm{H}), 7.11-7.08(\mathrm{~m}, 1 \mathrm{H}), 6.94-6.86(\mathrm{~m}, 2 \mathrm{H}), 6.79$ $-6.76(\mathrm{~m}, 1 \mathrm{H}), 6.58-6.55(\mathrm{~d}, J=7.8 \mathrm{~Hz}, 1 \mathrm{H}), 5.88-5.84(\mathrm{~d}, J=10.5 \mathrm{~Hz}, 1 \mathrm{H}), 2.74(\mathrm{~s}$, 
3H), $1.30(\mathrm{~s}, 3 \mathrm{H}), 1.19$ (s, 3H). ${ }^{1} H-N M R$ spectroscopy and all other spectroscopic data was in agreement with literature. ${ }^{34}$

2-hydroxy-3-methoxy-5-nitrobenzaldehyde (3B). 3B was prepared according to the procedure described by Roxburgh et al. ${ }^{35}$ Solid pale yellow 3B was prepared $(0.55 \mathrm{~g}, 0.60$ mmol, 42\%). ${ }^{1} \mathrm{H}$ NMR $\left(300 \mathrm{MHz}, \mathrm{CDCl}_{3}\right) \delta 11.74(\mathrm{~s}, 1 \mathrm{H}), 10.01(\mathrm{~s}, 1 \mathrm{H}), 8.24-8.23(\mathrm{~d}, J$ $=2.4 \mathrm{~Hz}, 1 \mathrm{H}), 7.95-7.94(\mathrm{~d}, J=2.7 \mathrm{~Hz}, 1 \mathrm{H}), 4.03(\mathrm{~s}, 3 \mathrm{H}) .{ }^{1} H-N M R$ spectroscopy and all other spectroscopic data was in agreement with literature. ${ }^{35}$

8-methoxy-6-nitro-1',3,3'-trimethylspiro-[2H-1-benzopyran-2,2'-indoline] (4B). 4B was prepared according to the procedure described by Roxburgh et al. ${ }^{35}$ Solid yellow 4B was prepared (1.59 g, $4.3 \mathrm{mmol}, 86 \%) .{ }^{1} \mathrm{H} \mathrm{NMR}\left(400 \mathrm{MHz}, \mathrm{CDCl}_{3}\right) \delta 7.70-7.69(\mathrm{~d}, J=$ $2.4 \mathrm{~Hz}, 1 \mathrm{H}), 7.63-7.62(\mathrm{~d}, J=2.4 \mathrm{~Hz}, 1 \mathrm{H}), 7.20-7.18(\mathrm{dt}, J=6.4,1.2 \mathrm{~Hz}, 1 \mathrm{H}), 7.08-7.07$ $(\mathrm{d}, J=6.4 \mathrm{~Hz}, 1 \mathrm{H}), 6.89-6.85(\mathrm{~m}, 2 \mathrm{H}), 6.56-6.54(\mathrm{~d}, \mathrm{~J}=7.6 \mathrm{~Hz}, 1 \mathrm{H}), 5.85-5.82(\mathrm{~d}, J=$ $10.4 \mathrm{~Hz}, 1 \mathrm{H}), 3.76$ (s, 3H), 2.76 (s, 3H), 1.29 (s, 3H), 1.18 (s, 3H). ${ }^{1} H$-NMR spectroscopy and all other spectroscopic data was in agreement with literature. ${ }^{35}$

\subsubsection{Donor-Acceptor Stenhouse Adduct (DASA)}

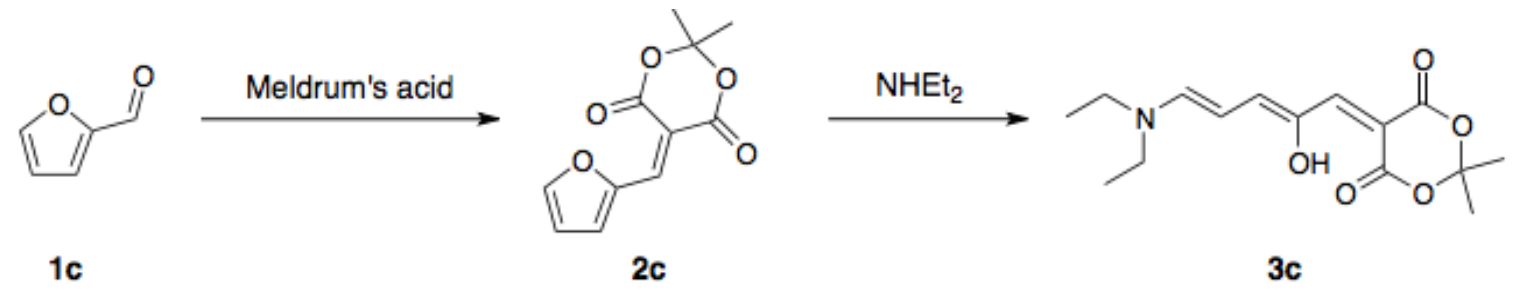

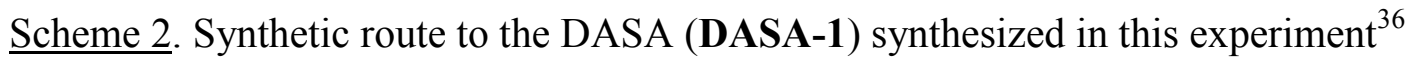


5-(2-furanylmethylene)-2,2-dimethyl-1,3-Dioxane-4,6-dione (2C). 2C was synthesized according to the method described by Helmy et al. ${ }^{36}$ Pure $2 \mathbf{C}$ was prepared as a bright yellow powder (1.78 g, $8.01 \mathrm{mmol}, 80 \%) .{ }^{1} \mathrm{H} \mathrm{NMR}\left(300 \mathrm{MHz}, \mathrm{CDCl}_{3}\right) \delta 8.48-8.46(\mathrm{~d}, J$ $=3.9 \mathrm{~Hz}, 1 \mathrm{H}), 8.36(\mathrm{~s}, 1 \mathrm{H}), 7.85-7.84(\mathrm{~m}, 1 \mathrm{H}), 6.76-6.74(\mathrm{~m}, 1 \mathrm{H}), 1.77(\mathrm{~s}, 6 \mathrm{H}) .{ }^{1} H-N M R$ spectroscopy and all other spectroscopic data was in agreement with literature. ${ }^{36}$

\section{5-((2Z,4E)-5-diethylamino)-2-hydroxypenta-2,4-dien-1-yliden-2,2-diethyl-1,3-}

dioxane-4,6-dione (3C). 3C was synthesized according to the method described by Helmy et al. ${ }^{36}$ Pure $3 \mathrm{C}$ was prepared as a dark red powder $(2.01 \mathrm{~g}, 6.81 \mathrm{mmol}, 68 \%) .{ }^{1} \mathrm{H}$ NMR (300 MHz, $\left.\mathrm{CDCl}_{3}\right) \delta 11.43(\mathrm{~m}, 1 \mathrm{H}), 7.24-7.20(\mathrm{~d}, J=12.3 \mathrm{~Hz}, 1 \mathrm{H}), 7.09(\mathrm{~s}, 1 \mathrm{H})$, 6.73-6.68 (dd, $J=12.3,1.2 \mathrm{~Hz}, 1 \mathrm{H}), 6.10-6.02(\mathrm{t}, J=12.3 \mathrm{~Hz}, 1 \mathrm{H}), 3.53-3.45(\mathrm{~m}, 4 \mathrm{H})$, $1.72(\mathrm{~s}, 6 \mathrm{H}), 1.38-1.28(\mathrm{~m}, 6 \mathrm{H}) .{ }^{1} H-N M R$ spectroscopy and all other spectroscopic data was in agreement with literature. ${ }^{36}$

\subsection{Photochemical Measurements}

\subsubsection{General Information}

All UV-Vis spectra were obtained using a Varian Cary 5 UV-Vis-NIR Spectrophotometer. Experiments were performed in ambient atmosphere unless otherwise indicated. Experiments performed under inert atmosphere were obtained by using an airtight chamber attached to the sample holder in the Varian Cary 5 UV-VisNIR Spectrophotometer. A positive flow of Ultra High Purity argon from Praxair was registered prior to each inert atmosphere experiment and all samples were degassed by a 
flow of argon for a minimum of 10 minutes before each experiment. All spectra were processed on SigmaPlot 10 and when 'smoothing' of data has been indicated, Loess smoother was used ( $\alpha=0.100$, polynomial degree of 1$)$. The sources of irradiation were light emitting diodes (LEDs) purchased from the LED Engin LZ1 series; they were mounted on a standard star board attached to a heat sink and were powered by a DC driver. LEDs used include: ultraviolet (365 nm, $395 \mathrm{~nm}$ and $405 \mathrm{~nm})$, blue $(460 \mathrm{~nm})$, green $(523 \mathrm{~nm})$ and amber $(590 \mathrm{~nm})$. For more information about the LEDs used, see the Appendix.

Experiments to determine the emissive properties of films were performed at Ottawa University in collaboration with the lab of Dr. Tito Scaiano.

\subsubsection{Thin Film Preparation}

The polystyrene used for the films was purchased from Aldrich and had a weight average molecular weight of $\sim 280,000$ by gas phase chromatography. Other samples of polystyrene are from the Supelco polystyrene analytical standards of low molecular weight kit. The $\left[\left\{\left(\mathrm{NH}_{3}\right)_{5} \mathrm{Ru}\right\}_{2} \mu\right.$-dicyd $]\left[\mathrm{BPh}_{4}\right]_{4}(\mathbf{1 1})$ used was synthesized as stated above. UltiDent glass microscope slides (frosted end and 1-1.2 mm thickness) were used as the substrate for all films and were rinsed with acetone prior to film preparation.

To prepare films containing SP-PS and 11, commercial polystyrene (various molecular weights, as above), $\mathbf{1 1}$ and 6- $\mathrm{NO}_{2} \mathrm{BIPS}$, or polystyrene and 6- $\mathrm{NO}_{2} \mathrm{BIPS}$ : 1) the various components were dissolved separately in solvent 2) equal volumes of solutions were combined 3) the combined solution was dropped onto a glass slide mounted in the center of the chuck of an Instras Scientific SCK100 Spin Coater and allowed to evaporate 
for $60 \mathrm{~s}, 3)$ the glass slide was accelerated to $180 \mathrm{rpm}$ and spun for a total of 10 minutes, 4) the glass slide was removed from the spin coater and placed in a vacuum desiccator for 24 hours and 5) the film was dried in a desiccator containing phosphorus pentoxide for 36 days. The volume of the combined solution and the concentration of each solution was dependent upon each experiment.

All films containing polystyrene and $\mathbf{1 1}$ were prepared using the following method: 1) polystyrene was dissolved in toluene at $18.3 \mathrm{mg} / \mathrm{ml}$ and $\mathbf{1 1}$ was dissolved in nitromethane at $23.9 \mathrm{mg} / \mathrm{ml}$ 2) equal volumes of both solutions were combined 3) $50 \mu \mathrm{L}$ of the combined solution was dropped onto a glass slide mounted in the center of the chuck of an Instras Scientific SCK100 Spin Coater, 3) the glass slide was accelerated to $2400 \mathrm{rpm}$ within 2 seconds and spun for a total of $10 \mathrm{~s}$ at $2400 \mathrm{rpm}, 4)$ the glass slide was removed from the spin coater and placed in a vacuum desiccator for 24 hours and 5) the film was dried in a desiccator containing phosphorus pentoxide for 3-6 days.

A sample film containing commercial polystyrene $\left(\mathrm{M}_{\mathrm{w}} 280,000\right.$ from SigmaAldrich) and 11 was prepared in the same method as listed above was characterized by scanning electron microscopy (SEM) to determine film thickness. The film was sputter coated with gold (99.99\%) with a Quorum Q150T sputter coater to create a conductive layer and was subsequently imaged using a Tescan Vega II XMU scanning electron microscope operating at $20 \mathrm{kV}$ with $10 \mathrm{kx}$ magnification, using a secondary electron detector and a working distance of $9 \mathrm{~mm}$. 


\subsubsection{Quantum Yield Measurements}

\subsubsection{1 $\mathrm{Fe}^{\mathrm{II}}$ Calibration Curve}

A stock solution of $0.136 \mathrm{M} \mathrm{Fe}^{\mathrm{II}}$ was prepared by dissolving $7.57 \mathrm{~g}^{\text {of }} \mathrm{FeSO}_{4}$ in 250 $\mathrm{ml}$ of $0.05 \mathrm{M} \mathrm{H}_{2} \mathrm{SO}_{4}$. The $\mathrm{Fe}^{\mathrm{II}}$ stock solution was standardized against $0.033 \mathrm{M}$ potassium dichromate using sodium diphenylsulfonate as indicator. Three solutions of $10 \mathrm{ml}$ of stock $\mathrm{Fe}^{\mathrm{II}}$ solution, $2 \mathrm{ml}$ of conc. $\mathrm{H}_{3} \mathrm{PO}_{4}$ and 8 drops of indicator solution $(25 \mathrm{mg}$ sodium diphenylsulfonate in $20 \mathrm{ml}$ distilled water) were titrated by potassium dichromate following standard procedure.

A calibration curve of $\mathrm{Fe}^{\mathrm{II}}$ was prepared to determine the molar extinction coefficient at $510 \mathrm{~nm}$. The stock solution of $\mathrm{Fe}^{\mathrm{II}}$ was diluted by dissolving $1 \mathrm{ml}$ of the standardized stock solution in $250 \mathrm{ml}$ of $0.05 \mathrm{M} \mathrm{H}_{2} \mathrm{SO}_{4}$. Five solutions were prepared in $25 \mathrm{ml}$ volumetric flasks. Each solution contained $5 \mathrm{ml}$ of $0.1 \%(\mathrm{w} / \mathrm{w}) 1,10$-phenanthroline in water, $5 \mathrm{ml}$ sodium acetate buffer $(150 \mathrm{ml}$ of $0.1 \mathrm{M}$ sodium acetate and $90 \mathrm{ml}$ of $0.05 \mathrm{M}$ sulfuric acid combined in a $250 \mathrm{ml}$ volumetric flask and diluted up to the mark with distilled water), $\mathrm{Fe}^{\mathrm{II}}$ diluted stock solution $(0,0.5,1.0,2.0$ or $2.5 \mathrm{ml})$, a volume of $0.05 \mathrm{M}$ aqueous $\mathrm{H}_{2} \mathrm{SO}_{4}$ equivalent to $10 \mathrm{ml}$ when combined with the $\mathrm{Fe}^{\mathrm{II}}$ stock solution and dilution up to the mark by distilled water. Each solution was incubated for 1 hour in the dark and the absorbance spectrum of each was collected from $350 \mathrm{~nm}$ to $700 \mathrm{~nm}$. The data obtained was used to calculate the extinction coefficient of $\mathrm{Fe}$ (II) at $510 \mathrm{~nm}$ (shown in Results and Discussion).

\subsubsection{Ferrioxalate Actinometry}


Potassium ferrioxalate was prepared by combining a solution of sodium oxalate ( $37 \mathrm{~g}$ in $150 \mathrm{ml}$ distilled water) and a solution of ferric chloride (20 g in $50 \mathrm{ml}$ distilled water). The resulting precipitate was recrystallized three times from warm distilled water under red light. The crystalline bright green solid, $\mathrm{K}_{3}\left[\mathrm{Fe}\left(\mathrm{C}_{2} \mathrm{O}_{4}\right)_{3}\right] \cdot 3 \mathrm{H}_{2} \mathrm{O}$, was vacuum dried for 20 hours and stored in the dark.

A stock solution of potassium ferrioxalate was prepared by dissolving $1.46 \mathrm{~g}$ of $\mathrm{K}_{3}\left[\mathrm{Fe}\left(\mathrm{C}_{2} \mathrm{O}_{4}\right)_{3}\right] \cdot 3 \mathrm{H}_{2} \mathrm{O}$ in a $25 \mathrm{ml}$ volumetric flask containing $2.5 \mathrm{ml} 0.05 \mathrm{M} \mathrm{H}_{2} \mathrm{SO}_{4}$ and diluting up to the mark with distilled water. The stock solution was further diluted by dissolving $0.5 \mathrm{ml}$ of the stock solution in a $50 \mathrm{ml}$ volumetric flask, adding $5 \mathrm{ml}$ of concentrated sulfuric acid and diluting up to the mark with distilled water. The absorbance spectrum from $350 \mathrm{~nm}$ to $700 \mathrm{~nm}$ of the solution was acquired.

To obtain the intensity of the light source used for SP-MC isomerization, $3 \mathrm{ml}$ aliquots of the potassium ferrioxalate stock solution were placed in a quartz cuvette with a $1 \mathrm{~cm}$ path length in the setup shown in the figure below. The samples were irradiated using the light source for the isomerization (365 $\mathrm{nm}$ LED) for varying amounts of times $(0,5,10$ and $15 \mathrm{~s})$. Immediately after irradiation, $1 \mathrm{ml}$ of the irradiated solution was added to a $25 \mathrm{ml}$ volumetric flask and dissolved in $5 \mathrm{ml} 0.1 \%(\mathrm{w} / \mathrm{w})$ 1,10-phenanthroline, $5 \mathrm{ml}$ sodium acetate buffer (as prepared above), $9 \mathrm{ml} 0.05 \mathrm{M} \mathrm{H}_{2} \mathrm{SO}_{4}$ and diluted up to the mark with water. The solution was incubated in the dark for 1 hour and the absorbance spectrum of the solution was obtained. These measurements were obtained immediately following the data from the SP-MC isomerization of the synthesized SPPS and used to calculate the intensity of the light source (shown in Results and Discussion). 


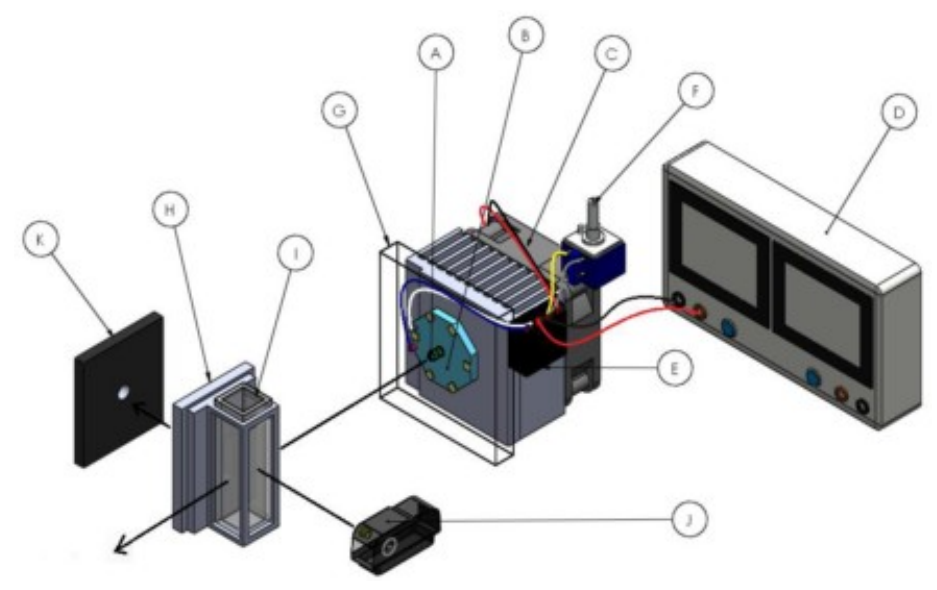

Figure 11. Instrumental setup for the quantum yield measurement: A) LED, B) standard star board LED mount, C) heat sink, D) DC power supply, E) buck puck DC driver, F) mounting apparatus for LED light source, G) neutral density filter (not used in this experiment), H) cuvette holder, I) quartz cuvette containing solution to be analyzed, J) detector and K) spectrophotometer light source. (Figure duplicated with permission) ${ }^{37}$

\subsubsection{SP-MC Isomerization Measurement}

A stock solution of SP-PS was prepared by dissolving $4.19 \mathrm{mg}$ of SP-PS in 100 $\mathrm{ml}$ toluene (spectro grade from Caledon Labs) in a $100 \mathrm{ml}$ volumetric flask. The extinction coefficient of SP-PS at the peak wavelength of MC $(590 \mathrm{~nm})$ was determined by irradiating the solution at $365 \mathrm{~nm}$ at varying lengths of time (using fresh solution each time) to determine the maximum absorbance at $590 \mathrm{~nm}$ before photobleaching occurred. The setup used was identical to that described in Figure 11 and these measurements occurred directly after determining the $365 \mathrm{~nm}$ LED light intensity. The maximum irradiation time was determined to be 45 seconds and the molar extinction coefficient was determined from the quantitative spectrum immediately after irradiation.

To determine the quantum yield of SP-MC isomerization, $3 \mathrm{ml}$ aliquots of the SPPS stock solution were placed in a quartz cuvette in the setup shown in Figure 11 and their initial absorbance spectrum (between $350 \mathrm{~nm}$ and $700 \mathrm{~nm}$ ) was obtained. The solutions were then irradiated using the $365 \mathrm{~nm}$ LED for varying amounts of time $(0,5$, 
$10,15,20,25,30,35,40$ and 45 s). Immediately after irradiation, the absorbance spectrum from 350 to $700 \mathrm{~nm}$ was obtained. The quantum yield was calculated using this information and the results are shown in Results and Discussion. 


\section{Chapter: Results and Discussion}

\subsection{Spiropyran-Polystyrene}

\subsubsection{Design of the Optical Switch}

A novel polymer (shown below) was designed and synthesized for application as an optical switch. The most basic requirement of the optical switch is the alternation between an 'on' state and an 'off' state that is controlled by light. The 'on' state requires a drastic increase in electron donation ability in comparison to the 'off' state in order for the optical switch to be useful for applications with the dinuclear ruthenium pentaamine complex, $\left[\left\{\mathrm{Ru}\left(\mathrm{NH}_{3}\right)_{5}\right\}_{2}(\mu\right.$-dicyd) $]\left[\mathrm{BPh}_{4}\right]_{4}$. This complex shows great sensitivity of the LMCT band (and, therefore, the conductive ability of the complex as part of a molecular wire or switch) to the electron donating nature of the outer-sphere. With this main principle in mind, the incorporation of 6- $\mathrm{NO}_{2} \mathrm{BIPS}$ into the structure of the monomer was efficient with regards to fulfilling the requirements. SPs are a well-known and wellstudied group of photochromic molecules able to alternate between two states with significantly different electron-donation ability, SP and MC, by exposure to long wave ultraviolet and visible light, respectively. 6- $\mathrm{NO}_{2} \mathrm{BIPS}$, the most widely studied derivative of SP, was selected from the SP derivatives as it is synthetically accessible and undergoes reversible switching. Most importantly, the substitution of the nitro group para to the phenoxide anion stabilizes the negative charge and allows for a greater lifetime of the $\mathrm{MC}$ form and, thus, for increased opportunity for interaction between $\mathrm{MC}$ and the ruthenium complex.

After selection of the photochromic moiety, the remainder of the photoswitch was designed to optimize the interaction between SP and the ruthenium complex. Firstly, the 
immobilization of $6-\mathrm{NO}_{2} \mathrm{BIPS}$ to a polymeric backbone was due to support in literature. ${ }^{13}$ The immobilization of SPs in photodynamic materials leads to reduced photodegradation and reduced aggregation of the MC isomer (which leads to a reduction in reversibility). For example, in a study testing the reversibility of photoswitching between SP and MC on two similar materials, one with anchored SP and another with non-immobilized SP, the loss of signal was $27 \%$ vs $57 \%$ after the $12^{\text {th }}$ isomerization cycle, respectively. ${ }^{38}$ Additionally, anchoring the SP to a polymer would aid in the formation of uniform thin films useful for application in information processing devices. The selection of polystyrene as the polymeric backbone over more common polymers used in photodynamic materials containing SP (for example, poly(methyl methacrylate)) was due to the low electron donor ability of the phenyl ring (Gutmann donor number of benzene is 0.1). ${ }^{12}$ This maximizes the response of the photoswitch containing SP because the LMCT band of the ruthenium complex would initially possess the largest extinction coefficient possible prior to exposure to MC. Finally, the purpose for the introduction of an alkyl linker between the polystyrene backbone and the photochromic moiety in the optical switch was two-fold: reduction of the aggregation between neighboring SPs and to reduce rigidity of the polymer to be synthesized by increasing the mobility of the pendant group. The synthesized polymer will be titled 'SP-PS' herein.

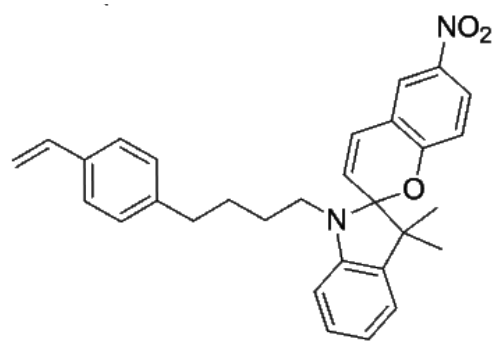

Figure 12. Structure of the monomer in SP-PS, mSP-PS 


\subsubsection{Synthesis of SP-PS}

A literature search revealed no precedence for a polymer structure adequately similar to the target design of the photoswitch. Therefore, a novel route was developed considering existing procedures, cost-effectiveness and simplicity of the included reactions - this route is shown below.

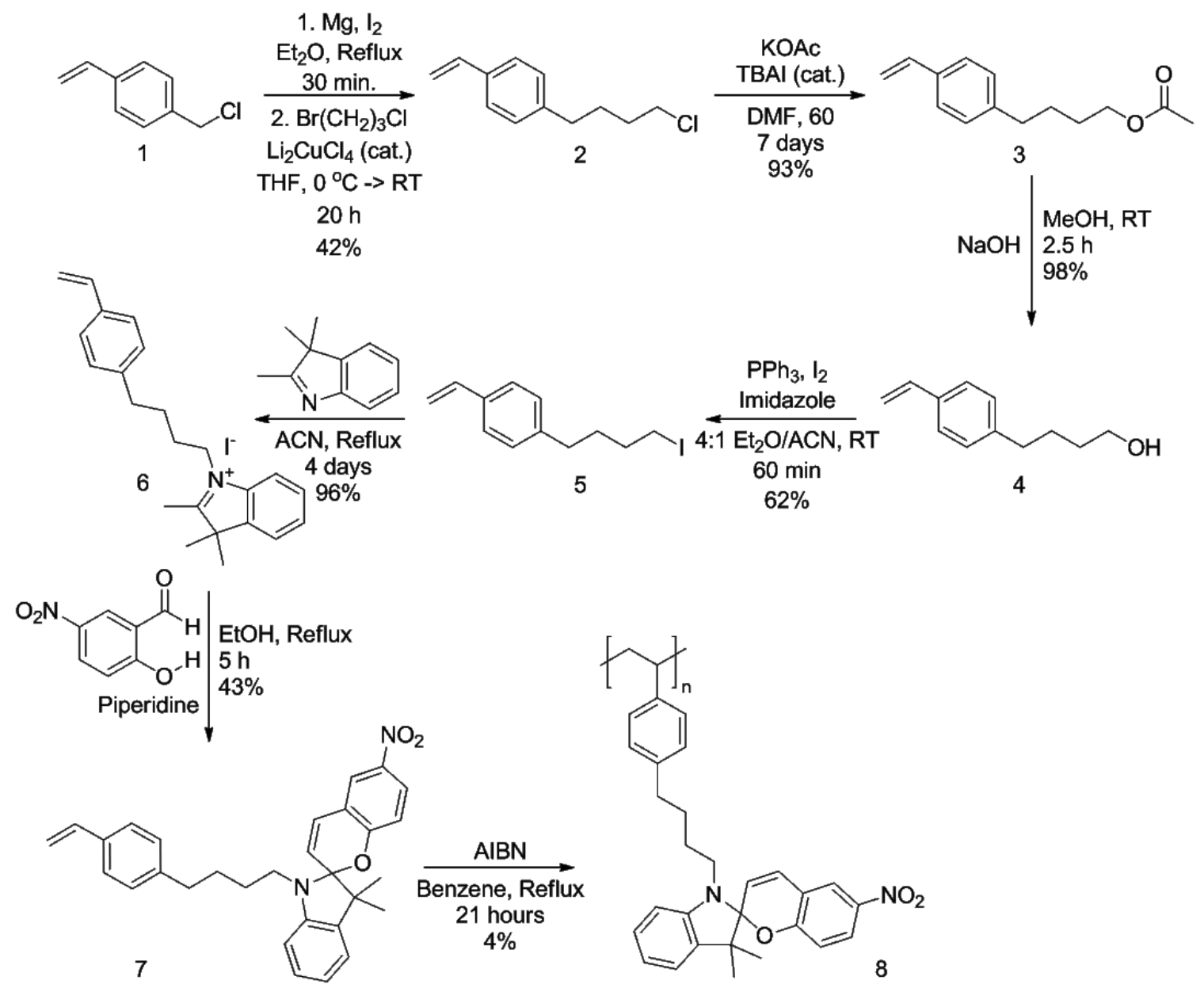

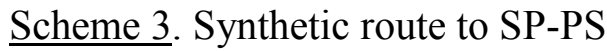

The pathway to intermediates $\mathbf{2 , 3}$ and $\mathbf{4}$ existed previously in literature ${ }^{30}$ whereas the remainder of reactions were performed using existing conditions from alternate substrates. The synthetic route commences with the formation of a Grignard reagent from 
the para-chloro substituted styrene that was chosen as a starting material as it is inexpensive in comparison to other substituted styrenes. The Grignard reaction with 1bromo-3-chloropropane produces intermediate 2 by the chemoselective reaction with the brominated terminal of the propane. An acylation reaction using TBAI as a catalyst produced 3 and a simple hydrolysis resulted in 4. An Appel reaction using well-known conditions followed to produce iodo derivative, 5. $^{31}$ This substrate is more reactive than the chloro derivative, $\mathbf{2}$, and an iodinated substrate is usually the starting point for the attachment of SPs. Subsequently, the typical procedure to synthesize 6-NO $\mathrm{NIPS}_{2}$ followed $-\mathrm{S}_{\mathrm{N}} 2$ reaction with the indole then a Knoevenagel condensation with the chromene moiety to produce the monomer, 7 . This route is advantageous because using any salicyaldehyde derivative easily changes the substitution pattern of the SP pendant group and the incorporation of SP into the polymer can be varied. Finally, the living free radical polymerization of the styrene using AIBN was performed to produce the polymer, 8. This method of polymerization was chosen as it is common for styrene polymerization.

The largest discrepancy between literature and experimental yield occurred for $\mathbf{2}$, which produced an experimental yield of $42 \%$ versus the $67 \%$ expected from literature. ${ }^{30}$ The difference in yield can be attributed to the difficulty of the purification process literature utilizes fractional distillation to separate $\mathbf{1}$ from $\mathbf{2}$, however, that was proven to be unfavourable due to the high temperature required and, experimentally, polymerization of both the product and the starting material occurred. Furthermore, dry column vacuum chromatography was also shown to be a weak separation method of $\mathbf{1}$ and 2. As the starting material and product were so similar, chromatography was only adequate for removing by-products. Complete conversion of starting material to product 
was decided to be the best route to pure $\mathbf{2}$. The overall yield of the monomer was $10 \%$ and it was most negatively affected by the first reaction of the synthetic route. Regardless, the quantity of monomer produced was adequate for our purpose.

The yield of the polymerization was extremely poor at only $4 \%$. Experimentally, the purification method of the polymer greatly contributed to the low yield. Purification was performed by precipitation of the polymer into methanol from an ethereal solution. Precipitation of the polymer was selective in that only polymer of high molecular weight was insoluble in methanol and would precipitate. It is possible that lower molecular weight polymer was soluble in methanol and was lost during the precipitation process. Experimental evidence for this exists in the form of a narrow peak in the chromatogram for the molecular weight determination (shown in Section 3.1.3.1). This narrow peak also suggests that the precipitated polymer possesses molecular weights on the higher tail end of a Gaussian curve describing the molecular weight distribution. Another factor greatly reducing the yield of the polymer was the design of the monomer itself. The inclusion of aromatic nitro group on the SP moiety, while useful for the application of the polymer, was a hindrance to the synthetic yield. Nitro functional groups are notorious for the production of polymers with low yield due to inhibition of free radicals. Aromatic nitro groups terminate propagating radicals either by attack of the radical on the para position of the phenyl ring (unlikely in this case) or by attack on the nitro group. Attack on the nitro group can lead to the terminated nitroso derivative, termination of the propagating radical on the nitro group and/or an ether linkage between terminated polymer chains. ${ }^{39}$ 


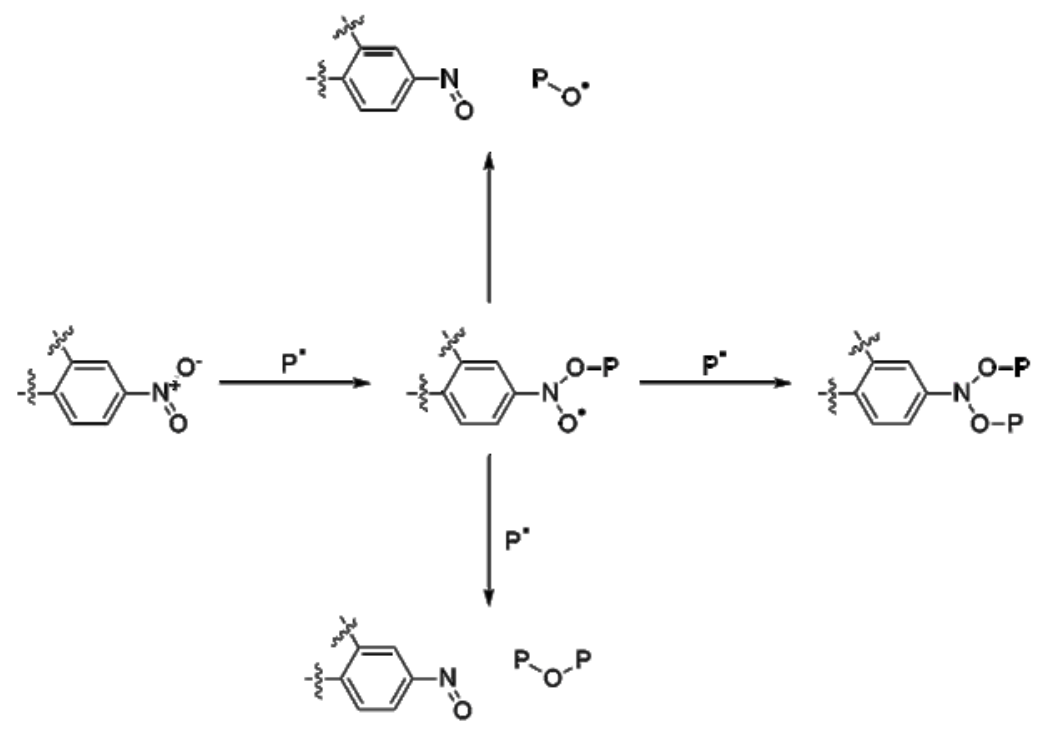

Scheme 4. Aromatic nitro functional group inhibition method in radical polymerization ( $\mathrm{P}$ is the propagating polymer chain)

Premature termination of the polymer chains would result in low molecular weight molecules that would be again removed by the precipitation of the polymer in methanol. While the yield was low, trials for testing our hypothesis were possible as well as characterization of the novel polymer, SP-PS.

\subsubsection{Properties of SP-PS}

Complete characterization (includes ${ }^{1} \mathrm{H}$ and ${ }^{13} \mathrm{C}$ NMR, IR, melting point, glass transition temperature and molecular weight) was performed on the novel intermediates, monomer and polymer. Integral characterization data will be presented and discussed below and the remainder of the characterization data of novel materials is attached in the Appendix. 


\subsubsection{Characterization}

mSP-PS was characterized by melting point, NMR and IR spectroscopy. The ${ }^{1} \mathrm{H}$ NMR spectrum in the aromatic region is shown below with the peak assignments,

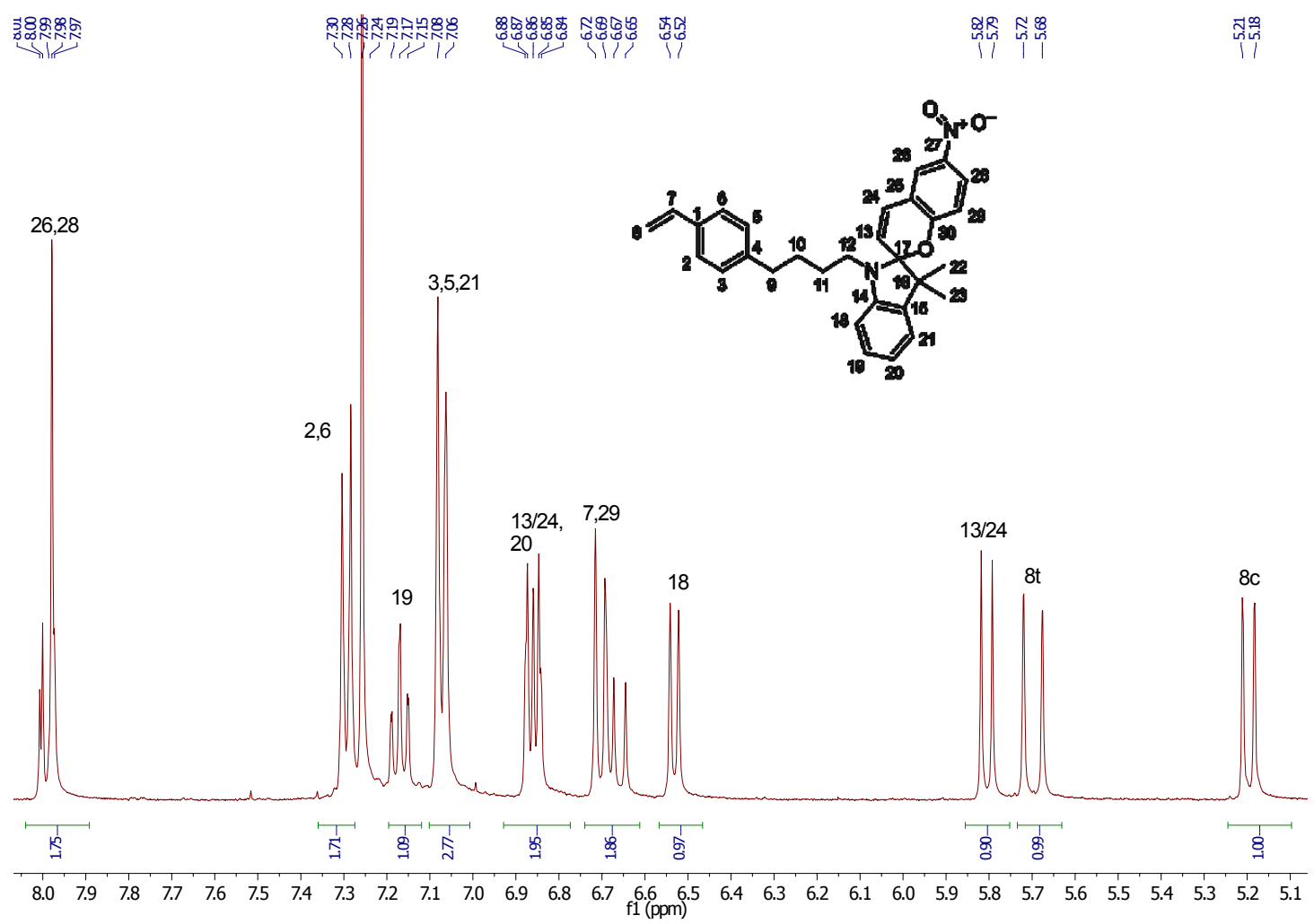

Figure 13. ${ }^{1} \mathrm{H}-\mathrm{NMR}$ spectrum of mSP-PS (7) at $400 \mathrm{MHz}$ in $\mathrm{CDCl}_{3}$ between 8.0 and 5.1 ppm

Peak assignments were difficult due to significant overlap - most protons from the SP and styrene moiety of the monomer have aromatic character. However, with the aid of COSY and HSQC NMR spectroscopy, the peaks were assigned and provided reasonable evidence for the synthesis of mSP-PS.

The ${ }^{1} \mathrm{H}$ NMR spectrum of SP-PS, below, shows a broadening of peaks in comparison to the ${ }^{1} \mathrm{H}$ NMR spectrum of mSP-PS. This is expected because of the range of chemical environments experienced by each of the protons in the monomeric units of 
the polymer. While individual peak assignment was not useful or possible, the information gained from this spectrum includes evidence for the polymerization of mSPPS and knowledge that the desired structure of the monomeric unit remains intact (the peak position, shape and integration are consistent with the spectrum of mSP-PS). In addition, the lack of sharp peaks in the spectrum indicates the absence of the monomer impurities (and even short chain polymers) and signifies the success of the purification process.

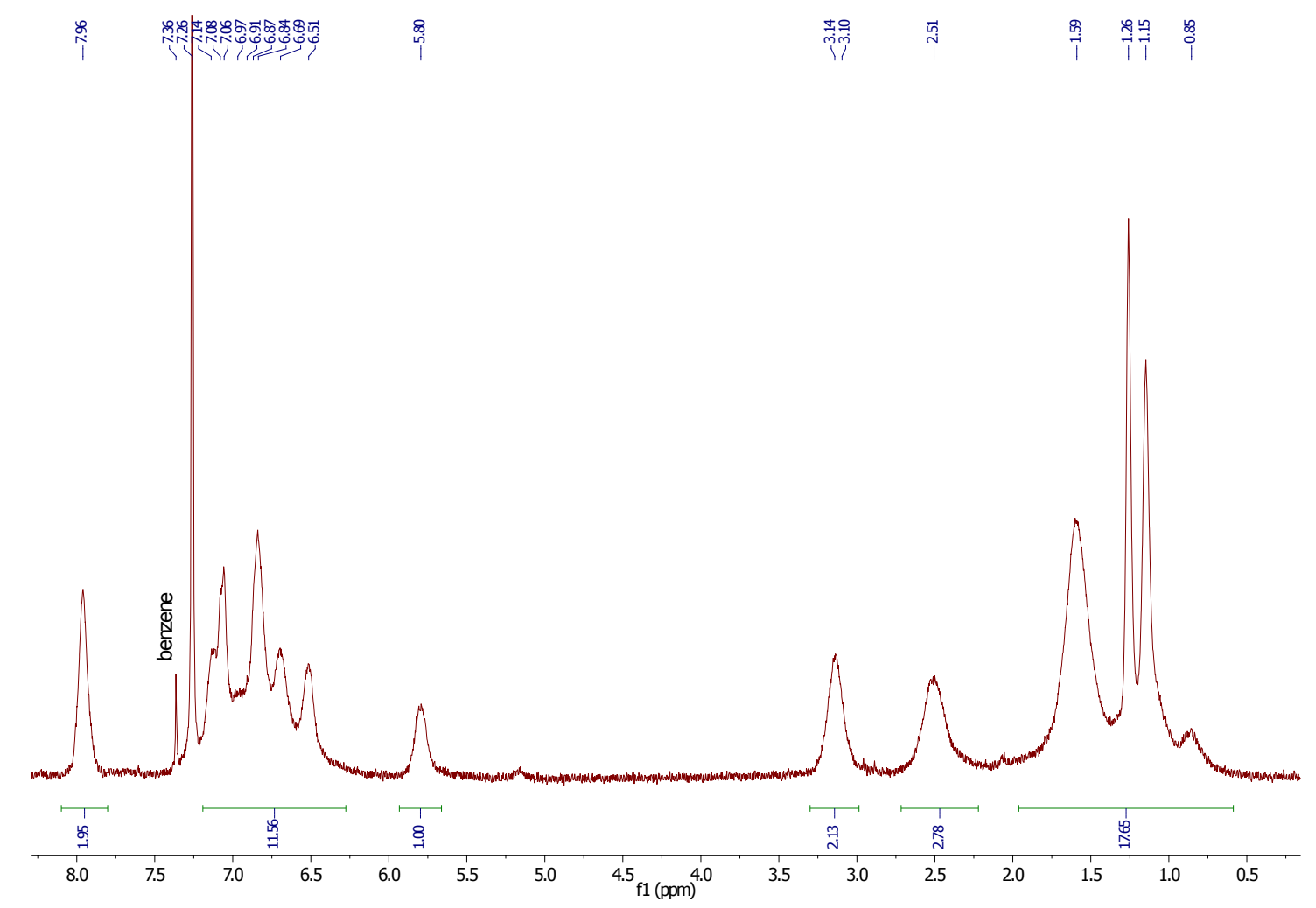

Figure 14. ${ }^{1} \mathrm{H}-\mathrm{NMR}$ spectrum of SP-PS (8) at $400 \mathrm{MHz}$ in $\mathrm{CDCl}_{3}$

It is important to know the molecular weight of a polymer sample as it is an indicator of mechanical properties including brittleness, tensile strength, hardness etc. There are several methods used to define the molecular weight of a polymer sample and 
only two will be utilized herein. The number average molecular weight, $M_{n}$, describes the average weight of a molecule in the polymer sample. The weight average molecular weight, $\mathrm{M}_{\mathrm{w}}$, describes the weight of each chain in the polymer sample by ascribing a greater contribution of longer polymer chains to the average molecular weight. $M_{n}$ and $\mathrm{M}_{\mathrm{w}}$ can be calculated using the following formulae,

$$
\begin{gathered}
M_{n}=\frac{\sum_{i=1}^{\infty} N_{i} M_{i}}{\sum_{i=1}^{\infty} N_{i}} \\
M_{w}=\frac{\sum_{i=1}^{\infty} N_{i} M_{i}^{2}}{\sum_{i=1}^{\infty} N_{i} M_{i}}
\end{gathered}
$$

Equation 3-2

where $\mathrm{N}_{\mathrm{i}}$ is the number of molecules with molecular weight, $\mathrm{M}_{\mathrm{i} .}{ }^{40}$ The molecular weight of SP-PS was determined using GPC, chromatography that separates according to molecular volume. The GPC used was attached to several detectors including a viscometer, a multi-angle laser light scattering detector and a differential refractometer each detector provides useful information. Calibration of the GPC was not necessary as the light scattering detector and viscometer provide the absolute $\mathrm{M}_{\mathrm{w}}$. The differential refractometer measures the difference between the refractive index of the eluent and the refractive index of the sample. ${ }^{40}$ The refractive index increment $(\mathrm{dn} / \mathrm{dc})$ is vital for data analysis from the multi-angle light scattering detector and the differential refractometer. The $\mathrm{dn} / \mathrm{dc}$ of polystyrene, $0.185 \mathrm{ml} / \mathrm{g}$, ${ }^{41}$ was used in this experiment as there were inadequate quantities of SP-PS to carry out the $\mathrm{dn} / \mathrm{dc}$ analysis of SP-PS and, therefore, there is some inherent error in the molecular weight calculations. The Mark-HouwinkStaudinger-Sakurada (MHSS) equation relates viscosity and molecular weight,

$$
[\eta]=\mathrm{KM}^{\mathrm{a}}
$$

Equation 3-3 
where $[\eta]$ is the intrinsic viscosity, $\mathrm{M}$ is the molecular weight and $\mathrm{K}$ and a are MHSS constants and exponents, respectively. ${ }^{42}$ This relationship is exploited throughout the molecular weight analysis of polymers.

The $\mathrm{M}_{\mathrm{n}}$ and $\mathrm{M}_{\mathrm{w}}$ of SP-PS were determined to be $63,980 \mathrm{~g} / \mathrm{mol} \pm 1.731 \%$ and $79,330 \mathrm{~g} / \mathrm{mol} \pm 2.46 \%$ by GPC (the chromatogram is shown below). The molecular weight determined for the polymer sample was much higher than anticipated due to the conditions favouring low molecular weights including high temperature and high initiator concentration. The polydispersity index or dispersity, $Ð$, of the polymer describes the molecular weight distribution of a sample and can be calculated using $Đ=\mathrm{M}_{\mathrm{w}} / \mathrm{M}_{\mathrm{n}}{ }^{43} \mathrm{Ð}$ was determined to be 1.24 for this sample of SP-PS - a value of 1 would signify a polymer sample with uniform molecular weight and only occurs in biological systems. ${ }^{40}$ $Đ$ obtained for this polymer sample was very low as $Đ$ values greater than 10 are possible and not uncommon. $Đ$ is dependent upon the method of polymerization and, as expected, $Đ$ is consistent with living free radical polymerization (free radical polymerization without a terminating agent present), whose dispersity often approaches 1. 


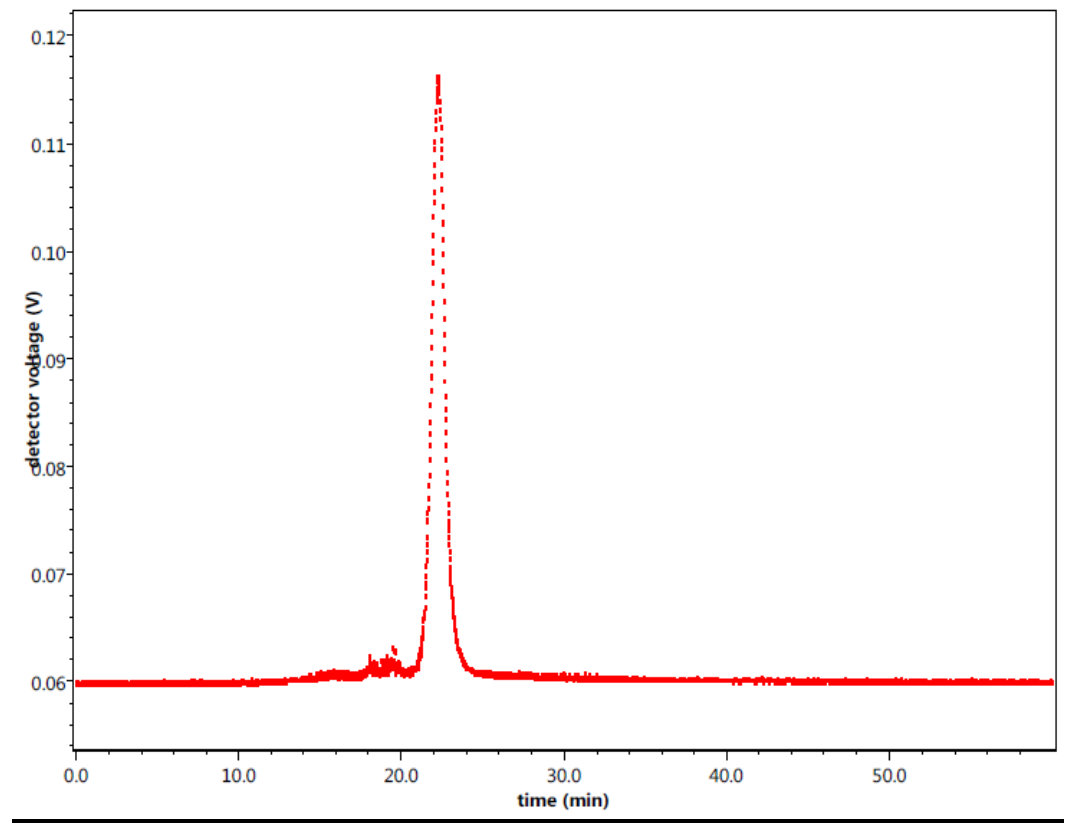

Figure 15. The detector response after separation of SP-PS by GPC as a function of elution time

DSC is used for the determination of the glass transition temperature, $T_{g}$. As a polymer sample is continuously cooled, the movement of the polymer chains is reduced and at low enough temperatures the viscosity has increased such that the movement of the polymer chains does not occur at a rate fast enough to maintain liquid characteristics. The polymer remains a liquid but is considered a 'glass' - the free volume in the polymer remains consistent and the polymer has very high viscosity and low compliance. The temperature at which this occurs is the $T_{g}$ and it is affected by several factors including $\mathrm{M}_{\mathrm{n}}$, the pressure and the rate of cooling. ${ }^{42}$ DSC uses a calorimeter to measure the difference in heat required to increase the temperature of a reference sample and an experimental sample by one degree. The output of DSC includes the plot of the endotherm versus the temperature and the $T_{g}$ may be determined by identifying an inflection point. ${ }^{44}$ The figure below shows the output of the DSC experiment for SP-PS 
with the $\mathrm{T}_{\mathrm{g}}$ identified at $118.41{ }^{\circ} \mathrm{C}$ as an inflection point; the heating rate of the experiment was $10^{\circ} \mathrm{C} / \mathrm{min}$. For comparison, polystyrene typically has an approximate $\mathrm{T}_{\mathrm{g}}$ of $100{ }^{\circ} \mathrm{C} .{ }^{41}$ The $\mathrm{T}_{\mathrm{g}}$ is increased relative to polystyrene, most likely due to stacking of the $\pi$ system and dipole interactions of the SP pendant groups on neighbouring chains of SPPS. In applications of SP-PS, a higher processing temperature would be required (if thermally casting films etc) due to the high $\mathrm{T}_{\mathrm{g}}$.

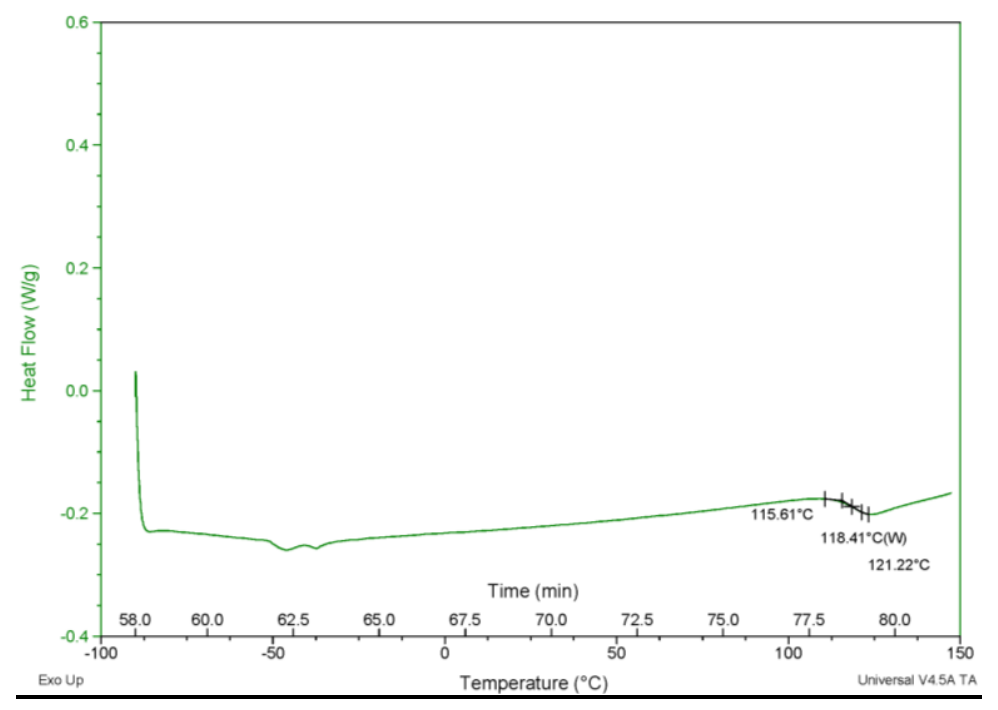

Figure 16. DSC curve for SP-PS showing an inflection by at $118.41{ }^{\circ} \mathrm{C}$

\subsubsection{Quantum Yield of SP-PS Isomerization}

The quantum yield of photoisomerization of SP-PS is the ratio of MC formation from SP and the number of photons absorbed upon irradiation with an LED at $365 \mathrm{~nm}$. The number of photons, or the intensity of the light source, was determined using ferrioxalate actinometry. Actinomtery is the calibration of a light source through the use of an actinometer - a chemical agent or physical device able to determine the photons emitted from a light source per unit of time. Potassium ferrioxalate, $\mathrm{K}_{3}\left[\mathrm{Fe}\left(\mathrm{C}_{2} \mathrm{O}_{4}\right)_{3}\right] \cdot 3 \mathrm{H}_{2} \mathrm{O}$, is a common standard chemical actinometer with well-studied 
quantum yields of photoconversion. The reduction of $\mathrm{K}_{3}\left[\mathrm{Fe}\left(\mathrm{C}_{2} \mathrm{O}_{4}\right)_{3}\right] \cdot 3 \mathrm{H}_{2} \mathrm{O}$ by light between 250-500 $\mathrm{nm}$ proceeds with consistent quantum yields, ${ }^{45}$

$$
\left[\mathrm{Fe}^{\mathrm{III}}\left(\mathrm{C}_{2} \mathrm{O}_{4}\right)_{3}\right]^{3-} \stackrel{\boldsymbol{h} \boldsymbol{v}}{\rightarrow}\left[\mathrm{Fe}^{\mathrm{II}}\left(\mathrm{C}_{2} \mathrm{O}_{4}\right)_{3}\right]^{4-}
$$

Equation 3-4

Measuring the absorbance of $\mathrm{K}_{3}\left[\mathrm{Fe}\left(\mathrm{C}_{2} \mathrm{O}_{4}\right)_{3}\right] \cdot 3 \mathrm{H}_{2} \mathrm{O}$ at $510 \mathrm{~nm}$ after irradiation allows the intensity of the light source, $I_{0}$, to be calculated using the following equation,

$$
I_{o}=\frac{A_{F e^{I I}(510 \mathrm{~nm})} x \mathrm{DF} \times V}{\left(1-10^{-A} \mathrm{Fe}^{I I I}(365 \mathrm{~nm})\right) \times \varepsilon_{\mathrm{Fe}} e_{(510 \mathrm{~nm})} x \ell \times \Phi_{365 \mathrm{~nm}} \times t}
$$

where $\mathrm{A}_{\mathrm{Fe}(\mathrm{III})(510 \mathrm{~nm})}$ is the absorbance of the diluted iron (III) solution after irradiation and complexation with 1,10-phenanthroline, DF is the dilution factor of the potassium ferrioxalate solution (25), $\mathrm{V}$ is the volume of the irradiated solution (in litres), $\mathrm{A}_{\mathrm{Fe}(\mathrm{III})(365}$ $\left.{ }_{\mathrm{nm}}\right)$ is the absorbance of the initial potassium ferrioxalate solution at $365 \mathrm{~nm}, \varepsilon_{\mathrm{Fe}(\mathrm{II})(510 \mathrm{~nm})}$ is the molar extinction coefficient of the iron (II) solution (experimentally determined as $\left.11.2 \times 10^{3} \mathrm{~L} \mathrm{~mol}^{-1} \mathrm{~cm}^{-1}\right), \ell$ is the path length $(1 \mathrm{~cm}), \Phi_{365 \mathrm{~nm}}$ is the quantum yield of the photoreduction of iron (III) at $365 \mathrm{~nm}$ from literature $(1.21)^{46}$ and $\mathrm{t}$ is the time of irradiation. $^{37}$ The intensity of the light was determined to be $3.62 \times 10^{-8} \pm 1.5 \times 10^{-9} \mathrm{~mol}$ photons $\mathrm{s}^{-1}$ after averaging the intensities calculated from 3 trials with varying lengths of irradiation.

The quantum yield of the photoisomerization of SP-PS, $\Phi_{\mathrm{SP}-\mathrm{MC}}$, was then determined by irradiating solutions of SP-PS at various recorded lengths of time and determining the moles of product formed. The extinction coefficient of the MC isomer of SP-PS $\left(\varepsilon_{\mathrm{MC}}\right), 1.04 \times 10^{4} \mathrm{~L} \mathrm{~mol}^{-1} \mathrm{~cm}^{-1}$, was obtained from the spectrum presenting the largest absorption at $593 \mathrm{~nm}$ after irradiation prior to photobleaching. This information was then used in the following equation for the quantum yield, 


$$
\Phi_{S P-M C}=\frac{\operatorname{mol}_{M C}}{m o l_{\text {photons }}}=\frac{C_{p} V}{I_{o}\left(1-10^{-A}\right) t}
$$

where $\mathrm{C}_{\mathrm{P}}$ is the concentration of the $\mathrm{MC}$ formed after irradiation (from $\mathrm{A}_{590 \mathrm{~nm}} / \varepsilon_{\mathrm{MC}} \ell-\ell$ is the path length of the cuvette $(1 \mathrm{~cm})$ and $\mathrm{A}_{590 \mathrm{~nm}}$ is the absorbance at $590 \mathrm{~nm}$ after irradiation), $\mathrm{V}$ is the volume of the irradiated solution $(0.003 \mathrm{~L}), \mathrm{I}_{\mathrm{o}}$ is the intensity of the light determined by actinometry $\left(3.62 \times 10^{-8}\right.$ mol photons $\left.\mathrm{s}^{-1}\right), \mathrm{A}$ is the absorbance of the solution at $365 \mathrm{~nm}$ at $0 \mathrm{~s}$ of irradiation, and $\mathrm{t}$ is length of irradiation at $365 \mathrm{~nm}$ in seconds. The figure below shows the quantum yield of the photoisomerization as a function of irradiation time. It should be noted that after $45 \mathrm{~s}$ of irradiation photobleaching occurred.

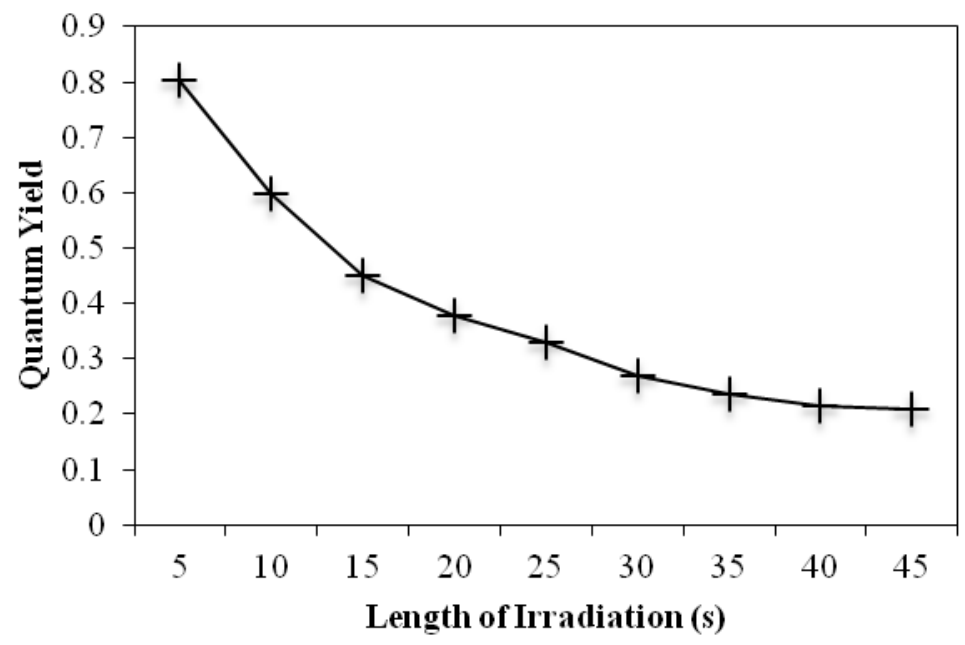

Figure 17. The quantum yield of SP-PS as a function of length of irradiation at $365 \mathrm{~nm}$

The quantum yields at $5 \mathrm{~s}$ was determined to be 0.80 . While the initial quantum yield is fairly high at 0.80 it is within range of literature values at 0.6 in toluene (the quantum yield in cyclohexane was determined to be 0.8$).{ }^{47}$ The use of toluene as the solvent for the measurements favours a higher quantum yield; it has been shown in literature that an increase in the polarity of the solvent results in a decrease in quantum 
yield ${ }^{47}$ High quantum yields are efficient for our application purposes as lower levels of irradiation reduce the probability of photodegradation of any metal complexes.

\subsection{Thin Films Containing $\left[\left\{\mathrm{Ru}\left(\mathrm{NH}_{3}\right)_{5}\right\}_{2}(\mu\right.$-dicyd $\left.)\right]\left[\mathrm{BPh}_{4}\right]_{4}$}

The following sections contain the results and discussion of photochemical studies of thin films. In each photochemical study a different thin film is used and the characterization of each film was not possible. The characterization of a representative thin film was performed and the results are generally applicable to all films made using the same technique (Section 3.2.1). All spectral data were obtained on a Cary 5 UV-VisNIR spectrophotometer from thin films on glass substrates. The spectral data were shown as absorbance (rather than molar extinction coefficient) versus wavelength due to the inability to determine concentration in some cases and due to the large number of estimations required for concentration determination in other cases. All data were smoothed using the LOESS function on SigmaPlot 10. Various light sources are used throughout the discussion, all LEDs are from LED Engin (with the exception of blue which was from Luxeon); herein the following colours refer to the following wavelengths, $\mathrm{UV}=365 \mathrm{~nm}$, blue $=447.5 \mathrm{~nm}$, green $=523 \mathrm{~nm}$ and amber $=590 \mathrm{~nm}$.

\subsubsection{Thin Film Characterization}

Scanning electron microscopy (SEM) was used to determine the film thickness in a sample film representative of all films containing only $\mathbf{1 1}$ and commercial polystyrene $\left(M_{w} 280,000\right)$ and the images are shown below. Several measurements were taken from an edge cut through the center of the film. The film thickness measurements ranged from 
$0.20-1.00 \mu \mathrm{m}$, with the average thickness determined to be $0.62 \mu \mathrm{m}$. In the images below, Figure 18A shows the method for film thickness measurements and Figure 18B shows the surface of the films. The surface of the films were non uniform and show aggregations of either polystyrene or complex.
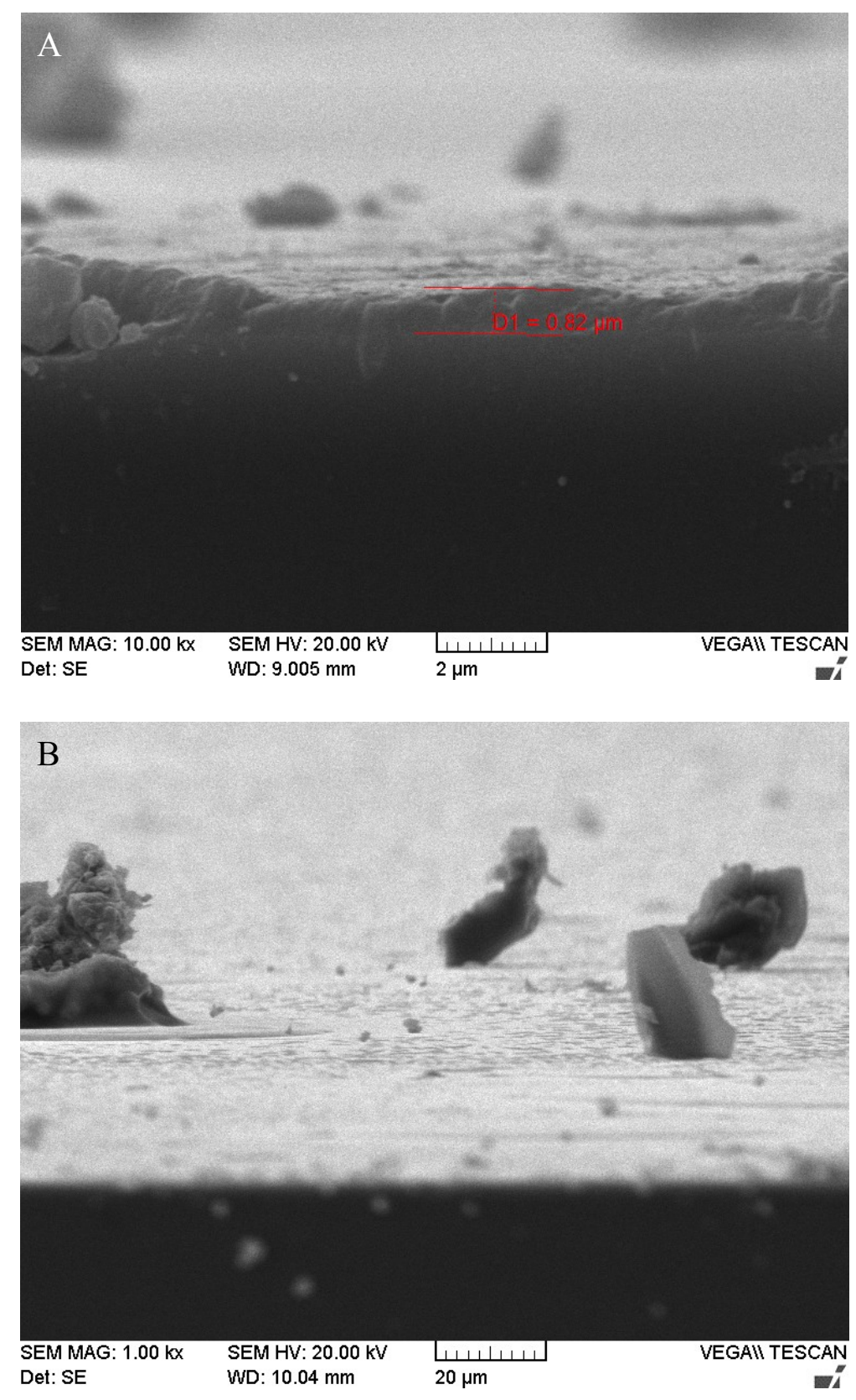

Figure 18. SEM images of a film of 11 and commercial polystyrene $\left(M_{w} 280,000\right)$ viewed through an edge in the center of the film (A) and the surface of the film at a shallow angle (B) 
Drop casting of the SP-PS films was carried out on the initial slides due to the simplicity of the method, the reduced volume of solvent and material required to prepare the films and the swiftness with which the slides were prepared. While drop-casting films was simple, it also presented several problems including: a lack of uniformity of films and increasing scattering when obtaining a spectrum. Spin casting of the films was performed when using polystyrene and 6- $\mathrm{NO}_{2} \mathrm{BIPS}$ versus SP-PS because more material was synthetically accessible. Spin casting produced thinner films with less scattering and more uniformity. The procedure for spin casting was altered during research; it was found that faster acceleration to the chosen rotation speed resulted in films that visibly produced less scattering.

Another vital variable in the preparation of the thin films was the dryness of the films. Removal of solvent and water was performed by placing the films under vacuum for $24 \mathrm{~h}$ and by incubation of the films in a dessicator containing phosphorus pentoxide, respectively. It was observed that increasing the dryness of the films produced a more dramatic effect in terms of the change in absorbance of the LMCT band (shown in

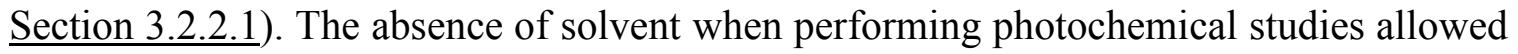
for further interaction between the ammines of the complex and MC as well as increasing the rigidity of the films.

The counterion used in the majority of these studies was tetraphenylborate, $\mathrm{BPh}_{4}{ }^{-}$. $\mathrm{BPh}_{4}{ }^{-}$was selected as a counterion as it is a weakly coordinating in comparison to other counterions previously reported with ruthenium complexes, such as $\mathrm{ClO}_{4}{ }^{-}$and $\mathrm{PF}_{6}{ }^{-48}$ The negative charge is centered on boron and is shielded by the large phenyl groups; it has a Gutmann donor number of $0 .{ }^{49}$ It was assumed that using a weakly coordinating counter 
anion would reduce aggregation of complexes in the film by ion pairing. Aggregation of complexes in the films would lead to broadening of the LMCT band and a reduction in intensity. Experimentally, this was observed: films prepared using $\mathrm{PF}_{6}{ }^{-}$as a counter anion were opaque in comparison to films using $\mathrm{BPh}_{4}{ }^{-}$and were not suitable for tests with chromophores.

\subsubsection{Photochemical Studies}

The methods used to demonstrate the change in films before and after irradiation were modified to eliminate the need for many assumptions and estimations required for determining film concentration. The percent change in absorbance upon initial irradiation $\left(\% \Delta_{\mathrm{A}}\right)$ and the percent recovery of the initial absorbance band $\left(\% \mathrm{R}_{\mathrm{t}}\right)$ after a period of time, $t$, are simple ways to show change in the properties of films and were calculated using the following formulae,

$$
\begin{aligned}
\% \Delta_{A} & =\frac{A_{r a d}-A_{i}}{A_{i}} \times 100 \% \\
\% \mathbf{R}_{t} & =\frac{A_{f}-A_{r a d}}{A_{i}-A_{\text {rad }}} \times 100 \%
\end{aligned}
$$

Equation 3-8

\subsubsection{Studies with Spiropyran}

The conditions of the photochemical studies of films performed with SP-PS and 11 were optimized to increase the likelihood of the donor-acceptor interaction and maintain consistent results. A broad band UV lamp with long wave and short wave functionalities and a Xenon Arc Lamp with light filters and a copper sulfate solution were initially used to provide UV and visible irradiation, respectively. LEDs replaced the two lamps and provided a simple, low cost and efficient energy source. LEDs have been 
shown to reduce the photodegradation often associated with SP systems. ${ }^{50}$ Additionally, the method used to prepare the films was optimized to give the most reproducible films. It was determined that spin coating was the most effective and reproducible when accelerating to high speeds in a short period of time. Lastly, experiments requiring an inert atmosphere were initially performed under a flow of argon directed at the slide. An air-tight chamber with transparent walls was later constructed with an attached bubbler to provide a space for adequate degassing of the system and an atmosphere free from oxygen.

A thin film was prepared using the novel polymer, SP-PS, and 11 (with SP-PS present in excess at 18 molar equivalents of monomer in SP-PS to 1 molar equivalent of 11) and was tested for photoactivity - the results are shown below in Figure 19. In Figure $\underline{19 \mathrm{~A}}$, a reduction in absorbance of the LMCT band of 11 by $53 \%$ was observed after $10 \mathrm{~s}$ of irradiation by an LED at $365 \mathrm{~nm}$ under argon. Photoisomerization of the SP moiety in SP-PS from SP to MC occurred and was represented by a drastic increase in the absorbance of the band at $590 \mathrm{~nm}$. It appeared as if the hypothesized interaction had occurred: formation of an anion (phenoxide in MC) resulted in a lower intensity LMCT band due to the interaction of the negative charge with the ammines of the complex. An unidentified broad shoulder on the low energy side of the LMCT band also appears after UV irradiation in Figure 19A. This new, low energy band may be due to decomposition products because it does not disappear when testing for reversibility. In Figure 19B, reversal of the interaction was attempted by irradiation of MC at $590 \mathrm{~nm}$. The slide was exposed to five 1-minute increments of visible light irradiation. This lead to a sequential decrease in MC absorbance and, therefore, conversion to SP, and it also oddly resulted in 
a further decrease in LMCT band absorbance equivalent to $9 \%$ of the initial LMCT band. Several possibilities were hypothesized: photobleaching of the complex by visible light and/or UV light, irreversible aggregation of MC in SP-PS and/or an irreversible interaction between the phenoxide of $\mathrm{MC}$ and the complex. Further investigation of the photoswitch was absolutely necessary.
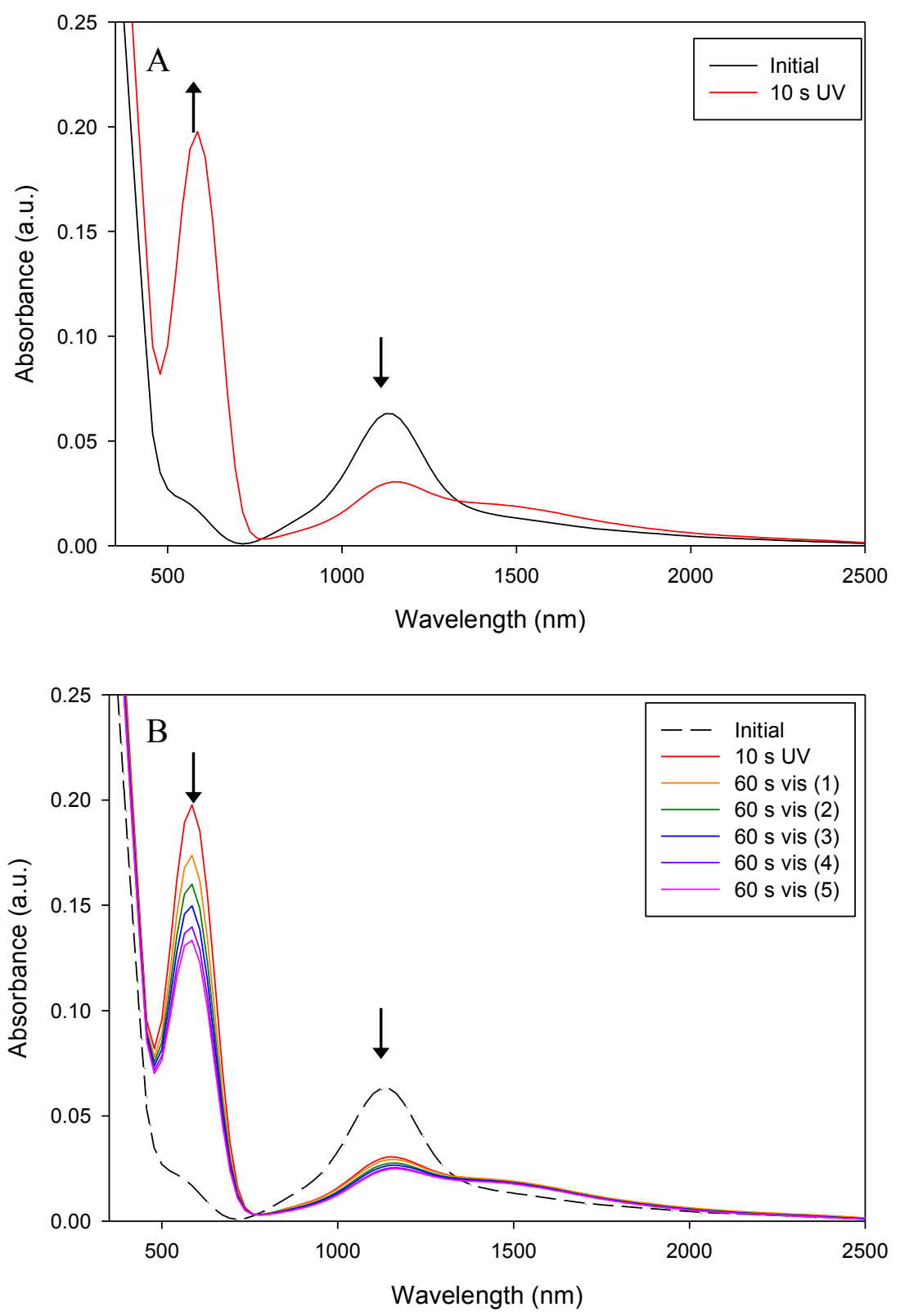

Figure 19. Film of SP-PS and 11 irradiated with an LED at $365 \mathrm{~nm}$ for $10 \mathrm{~s} \mathrm{(A)} \mathrm{and}$ subsequently irradiated at $590 \mathrm{~nm}$ for five 1-minute increments (B) under argon 
A blank test slide containing commercial polystyrene and $\mathbf{1 1}$ was prepared using the same method and tested using the same conditions as the film above; the results are shown below in Figure 20. Upon irradiation of the film at $365 \mathrm{~nm}$ for $10 \mathrm{~s}$, the LMCT band at $1123 \mathrm{~nm}$ decreased in absorbance by 19\%. Irradiation of the film by visible light at $590 \mathrm{~nm}$ in sequential five $60 \mathrm{~s}$ increments resulted in a further decrease of the LMCT band by an additional $6 \%$. Furthermore, the film was allowed to relax overnight in the ambient atmosphere (Figure 20B ) and regained an insignificant $1 \%$ intensity of the absorbance that could possibly be attributed to contraction of the film from drying. These photochemical measurements were the first time any photoactivity of the isolated complex was demonstrated. This complex initially served as the ideal candidate for incorporation into the photoswitch due to its complete lack of photochemistry observed in solution and, therefore, any concern about the complex seemed unnecessary. While the photochemistry of the complex was novel and warranted further investigation (see Section 3.2.2.2), the reactivity of the isolated complex to irradiation was significantly less than in the presence of SP (19\% vs 53\% reduction in LMCT band absorption) and, therefore, the possibility of an donor-acceptor interaction between SP and $\mathbf{1 1}$ remained promising. 

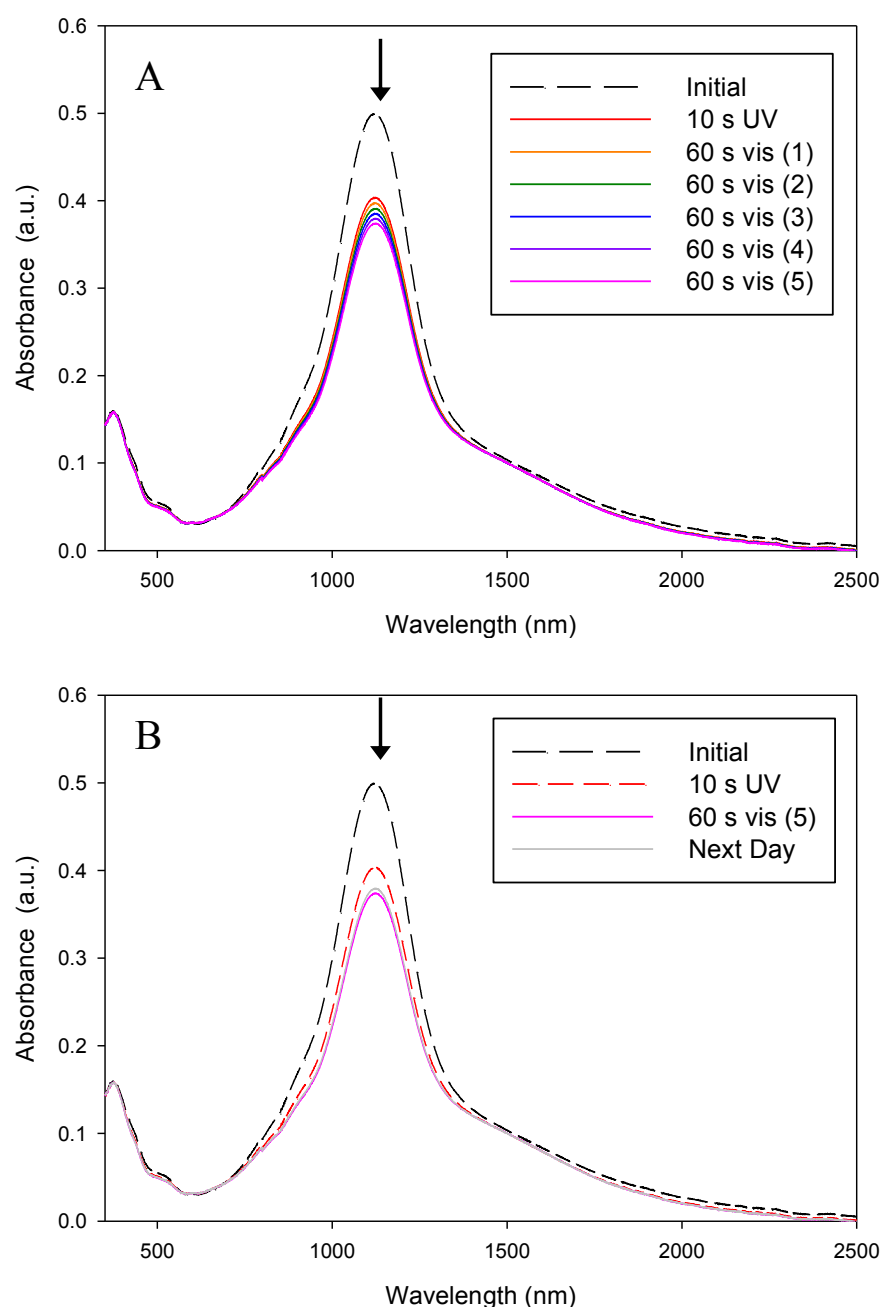

Figure 20. Thin film of polystyrene and $\mathbf{1 1}$ irradiated with an LED at $365 \mathrm{~nm}$ for $10 \mathrm{~s}$ (A) and subsequently $5 \times 60 \mathrm{~s}$ of visible light at $590 \mathrm{~nm}$ (B) all under argon with Next Day signifiying thermal relaxation in ambient atmosphere for one night

It should be noted that following the studies shown above, it was determined that the dryness of the films was correlated to the magnitude of the changes in absorbance. The film used for the experiment shown in Figure 21 (below) was dried under vacuum (to remove any organic solvents) and in a dessicator containing phosphorus pentoxide (to remove any water within the film) for a longer time than the films used for the experiments shown in Figure 19 and Figure 20. The substantial change in absorbance in response to UV irradiation in comparison to previous films is a function of the dryness of 
the films; as the films become drier and more rigid, relaxation of the excited state by rotation is further inhibited and may not occur as swiftly. The increase in lifetime of the excited state in drier films increases the yield of photoproducts. Additionally, the presence of solvent interferes with the donor-acceptor interaction between $\mathrm{MC}$ and the complex.

The SP form of 6-NO $\mathrm{NO}_{2} \mathrm{BIPS}$ is the favoured isomer in non-polar media such as polystyrene. While conversion of MC to SP may be accelerated by irradiation in the visible range it may also occur by thermal relaxation at room temperature. As irradiation in the visible range did not provide any reversibility of the LMCT band, thermal relaxation was attempted and the results are shown below in Figure 21. In Figure 21A, the thin film was irradiated in ambient atmosphere at $365 \mathrm{~nm}$ for $10 \mathrm{~s}$ and the LMCT band decreased in intensity by $74 \%$. Figure $21 \mathrm{~B}$ shows the change in the absorption spectrum caused by thermal relaxation over time and Figure 22 shows the $\% \mathrm{R}_{\mathrm{t}}$ as a function of time. After 2 days, the recovery due to thermal relaxation reaches a maximum at $13 \%$. The thermal recovery of the LMCT band may be limited by several factors, however, it was hypothesized that an irreversible donor-acceptor interaction between the complex and MC was more likely than an aggregation of adjacent MC isomers in SP-PS or degradation of the complex. Aggregation of MC isomers would lead to a shift in the peak maximum of the MC, which is not observed. Additionally, the LMCT band of the complex retains its appearance and maximum wavelength (experimentally, complex degradation typically results in a change in the absorbance spectrum) and the relaxation of $\mathrm{MC}$ to ground state isomer $\mathrm{SP}$ is incomplete (33\% relaxed after 24 hours). For comparison, a film composed solely of SP-PS thermally relaxed by $43 \%$ within 24 hours 
(under argon). Although incomplete, the partial isomerization of MC to SP was accompanied by an increase in absorbance of the LMCT band, the desired outcome, however, it was crucial to perform a blank due to the recent discovery of photoactivity of 11.
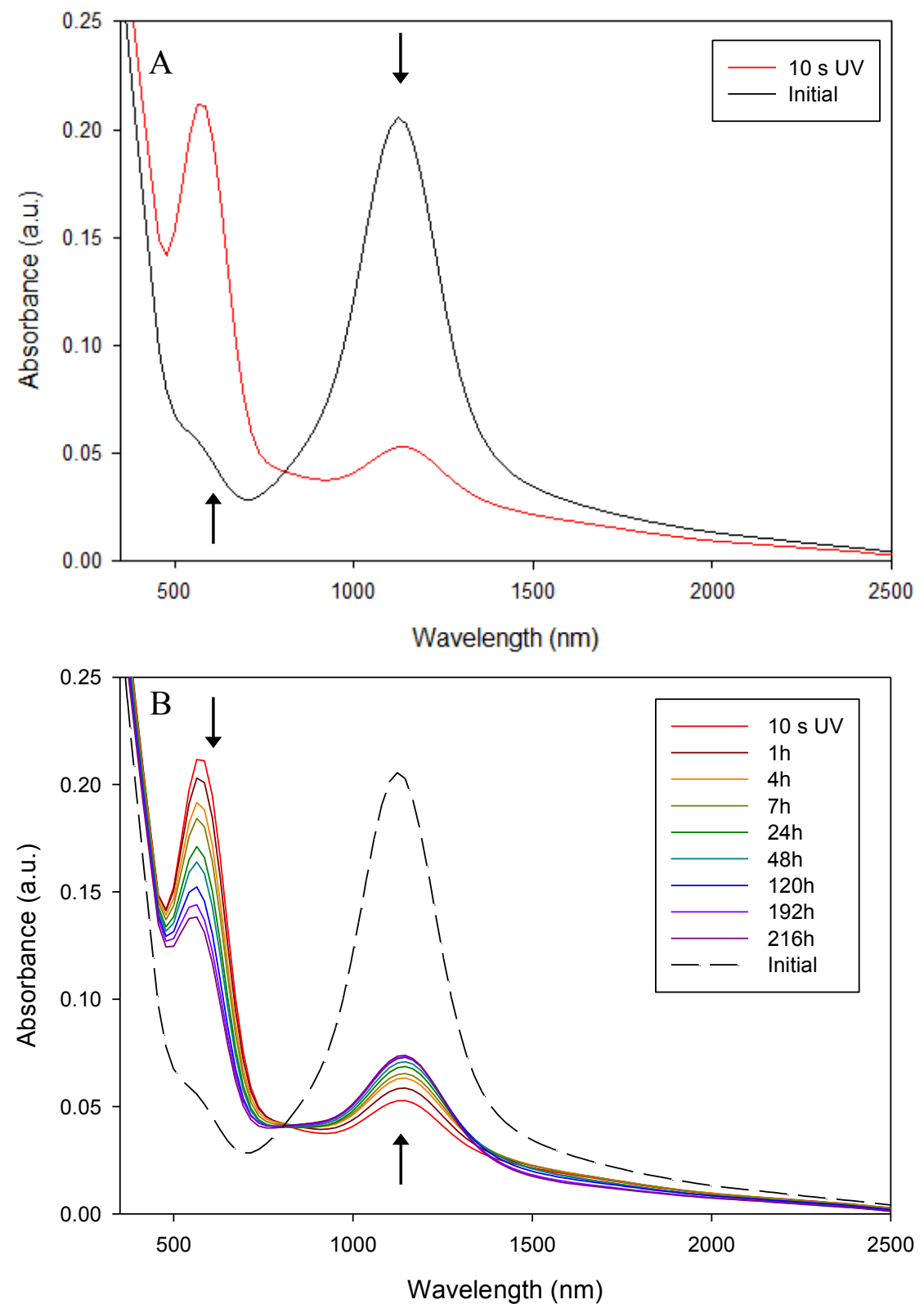

Figure 21. Thin film of SP-PS and $\mathbf{1 1}$ (4.5:1 molar equivalents of monomer in SP-PS to 11) irradiated at $365 \mathrm{~nm}$ for $10 \mathrm{~s} \mathrm{(A)} \mathrm{and} \mathrm{thermal} \mathrm{relaxation} \mathrm{of} \mathrm{the} \mathrm{film} \mathrm{over} \mathrm{time} \mathrm{in}$ ambient atmosphere (B) 


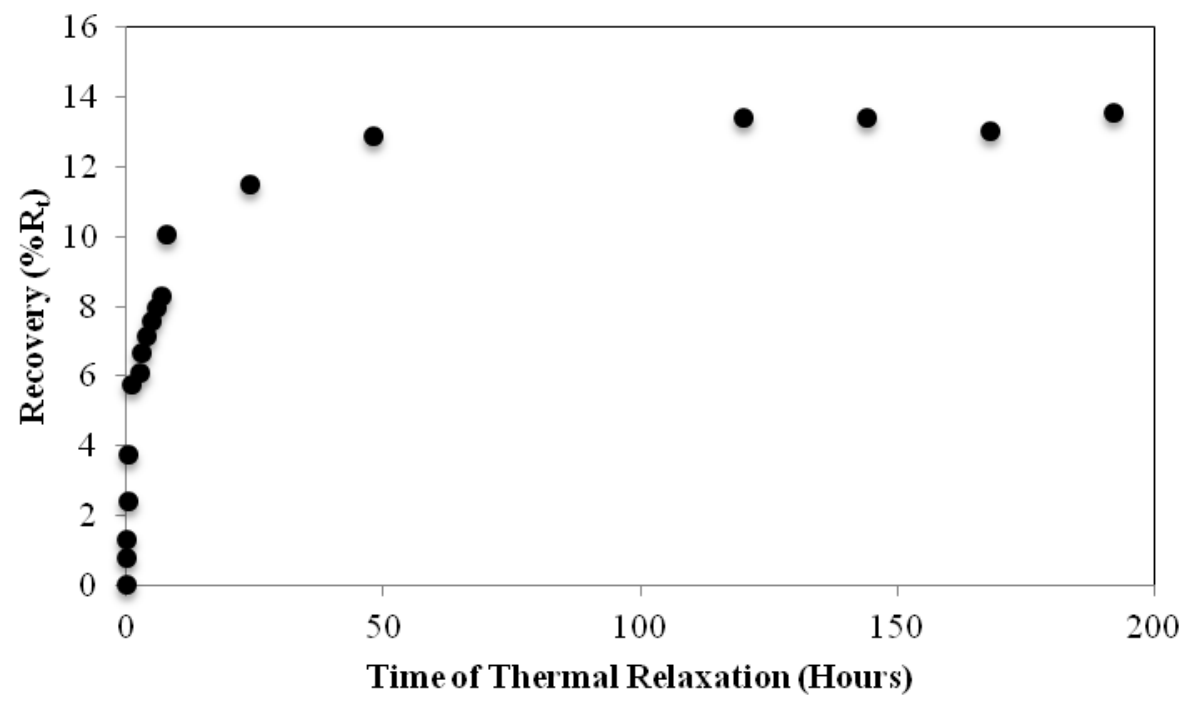

Figure 22. The recovery of the LMCT band of $\mathbf{1 1}$ as a function of thermal relaxation time for a thin film of SP-PS and $\mathbf{1 1}$ in ambient atmosphere

A blank test film was prepared by combining commercial polystyrene $\left(\mathrm{M}_{\mathrm{w}}\right.$ $280,000)$ and $\mathbf{1 1}$. The thermal relaxation of the film was monitored over a period of 2 hours after irradiation with a $365 \mathrm{~nm}$ LED for $5 \mathrm{~s}$ in ambient atmosphere. After an initial reduction in LMCT band absorbance of $63 \%$ due to UV irradiation, $37 \%$ of the absorbance was regained after 2 hours of thermal relaxation. The recovery of the LMCT band in the blank was significantly more than the recovery in the film containing SP (37\% vs $12 \%$ following 24 hours of relaxation after $10 \mathrm{~s}$ and $5 \mathrm{~s}$ of UV irradiation, respectively). The photoactivity of the blank is significant and inseparable from the activity observed from the film containing SP-PS. 

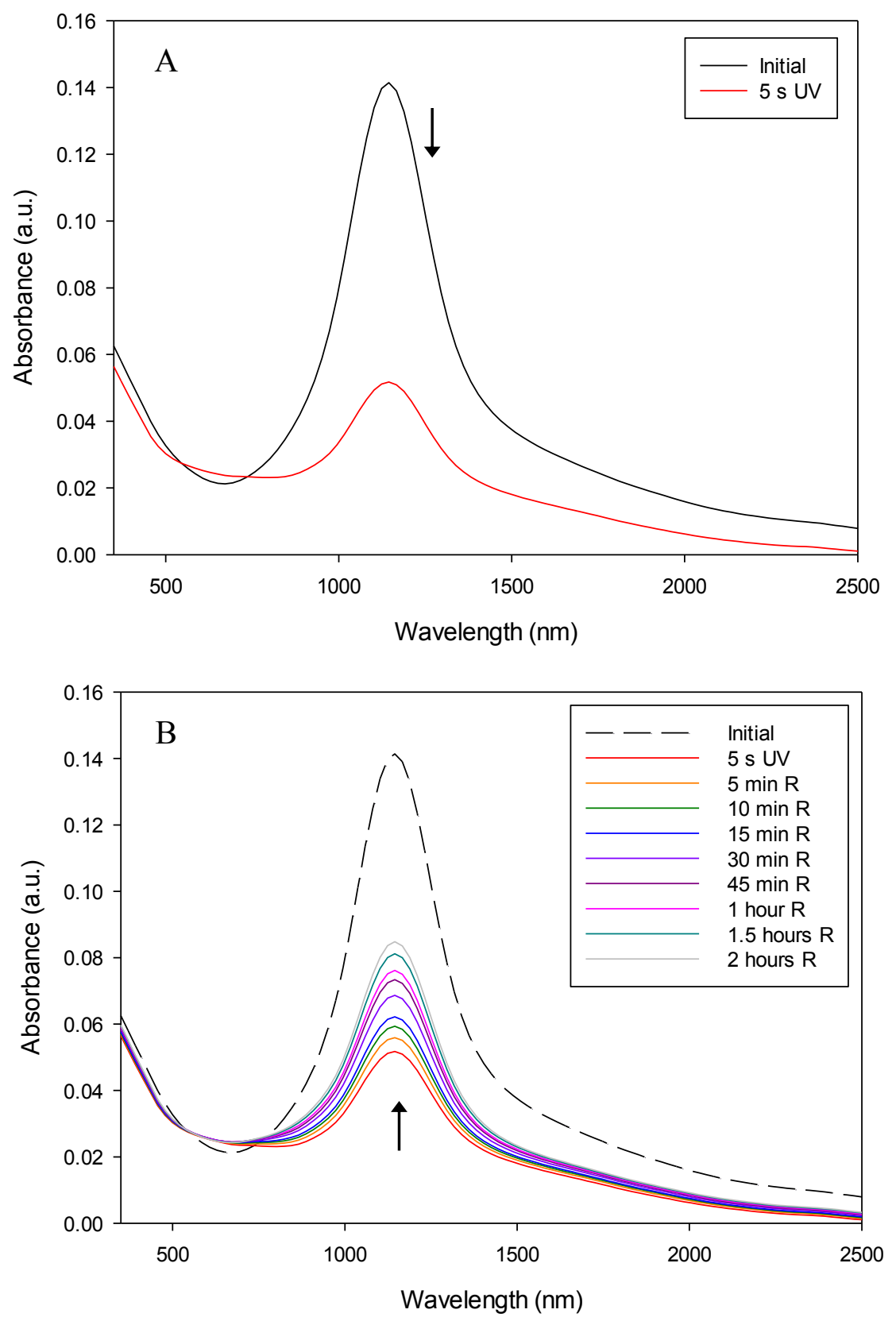

Figure 23. Thin film of commercial polystyrene (Mw 280,000) and $\mathbf{1 1}$ after irradiation at $365 \mathrm{~nm}$ for $5 \mathrm{~s}(\mathrm{~A})$ and the thermal relaxation (R) of the film over time (B) in ambient atmosphere

While the photochromism of $\mathbf{1 1}$ discovered in the blank was interesting and complicates the interpretation of data, it is possible that there is a combination of mechanisms causing the change in LMCT band absorbance. Evidence for the donoracceptor interaction between $\mathrm{MC}$ and $\mathbf{1 1}$ exists in the slow/incomplete isomerization 
from $\mathrm{MC}$ to $\mathrm{SP}$ in the presence of $\mathbf{1 1}$. Another experiment was performed comparing the reversibility of the photoisomerization of SP (in this case 6- $\mathrm{NO}_{2} \mathrm{BIPS}$ ) by thermal relaxation and visible light irradiation in commercial polystyrene $\left(\mathrm{M}_{\mathrm{w}} 280,000\right)$ in the absence and presence of the complex 11. It was hypothesized that the isomerization of $\mathrm{MC}$ to $\mathrm{SP}$ in 6-NO${ }_{2} \mathrm{BIPS}$ would be impeded by the interaction of $\mathrm{MC}$ with $\mathbf{1 1}$. Furthermore, by comparing the isomerization with or without the presence of 11, the impedance of isomerization by MC aggregation would be factored out. All films were prepared using identical methodologies and the data was collected in the same manner. The percent change in absorbance at $590 \mathrm{~nm}$ (MC absorption band) after irradiation vs time length of either visible irradiation or thermal relaxation was fitted using TableCurve assuming first order decay and data was extrapolated to produce the curves shown below in Figure 24. A t-test was performed on the extrapolated data: at $20 \mathrm{~min}$ of irradiation at $590 \mathrm{~nm}$ and $300 \mathrm{~min}$ of thermal relaxation. Statistically significant results were obtained using optical reversibility and thermal reversibility of MC with p-levels of 0.04062 and 0.01882 in one-tailed tests with equal variances (see Appendix for data). 


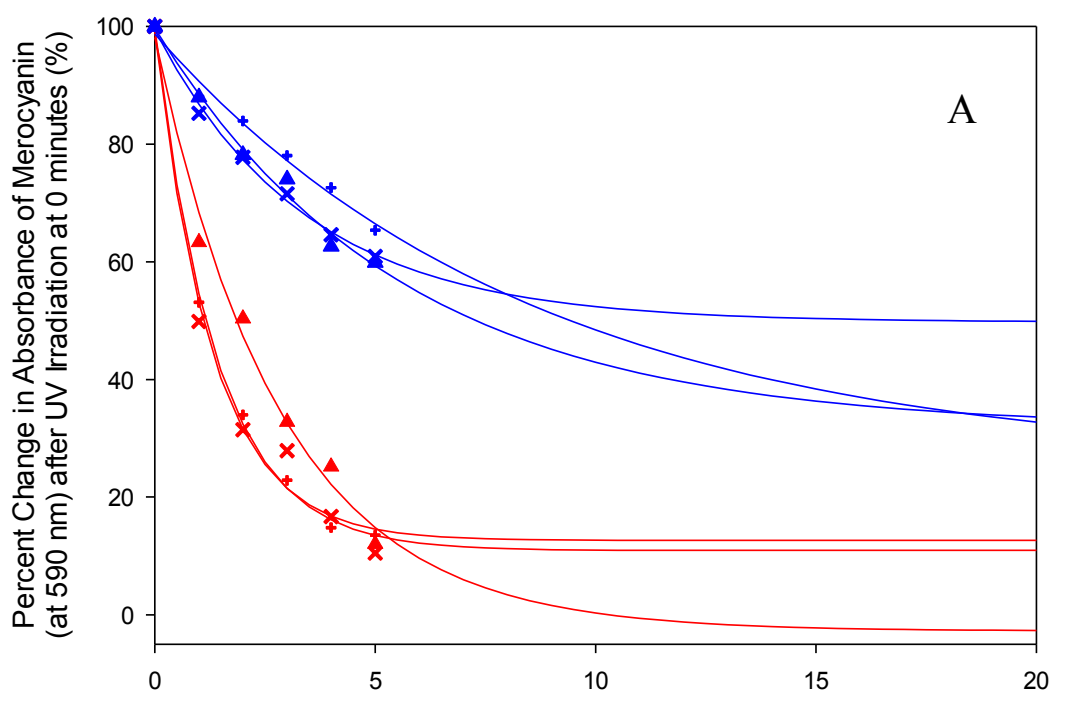

Time of Visible Irradiation at $590 \mathrm{~nm}$ (min)

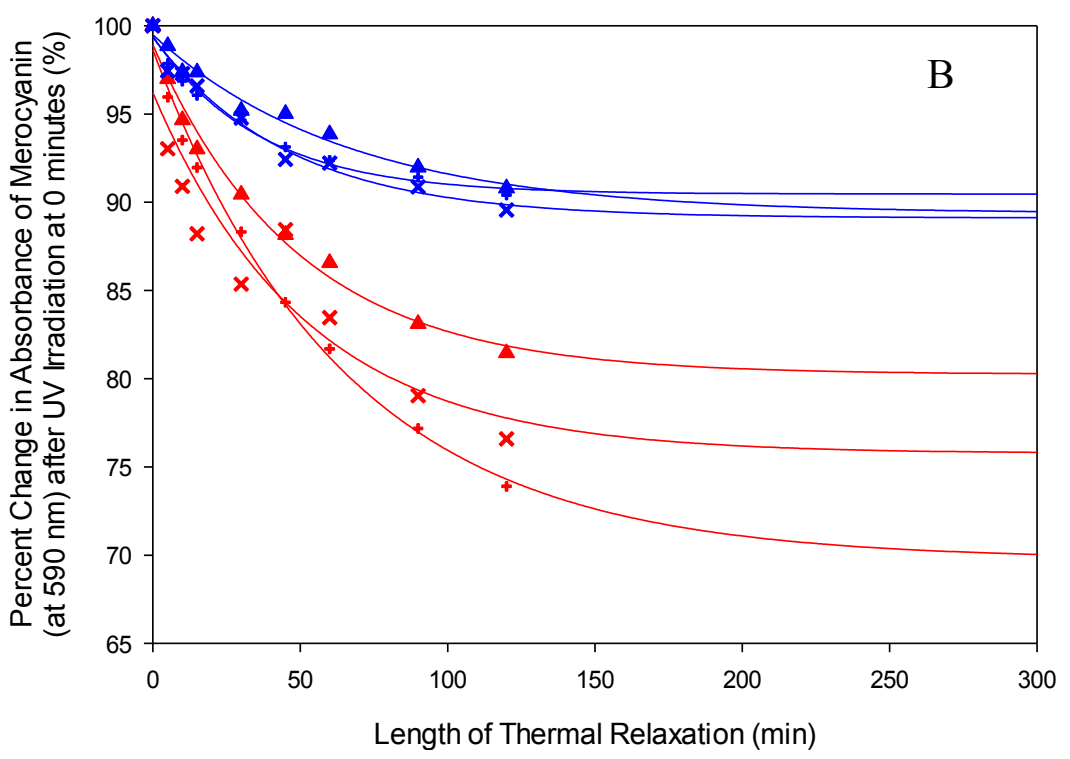

Figure 24. The percentage change in absorbance of merocyanin at $590 \mathrm{~nm}$ due to (A) irradiation by an LED at $590 \mathrm{~nm}$ or (B) thermal relaxation, after irradiation at $365 \mathrm{~nm}$ for $5 \mathrm{~s}$ of films composed of commercial polystyrene $\left(\mathrm{M}_{\mathrm{w}} 280,000\right)$ and 6- $\mathrm{NO}_{2} \mathrm{BIPS}$ with (blue) or without (red) complex 11. Smooth lines are fitted curves, while the data points are the data collected experimentally.

\subsubsection{Alternative Photoswitches}

Due to the unexpected observed photochemistry of 11, attempts were made to alter the chromophore and complex within the photoswitch. 11 was chosen for these 
studies because it has the largest response to changes in the outer sphere. However, complexes of the type $\left[\left\{\mathrm{Ru}\left(\mathrm{NH}_{3}\right)_{4}(\mathrm{py})\right\}_{2}(\mu-\mathrm{L})\right]^{4+}$, where $\mathrm{L}$ is an unsubstituted or dichloro or tetrachloro substituted dicyd ${ }^{2-}$ ligand, also respond to outer sphere perturbations in a similar manner (data shown below for the complex used in this study). ${ }^{11}$ For this reason, a film containing the complex $\left[\left\{\mathrm{Ru}\left(\mathrm{NH}_{3}\right)_{4}(\mathrm{py})\right\}_{2}(\mu\right.$-dicyd) $]\left[\mathrm{BPh}_{4}\right]_{4}$ and commercial polystyrene $\left(\mathrm{M}_{\mathrm{w}} 280,000\right)$ was prepared; $\mathrm{BPh}_{4}{ }^{-}$was used to reduce ion pairing of the complex in the film. Irradiating the blank with the light sources used in the previous studies produced results following the same pattern to those produced by $\mathbf{1 1}$ with the same magnitude, and was, therefore, not a suitable replacement.

Table 2. Molar extinction coefficient of the LMCT band at peak wavelength of $\left[\left\{\mathrm{Ru}\left(\mathrm{NH}_{3}\right)_{4}(\mathrm{py})\right\}_{2}(\mu\right.$-dicyd $\left.)\right]\left[\mathrm{PF}_{6}\right]_{4}$ in various solvents ${ }^{11}$

\begin{tabular}{c|cc}
\hline Solvent & $\begin{array}{c}\text { Gutmann Donor } \\
\text { Number }\end{array}$ & $\begin{array}{c}\varepsilon_{\max } \\
\left(\mathrm{L} \mathrm{mol}^{-1} \mathrm{~cm}^{-1}\right)\end{array}$ \\
\hline Nitromethane & 2.7 & $4.16 \times 10^{4}$ \\
Acetonitrile & 14.1 & $2.73 \times 10^{4}$ \\
DMSO & 29.8 & $1.36 \times 10^{4}$ \\
\hline
\end{tabular}

In another attempt to replace $\mathbf{1 1}$ with a complex that also responds to outer sphere perturbations from donor environments and could demonstrate the desired effect of SP, a mononuclear complex, $\left[\mathrm{Ru}\left(\mathrm{NH}_{3}\right)_{5}(\right.$ pcyd-Cl) $]\left[\mathrm{BPh}_{4}\right]_{2}$, was used (shown below). $\left[\mathrm{Ru}\left(\mathrm{NH}_{3}\right)_{5}(\mathrm{pcyd}-\mathrm{Cl})\right]\left[\mathrm{BPh}_{4}\right]_{2}$ was dissolved in solution with commercial polystyrene $\left(\mathrm{M}_{\mathrm{w}}\right.$ $280,000)$ and a film was prepared. After irradiation with light at $365 \mathrm{~nm}$ the LMCT band absorbance decreased and, therefore, the mononuclear complex was not suitable either. 


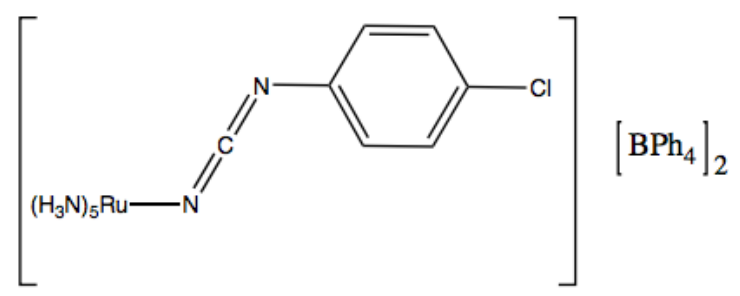

Figure 25. $\left[\mathrm{Ru}\left(\mathrm{NH}_{3}\right)_{5}(\mathrm{pcyd}-\mathrm{Cl})\right]\left[\mathrm{BPh}_{4}\right]_{2}$

After obtaining mixed results using SP-PS, films containing polystyrene, 11, and 6- $\mathrm{NO}_{2}-8-\mathrm{OMeBIPS}$ (shown below) were prepared. 6- $\mathrm{NO}_{2}-8-\mathrm{OMeBIPS}$ was synthesized from the readily available $o$-vanillin. It was hypothesized that a derivative of SP containing an electron-donating group ortho to the phenoxide would increase electron density at phenoxide position, making it a stronger electron-donating center for the ammines on 11 as well as increasing the rate of isomerization from MC to SP. The additional electron density in resonance with the phenoxide would destabilize the anion and increase the rate of isomerization to SP from MC while all preventing or limiting the irreversible back reaction. Testing of the films proved to be problematic due to a large amount of background scattering and inconsistent behavior of the chromophore. The crude results that were obtained demonstrated the same pattern observed in tests with SPPS and 11, decrease in LMCT band absorbance with visible and UV light.

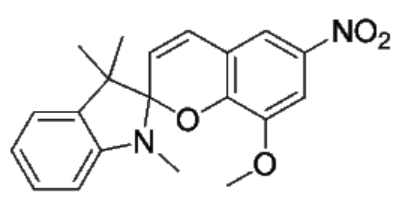

Figure 26. 6- $\mathrm{NO}_{2}-8-\mathrm{OMeBIPS}$

A novel class of organic photochromic molecules were published in literature termed donor-acceptor Stenhouse adducts (DASAs). These novel photochromic molecules boast two-step multi-gram scale procedures with cheap, readily accessible starting materials, tunability and operate using visible light. DASAs are negatively 
photochromic, they photoisomerize when irradiated with visible light and proceed from a hydrophobic, coloured isomer to a hydrophilic colourless isomer. ${ }^{36}$ The isomerization from colourless to coloured form occurs by thermal relaxation in the dark; this is shown in the figure, below, with the derivative shown being the one utilized in this study.
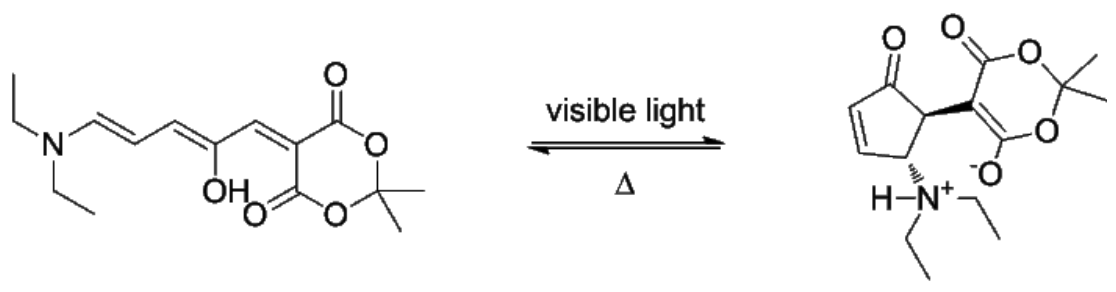

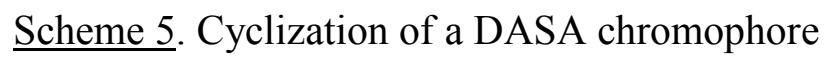

Several films containing commercial polystyrene (Mw 280,000), 11 and the DASA shown above were prepared. The films were irradiated using green light $(523 \mathrm{~nm})$ and the films produced favourable results: the LMCT band decreased in the presence of the closed, zwitterionic chromophore and the LMCT band intensity was regained upon thermal relaxation. However, upon comparison of the LMCT band in the blank test films to the films containing the DASA chromophore, there was no difference in contrast to the SP-PS films. These results led to studies concerning the exciting photochemistry of $\mathbf{1 1}$ in polymer matrices.

\subsubsection{Studies of $\left[\left\{\mathrm{Ru}\left(\mathrm{NH}_{3}\right)_{5}\right\}_{2}(\mu\right.$-dicyd $\left.\left.)\right][\mathrm{BPh}]_{4}\right]_{4}$}

Throughout previous photochemical studies the intention was to create a photoswitch capable of creating a donor interaction with 11. Various attempts were made with many different experimental conditions and chemical components and, although it was not possible to isolate the donor-acceptor interaction between $\mathrm{MC}$ and $\mathbf{1 1}$, evidence 
for the interaction exists (see 3.2.2.1). During these studies it became apparent that 11 possessed previously undiscovered solid-state photochemistry. Previous Crutchley group experience has shown no photochemistry of ruthenium phenylcyanamide complexes in solution, however, LED sources are very intense and irradiate over a very narrow bandwidth. Irradiation of $\mathbf{1 1}$ in acetonitrile using various light sources (blue, green and amber) and irradiation times of $2 \mathrm{~min}$ in ambient conditions showed no evidence for photochemistry. In retrospect, $\mathbf{1 1}$ in solution had many outlets to disperse excess energy due to irradiation but in films the movement of molecules is seriously hindered and fewer pathways for energy release are available - this is most likely what lead to interesting photochemistry. This unexpected photochromism is previously unexplored and may possibly lead to the development of a NIR photoswitchable material.

A systematic study of $\mathbf{1 1}$ in semi-solid state in thin films of polystyrene was carried out. Thin films of $\mathbf{1 1}$ dispersed in high $\mathrm{M}_{\mathrm{w}}$ polystyrene $(280,000)$ were made and the optical activity of $\mathbf{1 1}$ was tested in ambient atmosphere using $30 \mathrm{~s}$ of various light sources - the results are shown in the spectra and the table summarizes the findings, both below. 

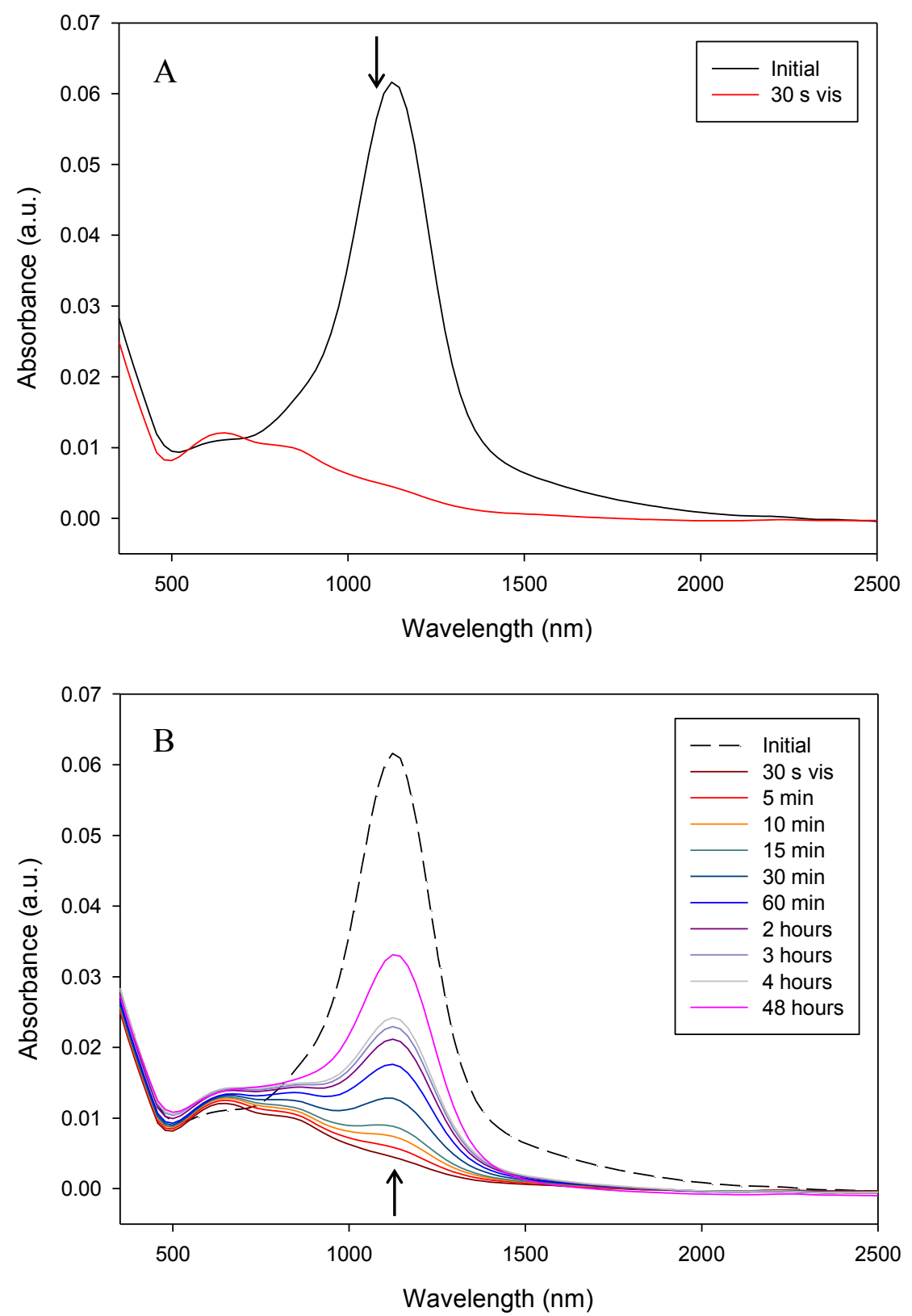

Figure 27. Thin film of $\mathbf{1 1}$ in polystyrene $\left(\mathrm{M}_{\mathrm{w}} 280,000\right)$ after $30 \mathrm{~s}$ of irradiation at 447.5 $\mathrm{nm}$ in ambient atmosphere (A) and thermal relaxation (B) 

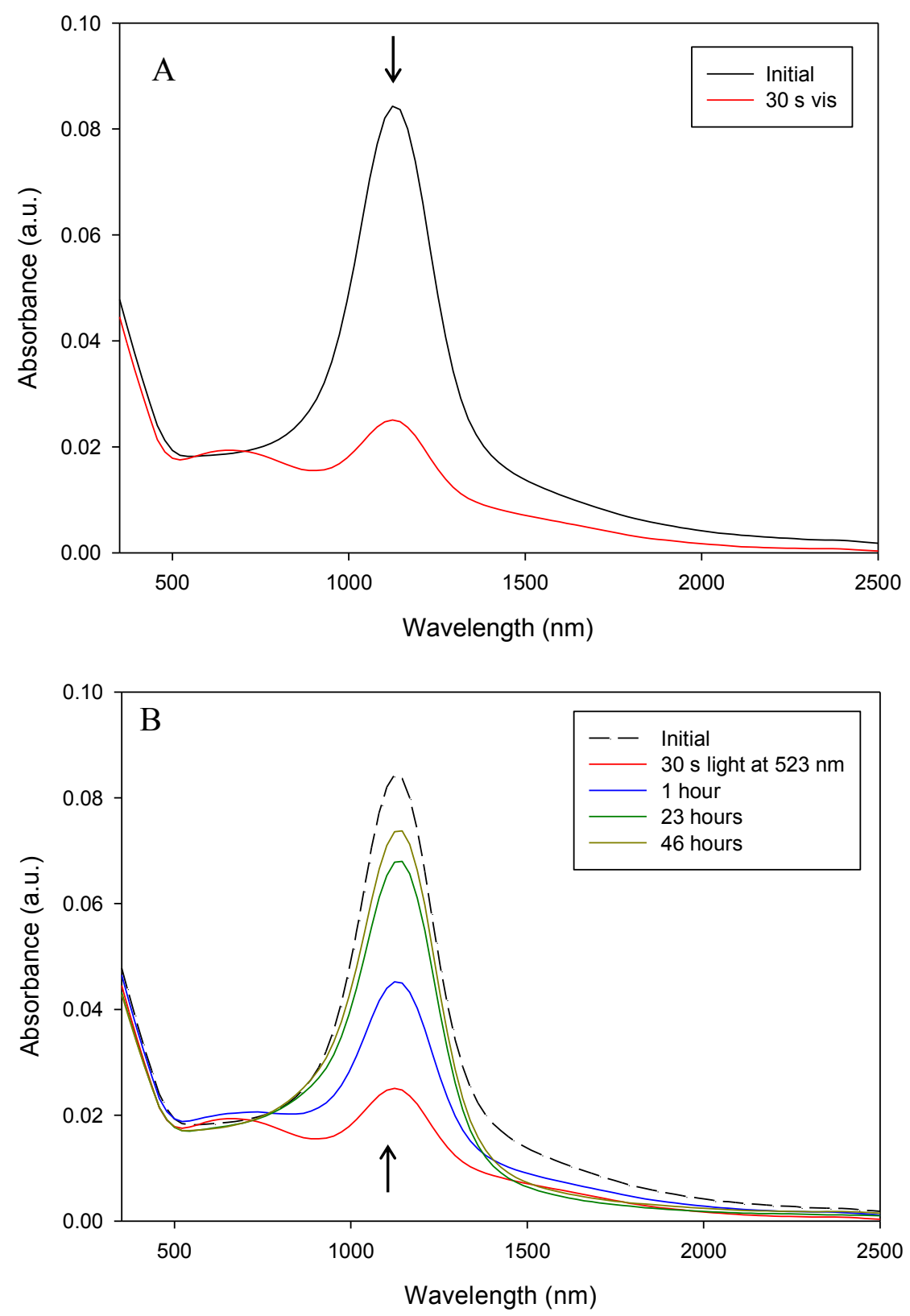

Figure 28. Thin film of 11 in polystyrene $\left(\mathrm{M}_{\mathrm{w}} 280,000\right)$ after $30 \mathrm{~s}$ of irradiation at $523 \mathrm{~nm}$ in ambient atmosphere (A) and thermal relaxation (B) 

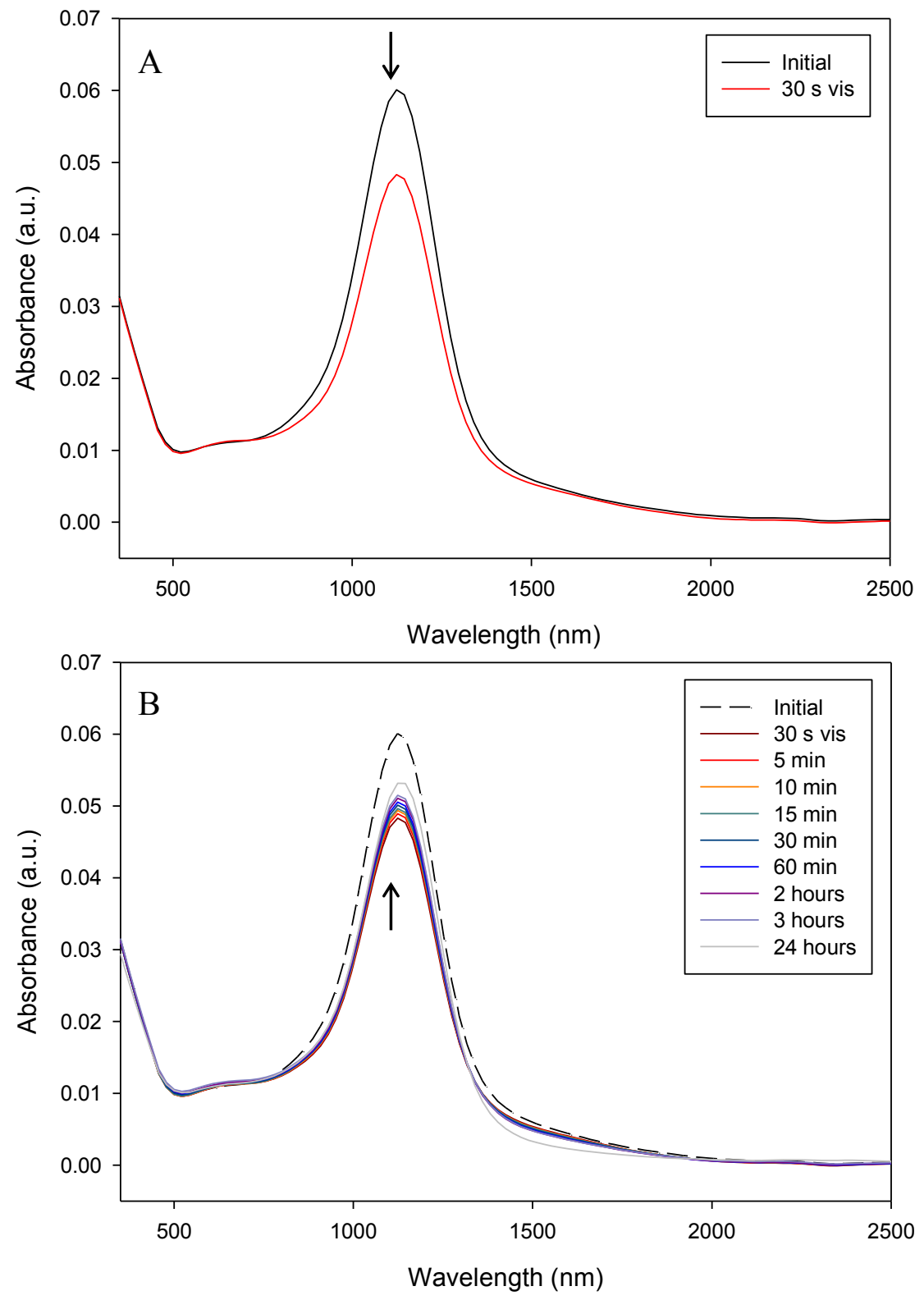

Figure 29. Thin film of $\mathbf{1 1}$ in polystyrene $\left(\mathrm{M}_{\mathrm{w}} 280,000\right)$ after $30 \mathrm{~s}$ of irradiation at $590 \mathrm{~nm}$ in ambient atmosphere (A) and thermal relaxation (B) 
Table 3. Change in the LMCT band $(1123 \mathrm{~nm})$ of $\mathbf{1 1}$ after irradiation by LED

\begin{tabular}{c|cccc}
\hline Light Source & & \multicolumn{3}{c}{$\% \mathrm{R}_{\mathrm{t}}$} \\
\cline { 2 - 5 } $\begin{array}{c}\text { Wavelength } \\
\lambda(\mathrm{nm})\end{array}$ & $\% \Delta_{\mathrm{A}}$ & $\mathrm{t}=1 \mathrm{~h}$ & $\mathrm{t}=24 \mathrm{~h}$ & $\mathrm{t}=48 \mathrm{~h}$ \\
\hline 447.5 & & 23 & - & 50 \\
523 & -92 & 34 & $72(23 \mathrm{~h})$ & $82(46 \mathrm{~h})$ \\
590 & -70 & 24 & - & - \\
\hline
\end{tabular}

The results displayed significant drops in absorbance intensity after irradiation at $460 \mathrm{~nm}$ and $523 \mathrm{~nm}$ at $92 \%$ and $70 \%$, respectively. The sample irradiated with green light showed the greatest recovery overall and was, therefore, chosen for further studies. Light sources with wavelengths below $447.5 \mathrm{~nm}$ and above $590 \mathrm{~nm}$ were not studied due to the apparent photobleaching in the UV and the lack of photochemistry at longer wavelengths.

The effect of the molecular weight of polystyrene in the films was also studied. The molecular weight of polystyrene was varied over 3 orders of magnitude, irradiated with green light and the recovery of the LMCT band was monitored (the results for the film containing polystyrene at $\mathrm{M}_{\mathrm{w}} 2,500$ are shown below). It was found that the recovery of the LMCT band was affected by the molecular weight; higher molecular weight produced films with greater recovery. After $24 \mathrm{~h}$, the films containing polystyrene of $\mathrm{M}_{\mathrm{w}}$ 2,500 and 280,000 recovered by $37 \%$ and $72 \%$, while the initial decrease in absorbance after irradiation was similar, $67 \%$ and $70 \%$, respectively. Higher molecular weight polymers are more rigid than lower molecular weight polymers of the same type (the $\mathrm{T}_{\mathrm{g}}$ increases with increasing molecular weight). ${ }^{51}$ Increasing the rigidity of the sample matrix would limit movement upon UV irradiation and could reduce the difficulty of relaxation to the ground state. Of the two pathways for relaxation from the metastable 
state, relaxation to starting materials or decomposition, higher molecular weight polymers favour recovery of the LMCT band and, therefore, recovery of starting materials.
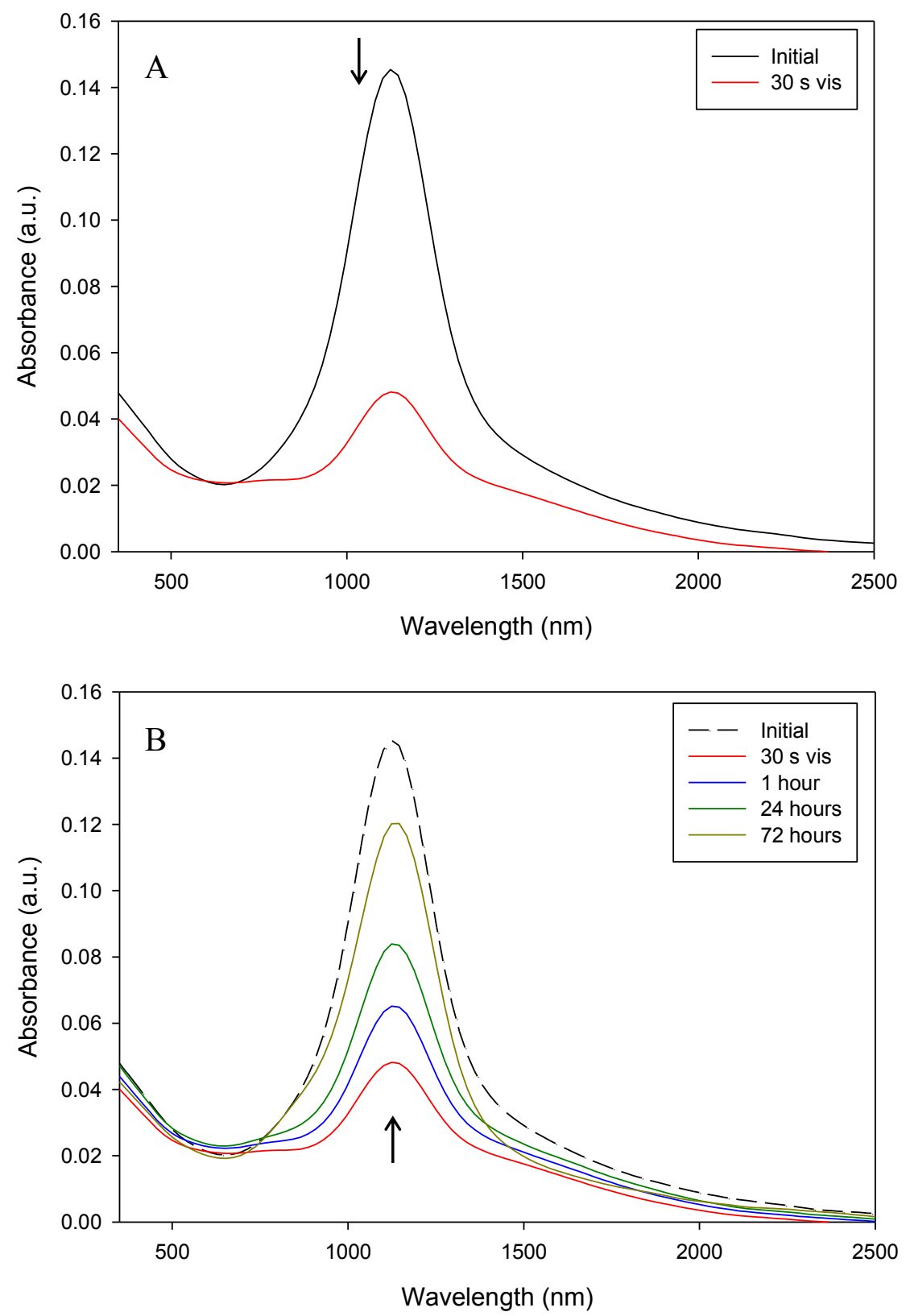

Figure 30. Thin film of 11 in polystyrene $\left(\mathrm{M}_{\mathrm{w}} 2,500\right)$ after $30 \mathrm{~s}$ of irradiation at $523 \mathrm{~nm}$ in ambient atmosphere (A) and thermal relaxation (B)

The reversibility of the effect had been optimized, however, the cause of the activity remained to be determined. The study was repeated in an air-tight chamber under 
argon to ensure the absence of oxygen and would determine if oxygen was a contributor to the effect. A thin film containing commercial polystyrene $\left(\mathrm{M}_{\mathrm{w}} 280,000\right)$ and $\mathbf{1 1}$ was prepared and irradiated with $523 \mathrm{~nm}$ light for $30 \mathrm{~s}$. The LMCT band absorbance decreased by $30 \%$ (shown in Figure 31A) and compared to the reduction in absorbance in ambient atmosphere (70\%), this was very low. The film was monitored over a period of 24 hours under argon and no recovery of the LMCT band was observed. When the flow of argon was halted and the film was exposed to the ambient atmosphere, a slight increase in LMCT band absorbance was observed along with a loss of the low energy broad shoulder of the LMCT band (shown in Figure 31B). While it appeared the loss of the LMCT band was a combination of events, oxygen was absolutely necessary for recovery. 

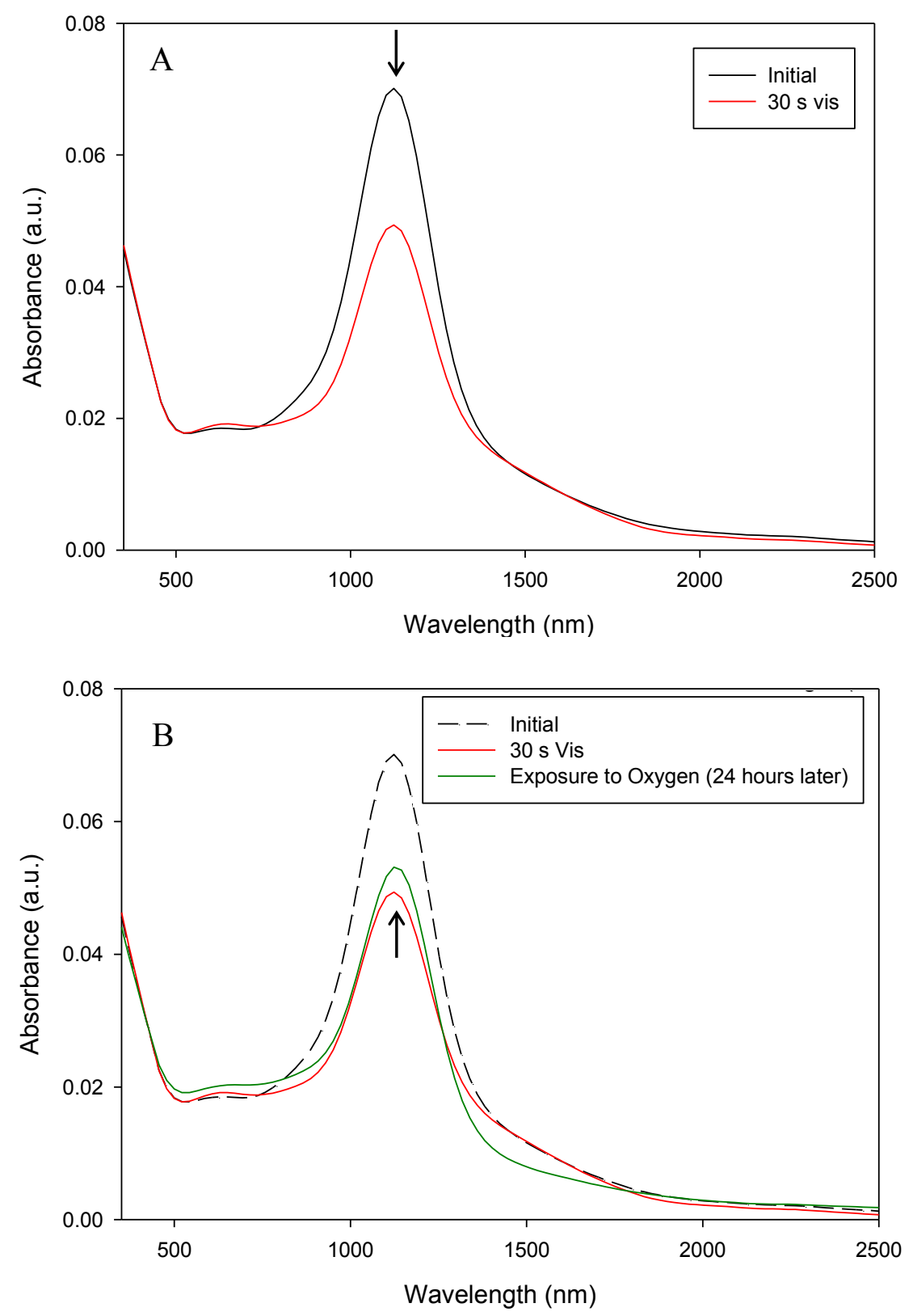

Figure 31. Thin film of 11 in polystyrene $\left(\mathrm{M}_{\mathrm{w}} 280,000\right)$ after $30 \mathrm{~s}$ of irradiation at $523 \mathrm{~nm}$ under argon (A) and exposure to oxygen after relaxation under argon for 24 hours (B)

The origin of the effect was unclear based on the previously performed experiments and several hypotheses were formulated (shown, below, in Figure 32) beginning with the irradiation of the ground state complex, $\mathrm{C}$, to the complex in the excited state, $C^{*}$ : 


$$
\boldsymbol{C}+\boldsymbol{h} \boldsymbol{v} \rightarrow \boldsymbol{C}^{*}
$$

Equation 3-9

In the electron transfer hypothesis, electron transfer between the complex excited state and oxygen, in the presence of water or a proton source, generates superoxide that then back transfers the electron. In the energy transfer hypothesis, $\mathbf{1 1}$ acts as a photosensitizer and generates singlet oxygen, the singlet oxygen may then react with the complex to form a new chemical species $\left(\mathrm{C}_{2} \mathrm{O}_{2}\right)$ or generate superoxide. In the chemical reaction hypothesis, a reversible chemical reaction or temporary rearrangement of the complex is possible and generates a new product containing oxygen $\left(\mathrm{P}_{2}, \mathrm{O}_{2}\right)$. Another pathway from the metastable state includes the decomposition pathway that would include the formation of a new product $\left(\mathrm{P}_{1}\right)$. To test these hypotheses, several experiments would need to be performed.

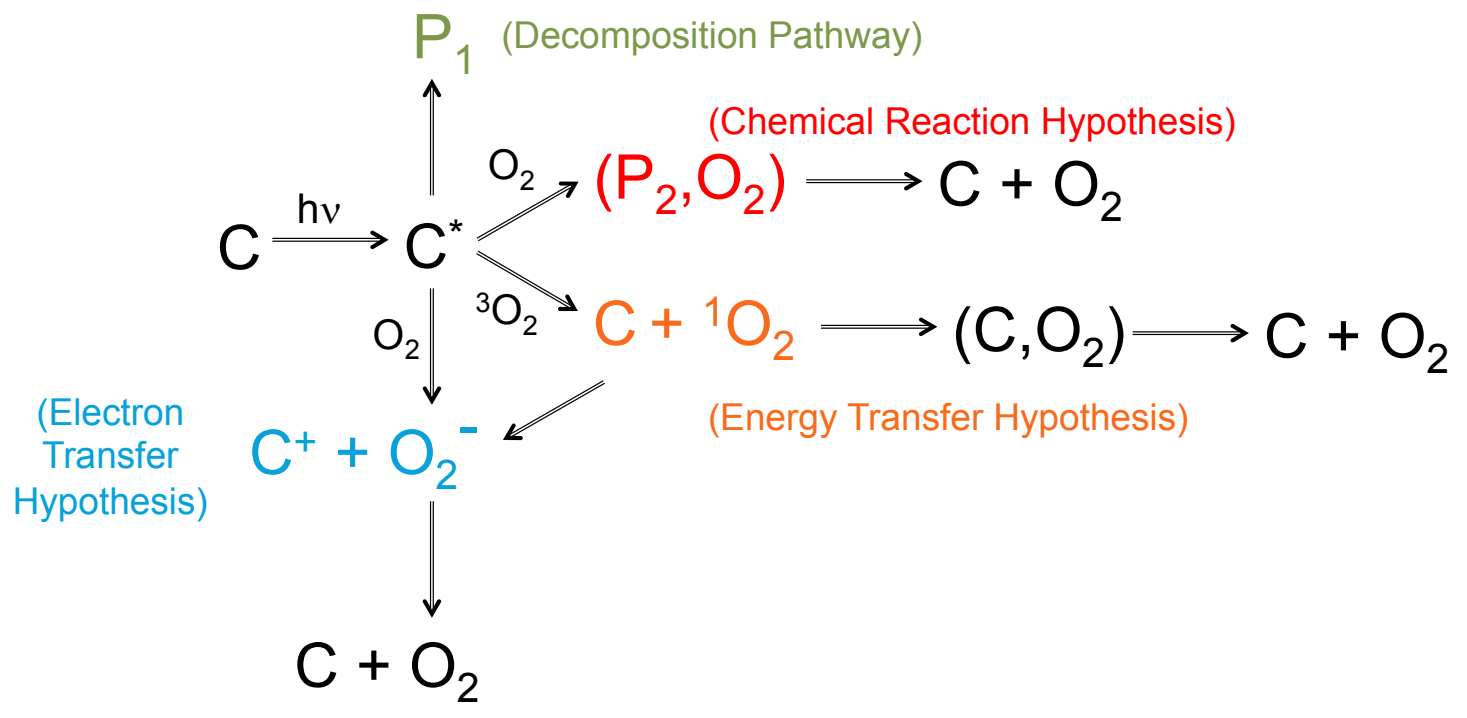

Figure 32. Hyposthesized mechanisms for the photoactivity and reversibility of $\left[\left\{\mathrm{Ru}\left(\mathrm{NH}_{3}\right)_{5}\right\}_{2}(\mu\right.$-dicyd) $]\left[\mathrm{BPh}_{4}\right]_{4}$ (where $\mathrm{C}$ is the complex, $\mathrm{C} *$ is the complex excited state and $\mathrm{P}_{1} / \mathrm{P}_{2}$ are new products).

Determining the involvement of singlet oxygen in this mechanism would be the simplest starting point as the presence of singlet oxygen is marked by an emission at 
$1270 \mathrm{~nm} .^{23}$ A solution of $\mathbf{1 1}$ in acetonitrile was prepared and the emission at $1270 \mathrm{~nm}$ was monitored as the film was irradiated into the LMCT band in ambient atmosphere by a laser at $1064 \mathrm{~nm}$. Although no emission was observed in solution and it is necessary to repeat the experiment in the solid-state it is unlikely singlet oxygen in involved in this mechanism. The maximum wavelength of the complex LMCT band occurs at $1123 \mathrm{~nm}$; after irradiation into the LMCT band of the complex and subsequent vibrational relaxation, it is unlikely that the excited triplet state of the complex exists at a high enough energy to excite ground state triplet oxygen to singlet oxygen.

The emission profile in the NIR was then monitored to determine the energy of the excited state. A film of 11 and commercial polystyrene $\left(M_{w} 280,000\right)$ was prepared and no emission properties were observed in the region lower in energy than the LMCT band. Determination of the energy of the excited state was attempted through transient absorption spectroscopy; however, the energy of the required irradiation was too high for films prepared with polystyrene. As the energy of the energy of the excited state was not yet determined, the electron transfer pathway remains a possibility and the presence of superoxide may also be determined by 'spin-trapping' in combination with EPR (electron paramagnetic resonance) spectroscopy. ${ }^{52}$ It is important to note, however, that the rate of reversibility is slow in comparison to typical electron transfer timescales and, thus, electron transfer seems improbable.

It is also possible that there are several mechanisms working in tandem to produce the observed photochemistry of 11. The decomposition pathway and the chemical reaction hypothesis present likely ideas as to the mechanism of this effect, with the latter idea representing a reversible process. The decomposition pathway may be present; when 
excitation of the complex occurs at high energy, it is possible the complex fragments due to the limited relaxation pathways and, therefore, reversibility would be reduced. In the chemical reaction hypothesis, irradiation of the complex to the excited state could include a ligand-to-metal charge transfer from $\operatorname{dicyd}^{2-}$ to the ruthenium (III) metal centre in $\mathbf{1 1}$ to produce ruthenium (II) and dicyd - - this reduction would cause a loss in the LMCT band of 11. As reversibility is observed in the presence of oxygen, it is possible that molecular oxygen coordinates to ruthenium (II) to form a seven-coordinate metastable species that is stabilized by interaction of oxygen with the dicyd ligand. This species would exist in equilibrium and reversibility is possible as the oxygen would be labile. This hypothesis could be tested through observation of the dicyanamide vibration (by IR spectroscopy) as 11 is irradiated and thermally relaxes. Changes in the rate of relaxation through increasing oxygen concentration and temperature would be monitored to gain additional evidence in support of this hypothesis. 


\section{Chapter: Conclusions and Future Work}

A novel photochromic polymer (SP-PS) with a styrene backbone linked to SP through an alkyl chain was synthesized at a $4 \%$ yield overall. UV irradiation of SP-PS induces photoisomerization from SP to MC and the back-reaction occurs thermally or by visible irradiation. SP-PS was characterized by ${ }^{1} \mathrm{H}-\mathrm{NMR}$ spectroscopy, DSC and GPC. The $\mathrm{T}_{\mathrm{g}}$ was determined to be $118.41{ }^{\circ} \mathrm{C} ; \mathrm{M}_{\mathrm{n}}$ was determined to be $63,980 \mathrm{~g} / \mathrm{mol} \pm$ $1.731 \%(\mathrm{D}=1.24)$ and $\Phi_{365} \mathrm{~nm}$ for SP-MC photoisomerization was 0.80 after $5 \mathrm{~s}$ in toluene.

When SP-PS is combined with $\left[\left\{\mathrm{Ru}\left(\mathrm{NH}_{3}\right)_{5}\right\}_{2}(\mu\right.$-dicyd) $]\left[\mathrm{BPh}_{4}\right]_{4},\left(\right.$ dicyd $^{2-}$ is the dicyanamido benzene dianion), in thin films, a NIR photoswitchable material results. The $\left[\left\{\mathrm{Ru}\left(\mathrm{NH}_{3}\right)_{5}\right\}_{2}(\mu\right.$-dicyd) $)\left[\mathrm{BPh}_{4}\right]_{4} \mathrm{LMCT}$ band is significantly affected by the nature of the electron donating ability of the outer sphere and the interaction between MC in SP-PS and $\left[\left\{\mathrm{Ru}\left(\mathrm{NH}_{3}\right)_{5}\right\}_{2}(\mu\right.$-dicyd) $]\left[\mathrm{BPh}_{4}\right]_{4}$ was hypothesized to mimic this effect. Studies of SP-PS and $\left[\left\{\mathrm{Ru}\left(\mathrm{NH}_{3}\right)_{5}\right\}_{2}(\mu\right.$-dicyd) $]\left[\mathrm{BPh}_{4}\right]_{4}$ were difficult to interpret due to photoactivity in the blanks so interaction between $\mathrm{MC}$ and $\left[\left\{\mathrm{Ru}\left(\mathrm{NH}_{3}\right)_{5}\right\}_{2}(\mu\right.$-dicyd) $]\left[\mathrm{BPh}_{4}\right]_{4}$ was observed indirectly through comparison of MC-SP photoisomerization rates. The rate of the photoisomerization of MC to SP by visible and thermal relaxation in films containing SP-PS and the complex and films without the complex were compared. Statistical analysis was performed using a t-test on extrapolated data; the rates of optical and thermal reversibility of MC showed statistically significant differences in the presence of the complex (p-levels of 0.04062 and 0.01882 , respectively, in one-tailed tests with equal variances). 
Testing blanks of the thin films used in studies on the interaction of SP-PS with $\left[\left\{\mathrm{Ru}\left(\mathrm{NH}_{3}\right)_{5}\right\}_{2}(\mu\right.$-dicyd) $]\left[\mathrm{BPh}_{4}\right]_{4}$ led to the discovery of unique solid-state photochemistry of the complex. Thin films composed of $\left[\left\{\mathrm{Ru}\left(\mathrm{NH}_{3}\right)_{5}\right\}_{2}(\mu\right.$-dicyd $\left.)\right]\left[\mathrm{BPh}_{4}\right]_{4}$ in polystyrene were characterized by SEM to have a thickness of $0.62 \mu \mathrm{m}$. Irradiation of these films for $30 \mathrm{~s}$ by a $523 \mathrm{~nm}$ LED reduced LMCT band absorbance by $70 \%$ and $82 \%$ recovery was observed after $46 \mathrm{~h}$ in ambient atmosphere. Using a polymer matrix with a higher molecular weight optimized recovery of the LMCT band of the complex. In films composed of polystyrene, $\mathrm{M}_{\mathrm{w}} 2,500$ or $\mathrm{M}_{\mathrm{w}} 280,000$, and $\left[\left\{\mathrm{Ru}\left(\mathrm{NH}_{3}\right)_{5}\right\}_{2}(\mu \text {-dicyd)][BPh}]_{4}\right.$, recovery of $37 \%$ and $72 \%$, respectively, was observed 24 hours after $30 \mathrm{~s}$ of visible irradiation at $523 \mathrm{~nm}$. The initial decrease in absorbance after irradiation was similar, however, at $67 \%$ and $70 \%$, respectively. The mechanism of this effect remains to be determined.

Future studies will be carried out to determine the mechanism of this effect. As previously mentioned, the presence of singlet oxygen in films will be monitored. Also, the sample matrix must first be adjusted to withstand the temperature and wavelengths of irradiation useful in transient absorption spectroscopy (TAS) studies of the excited state. TAS studies of the films in inert conditions and in the presence of oxygen will be the initial steps in the determination of the mechanism. As mentioned previously, studies observing changes in the dicyanamide vibration by IR spectroscopy before irradiation and during thermal relaxation will also be carried out. A systematic study of the observed effect in various complexes with different substitution patterns will also be studied to aid in the determination of mechanism. Optimizing the reversibility by increasing the speed 
of recovery may be possible once the mechanism is known and this could lead to the creation of a NIR photoswitchable material. 


\section{References}

(1) Balzani, V.; Credi, A.; Venturi, M. Nano Today 2007, 2, 18-25.

(2) Ward, M. D. Chem. Soc. Rev. 1995, 24, 121-134.

(3) Naklicki, M. Inner-sphere and outer-sphere perturbations of the rutheniumcyanamide bond in mononuclear and dinuclear pentaammineruthenium complexes of 1,4-dicyanamidobenzene ligands, Carleton University, 1995, p. 156.

(4) Robin, M. B. Adv. Inorg. Chem. 1968, 10, 247-422.

(5) Demadis, K. D.; Hartshorn, C. M.; Meyer, T. J. Chem. Rev. 2001, 101, 2655-2685.

(6) Evans, C. E. B.; Naklicki, M. L.; Rezvani, A. R.; White, C. A.; Kondriatiev, V. V.; Crutchley, R. J. J. Am. Chem. Soc. 1998, 120, 13096-13103.

(7) Hillman, M.; Kvickt, A. Organometallics 1983, 2, 1780-1785.

(8) Kirchner, R. F.; Loew, G. H.; Mueller-Westerhoff, U. T. Inorg. Chem. 1976, 15, 2665-2670.

(9) DeRosa, M. C. Transition metal complexes for electronic and sensing applications, Carleton University, 2003, p. 325.

(10) Hush, N. S. Prog. Inorg. Chem. 1961, 8, 391-444.

(11) Evans, C. E. B. An Investigation of Superexchange in Dinuclear Ruthenium Complexes, Carleton University, 1997, pp. 84, 87.

(12) Gutmann, V. Electrochim. Acta 1976, 21, 661-670.

(13) Klajn, R. Chem. Soc. Rev. 2014, 43, 148-184.

(14) Orgiu, E.; Samorì, P. Adv. Mater. 2014, 26, 1827-1845.

(15) Fischer, E.; Hirshberg, Y. J. Chem. Soc. 1952, 4522-4524.

(16) Florea, L.; Diamond, D.; Benito-Lopez, F. Macromol. Mater. Eng. 2012, 297, $1148-1159$.

(17) Samat, A.; De Keukelaire, D.; Guglielmetti, R. Bull. Soc. Chim. Belg. 1991, 100, $679-700$.

(18) Berkovic, G.; Krongauz, V.; Weiss, V. Chem. Rev. 2000, 100, 1741-1754. 
(19) Mulliken, R. S. Phys. Rev. 1928, 32, 880-887.

(20) Ellis, J. W.; Kneser, H. O. Zeitschrift fuer Phys. 1933, 86, 583-591.

(21) Krasnovsky, A. A. J. Photochem. Photobiol. A Chem. 2008, 196, 210-218.

(22) Khan, A. U.; Kasha, M. J. Chem. Phys. 1963, 39, 2105-2106.

(23) Derosa, M. C.; Crutchley, R. J. Coord. Chem. Rev. 2002, 234, 351-371.

(24) Ogilby, P. R. Photochem. Photobiol. 2006, 82, 1133-1135.

(25) Schmidt, R. Photochem. Photobiol. 2006, 82, 1161-1177.

(26) Pefkianakis, E. K.; Christodouleas, D.; Giokas, D. L.; Papadopoulos, K.; Vougioukalakis, G. C. Eur. J. Inorg. Chem. 2013, 2013, 4628-4635.

(27) Muazzani, Q. G.; Sun, H.; Hoffman, M. Z.; Ford, W. E.; Rodgers, M. A. J. J. Phys. Chem. 1994, 98, 1145-1150.

(28) Song, C.; Zhang, J. In PEM Fuel Cell Electrocatalysts and Catalyst Layers; Springer London, 2008; pp. 89-134.

(29) Xie, X.; Mistlberger, G.; Bakker, E. J. Am. Chem. Soc. 2012, 134, 16929-16.

(30) Spanka, C.; Clapham, B.; Janda, K. D. J. Org. Chem. 2002, 67, 3045-3050.

(31) Spino, C.; Barriault, N. J. Org. Chem. 1999, 64, 5292-5298.

(32) Naklicki, M. L.; White, C. A.; Plante, L. L.; Evans, C. E. B.; Crutchley, R. J. Inorg. Chem. 1998, 37, 1880-1885.

(33) Ueno, Y.; Jose, J.; Loudet, A.; Perez-Bolivar, C.; Anzenbacher, P.; Burgess, K. J. Am. Chem. Soc. 2011, 133, 51-55.

(34) Li, Y.; Duan, Y.; Li, J.; Zheng, J.; Yu, H.; Yang, R. Anal. Chem. 2012, 84, 4732 4738.

(35) Roxburgh, C. J.; Sammes, P. G.; Abdullah, A. Dye. Pigment. 2009, 82, 226-237.

(36) Helmy, S.; Oh, S.; Leibfarth, F. A.; Hawker, C. J.; Alaniz, J. R. De. J. Org. Chem. 2014, 79, 11316-11329.

(37) Choudhuri, M. M. R. Redox Ambi-valence of Phenylcyanamide Ligands in Ruthenium Complexes, Carleton University, 2013, p. 503. 
(38) Radu, A.; Byrne, R.; Alhashimy, N.; Fusaro, M.; Scarmagnani, S.; Diamond, D. J. Photochem. Photobiol. A Chem. 2009, 206, 109-115.

(39) Odian, G. In Principles of Polymerization; Wiley-Interscience, 2004; pp. 262-263.

(40) Salvidar-Guerra, E.; Vivaldo-Lima, E. Handbook of Polymer Synthesis, Characterization, and Processing; 2013; p. 658.

(41) Mark, J. E. Polymer Data Handbook, 2nd ed.; 2009; pp. 1031-1037.

(42) Mark, J. E. Physical Properties of Polymers Handbook; 2007; pp. 187-188, 305307.

(43) Stepto, R. F. T. Pure Appl. Chem. 2009, 81, 351-353.

(44) Sperling, L. H. Introduction to Physical Polymer Science; 2001; pp. 31, 64, 67, 173, 202, 208, 209, 252, 252, 323.

(45) Kuhn, H. J.; Braslavsky, S. E.; Schmidt, R. Pure Appl. Chem. 1989, 61, 187-210.

(46) Demas, J. N.; Bowman, W. D.; Zalewski, E. F.; Velapoldi, R. A. J. Phys. Chem. 1981, 85, 2766-2771.

(47) Chibisov, A. K.; Gorner, H. J. Phys. Chem. A 1997, 101, 4305-4312.

(48) Linert, W.; Camard, A.; Armand, M.; Michot, C. Coord. Chem. Rev. 2002, 226, $137-141$.

(49) Linert, W.; Jameson, R. F.; Taha, A. J. Chem. Soc. Dalt. Trans. 1993, 3181-3186.

(50) Radu, A.; Scarmagnani, S.; Byrne, R.; Slater, C.; Tong Lau, K.; Diamond, D. J. Phys. D. Appl. Phys. 2007, 40, 7238-7244.

(51) Plazek, D. J.; Ngai, K. L. The Glass Temperature; Vol. vi, pp. 187-188.

(52) Hardy, M.; Poulhe, F.; Rizzato, E.; Rockenbauer, A.; Banaszak, K.; Karoui, H.; Kalyanaraman, B.; Tordo, P.; Ouari, O. Chem. Res. Toxicol. 2014, 27, 1155-1165. 


\section{Appendices}

Appendix 1 - Spectroscopic Characterization of Novel Intermediates in the Synthesis of SP-PS

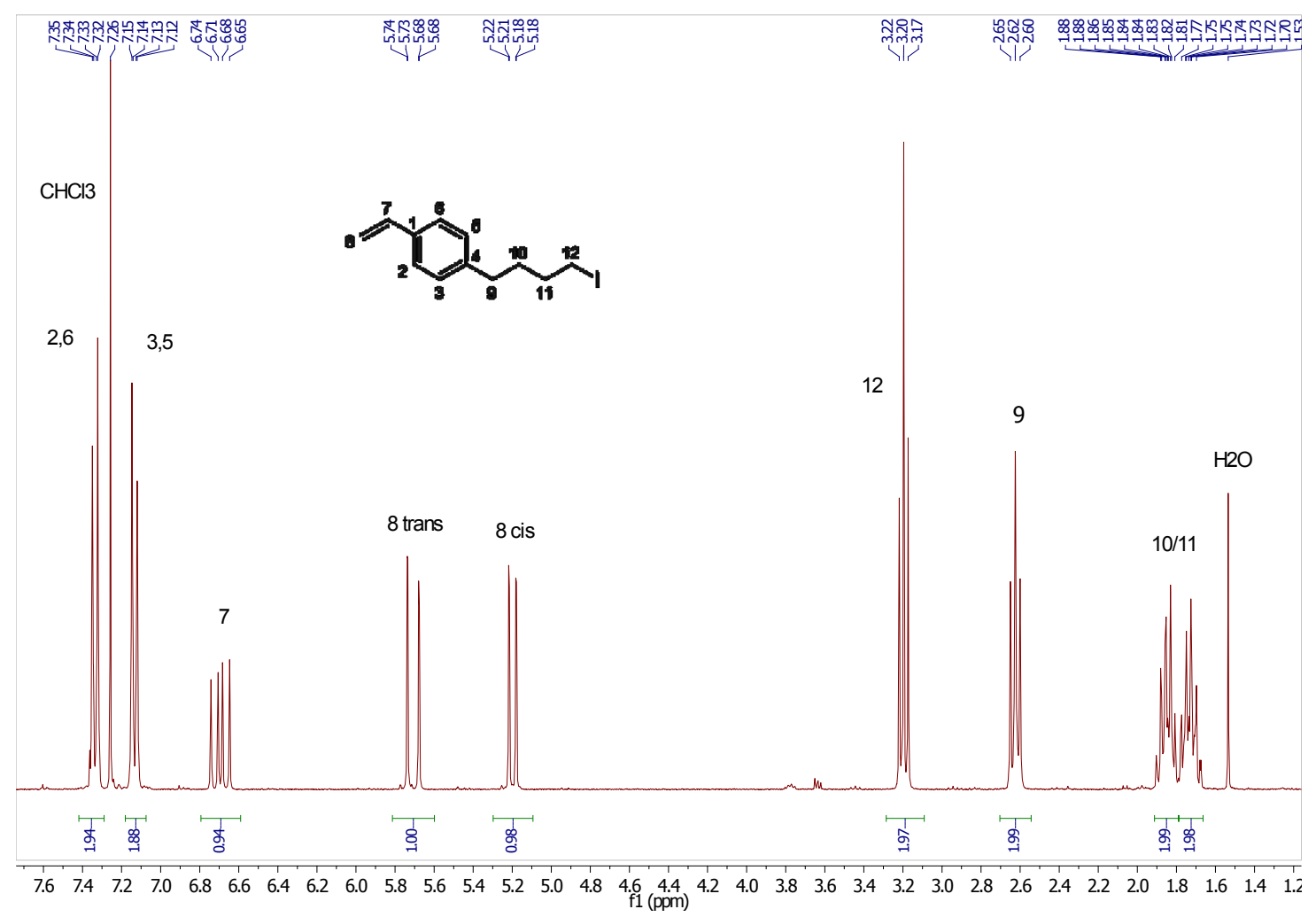

Figure 33. ${ }^{1} \mathrm{H}-\mathrm{NMR}$ spectrum of 5 at $300 \mathrm{MHz}$ in $\mathrm{CDCl}_{3}$ 


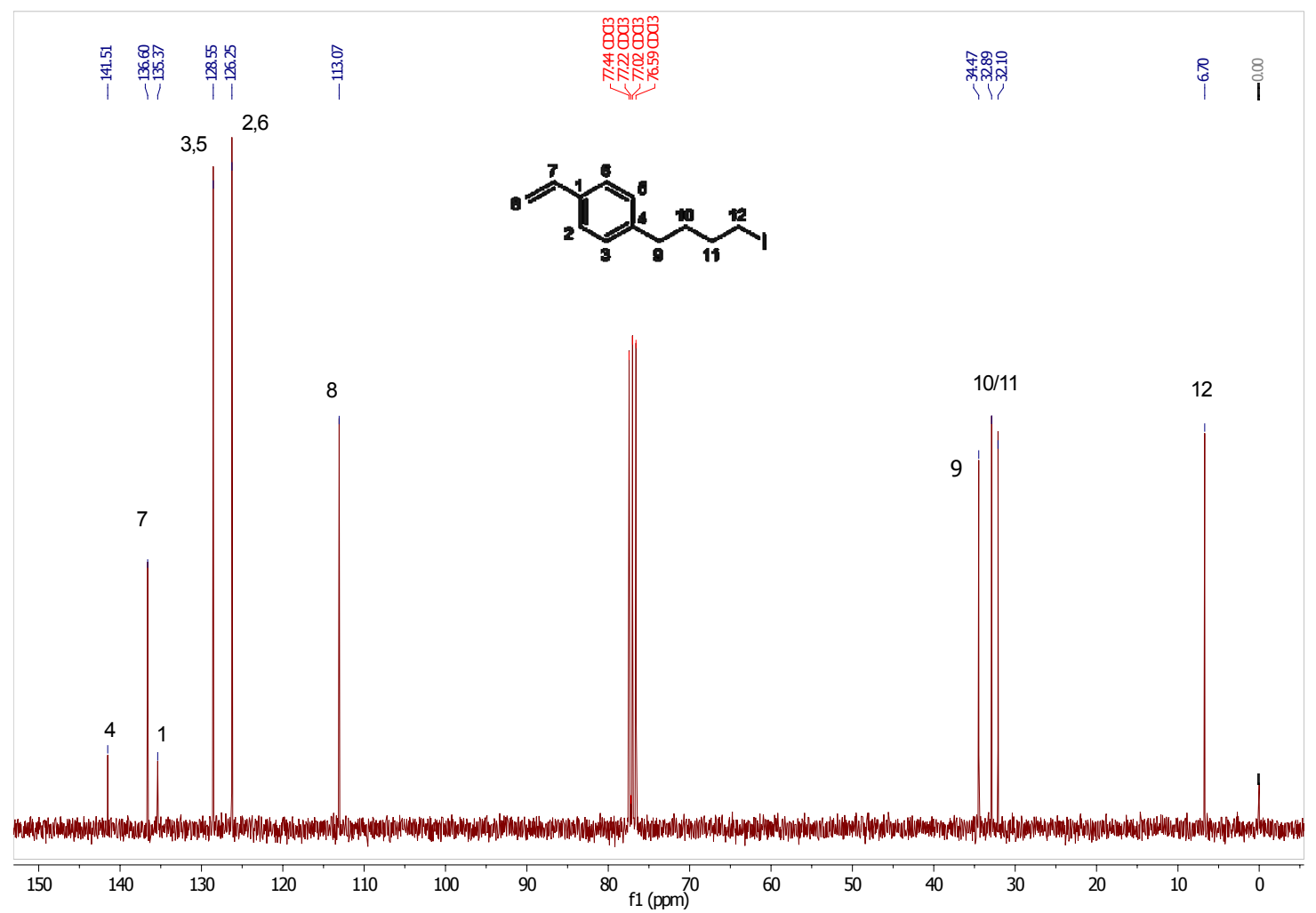

Figure $34 .{ }^{13} \mathrm{C}$-NMR spectrum of 5 at $75 \mathrm{MHz}$ in $\mathrm{CDCl}_{3}$ 


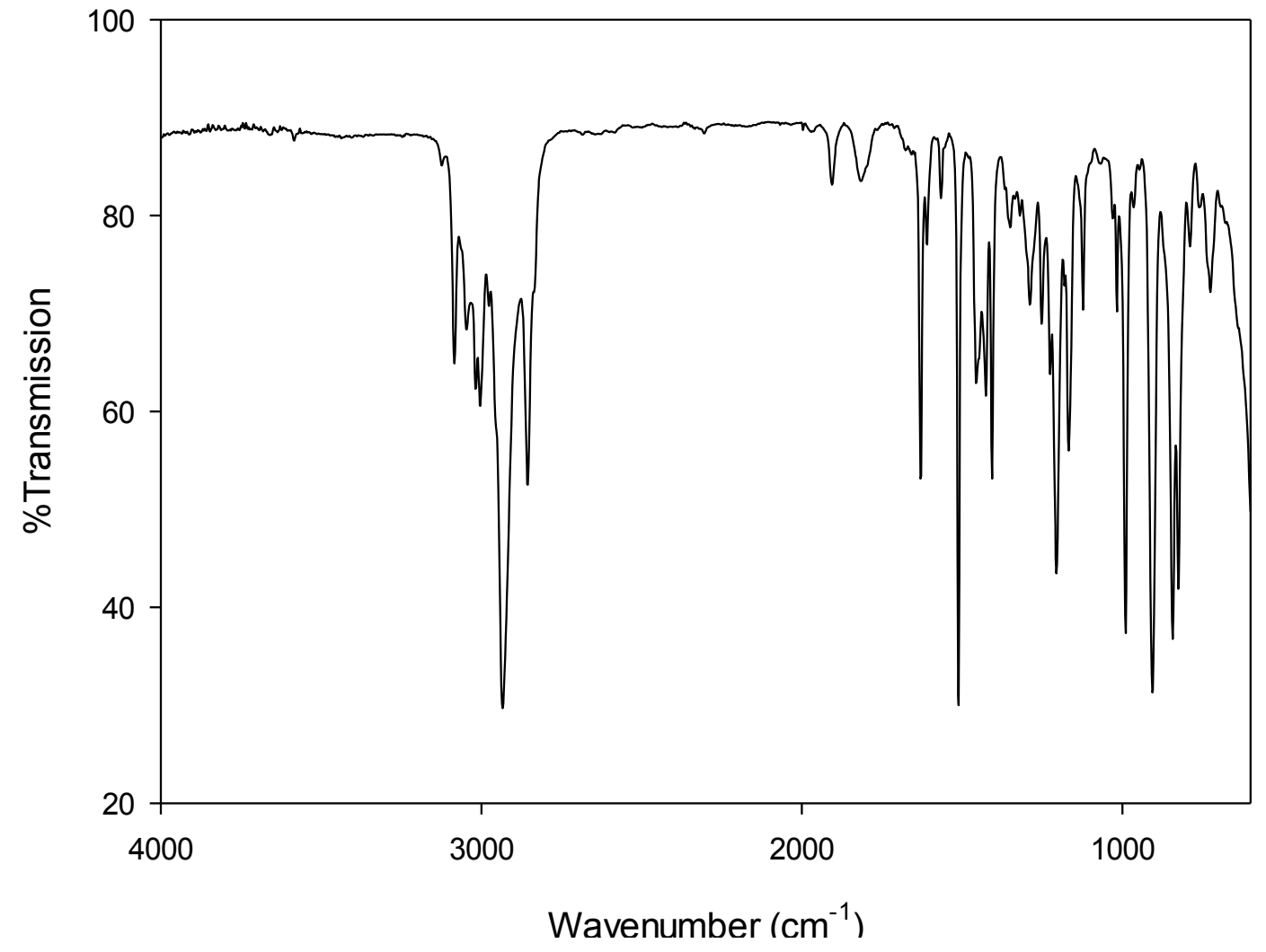

Figure 35. FT-IR Spectrum of 5 in a KBr Pellet 


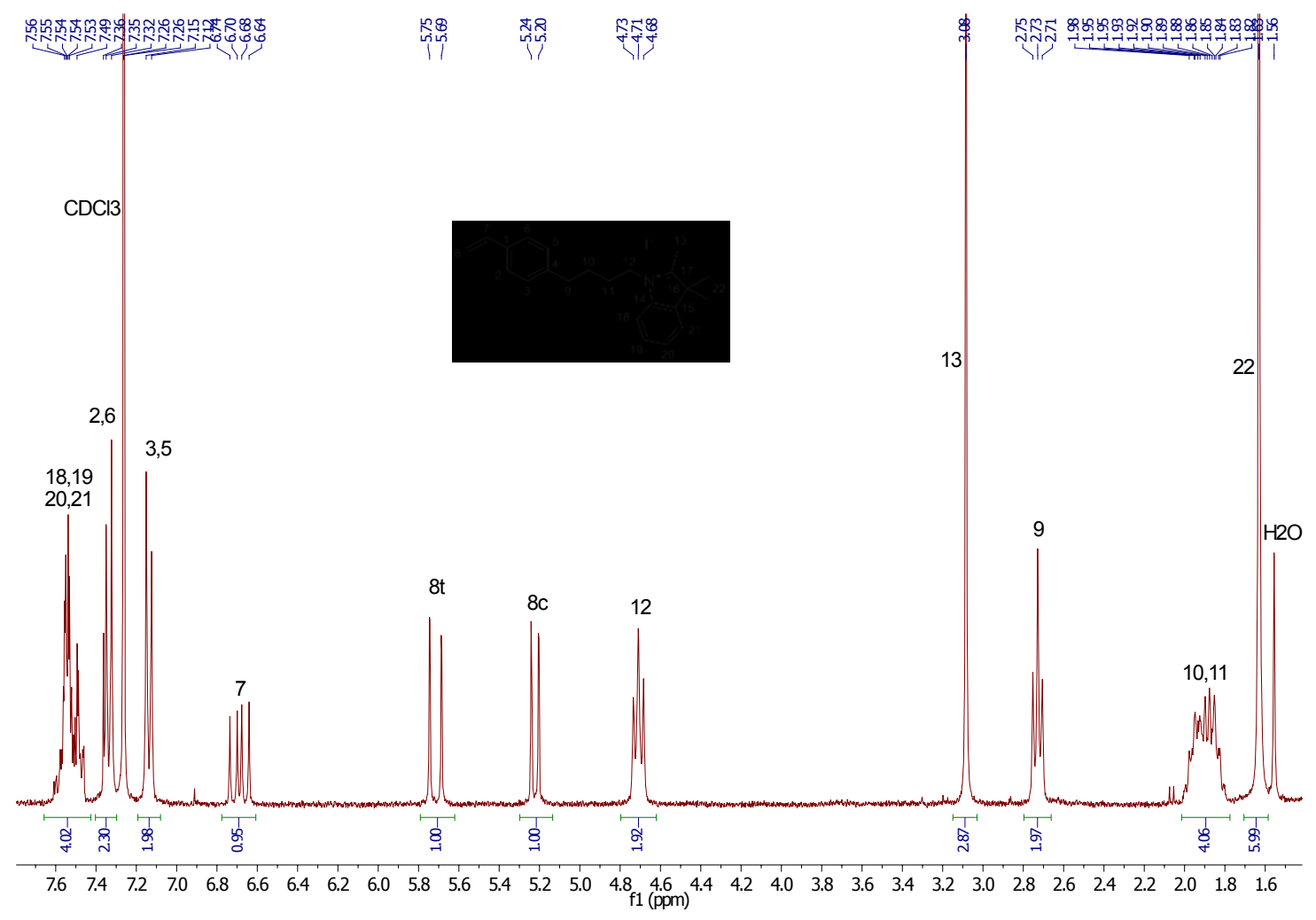

Figure 36. ${ }^{1} \mathrm{H}-\mathrm{NMR}$ spectrum of 6 at $300 \mathrm{MHz}$ in $\mathrm{CDCl}_{3}$ 


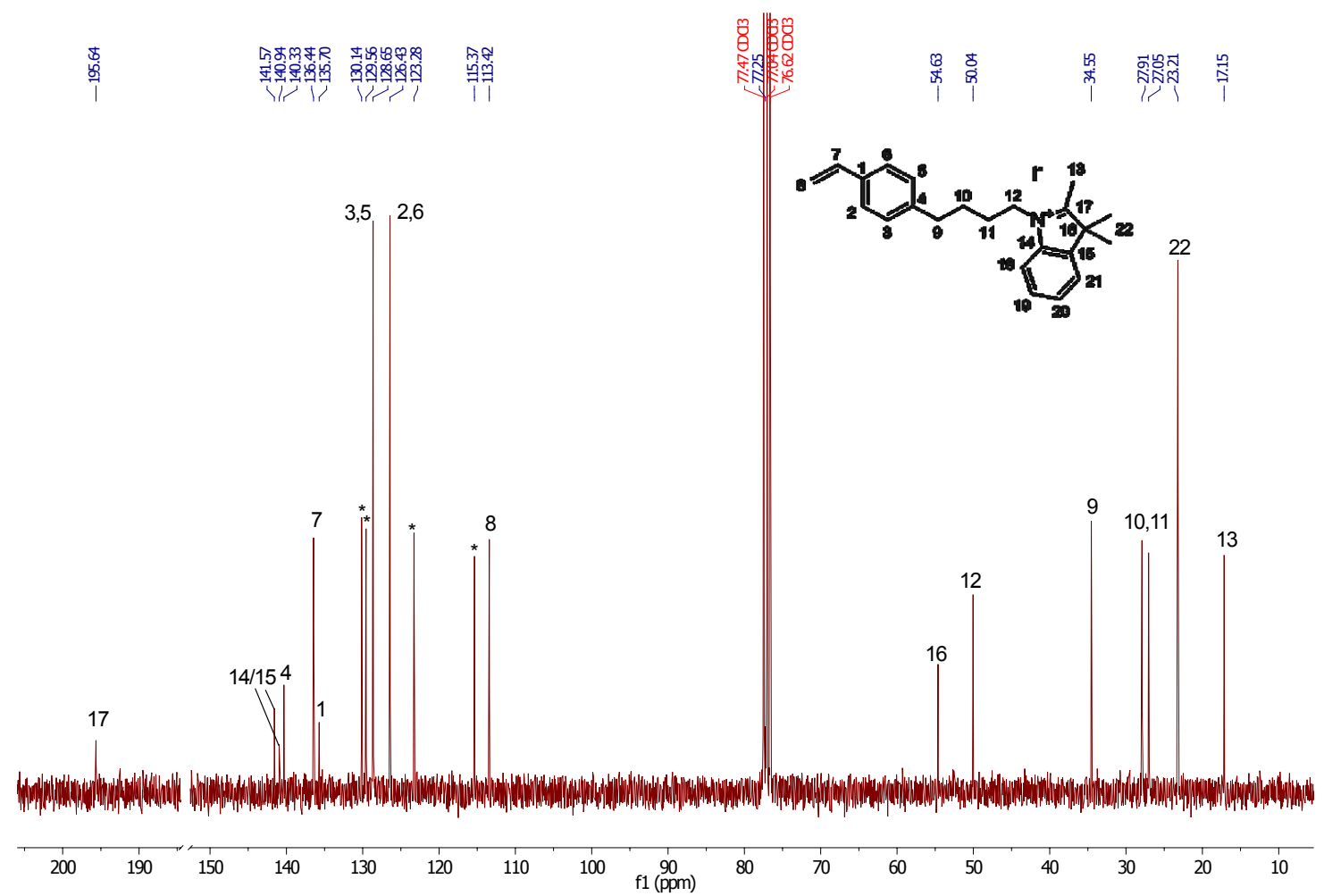

Figure 37. ${ }^{13} \mathrm{C}$-NMR spectrum of 6 in $\mathrm{CDCl}_{3}$ at $75 \mathrm{MHz}$, Carbons denoted by * are 18 , 19,20 , or 21 


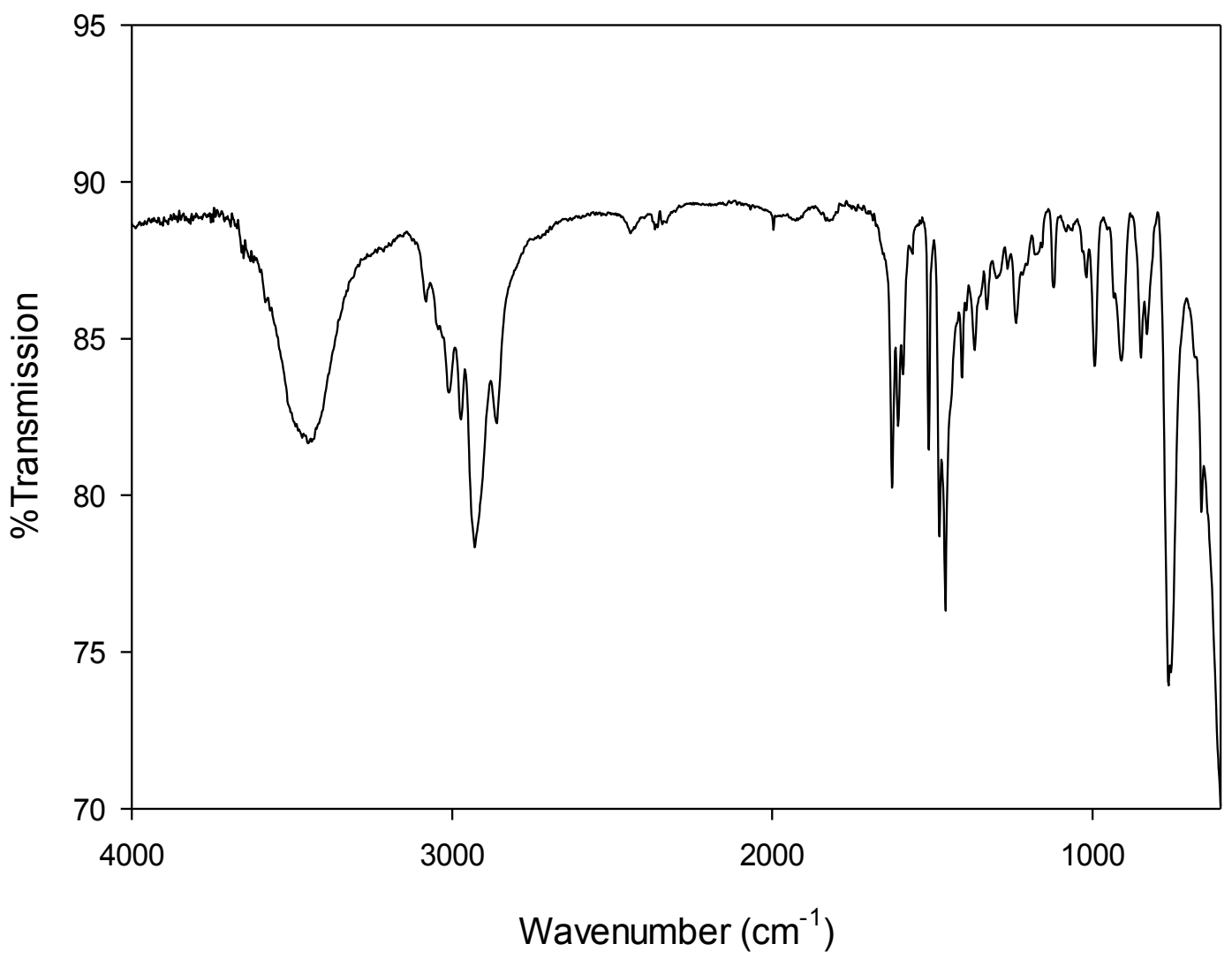

Figure 38. IR spectrum of 6 in a $\mathrm{KBr}$ pellet 


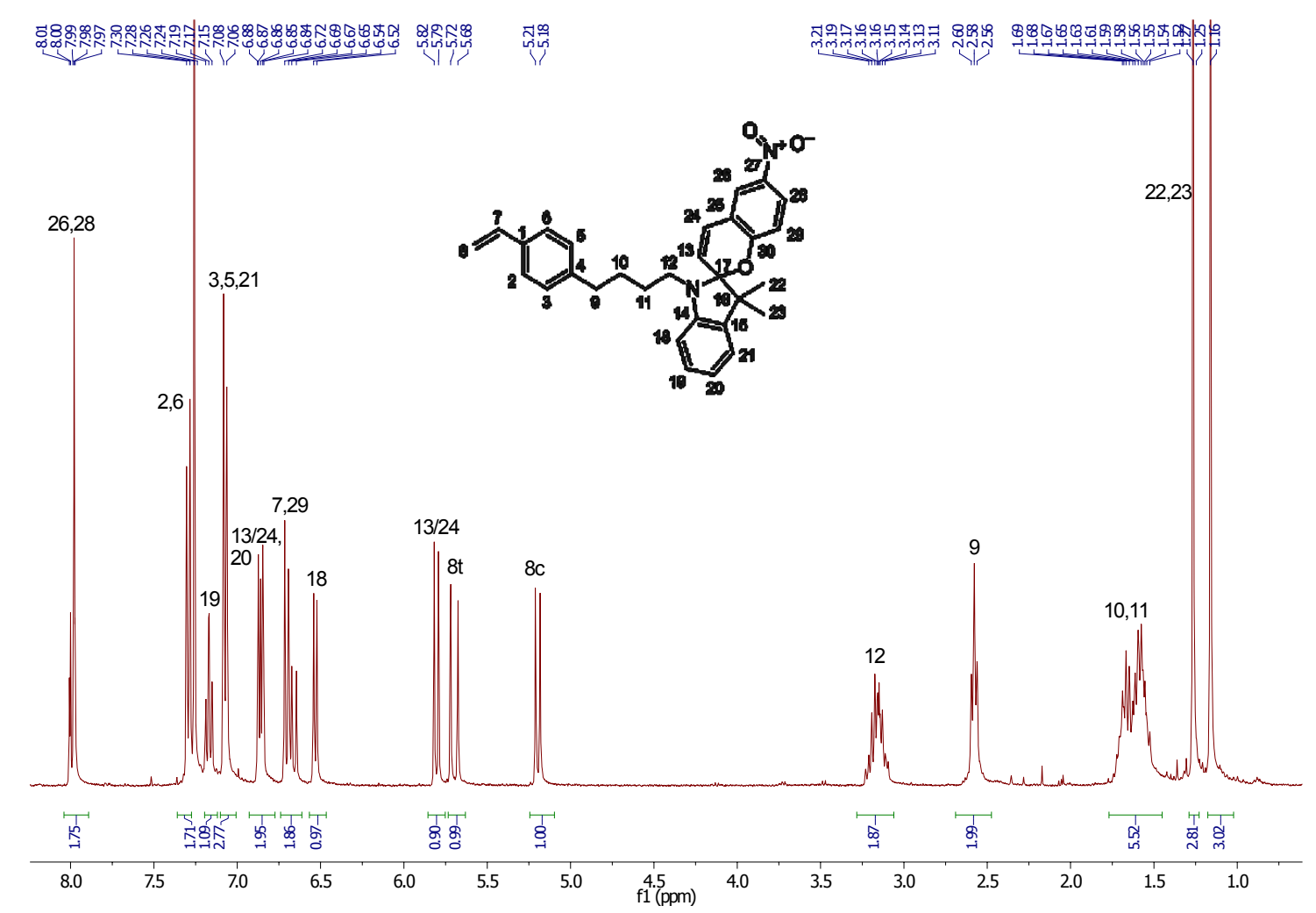

Figure 39. ${ }^{1} \mathrm{H}-\mathrm{NMR}$ spectrum of mSP-PS (7) at $400 \mathrm{MHz}$ in $\mathrm{CDCl}_{3}$ 


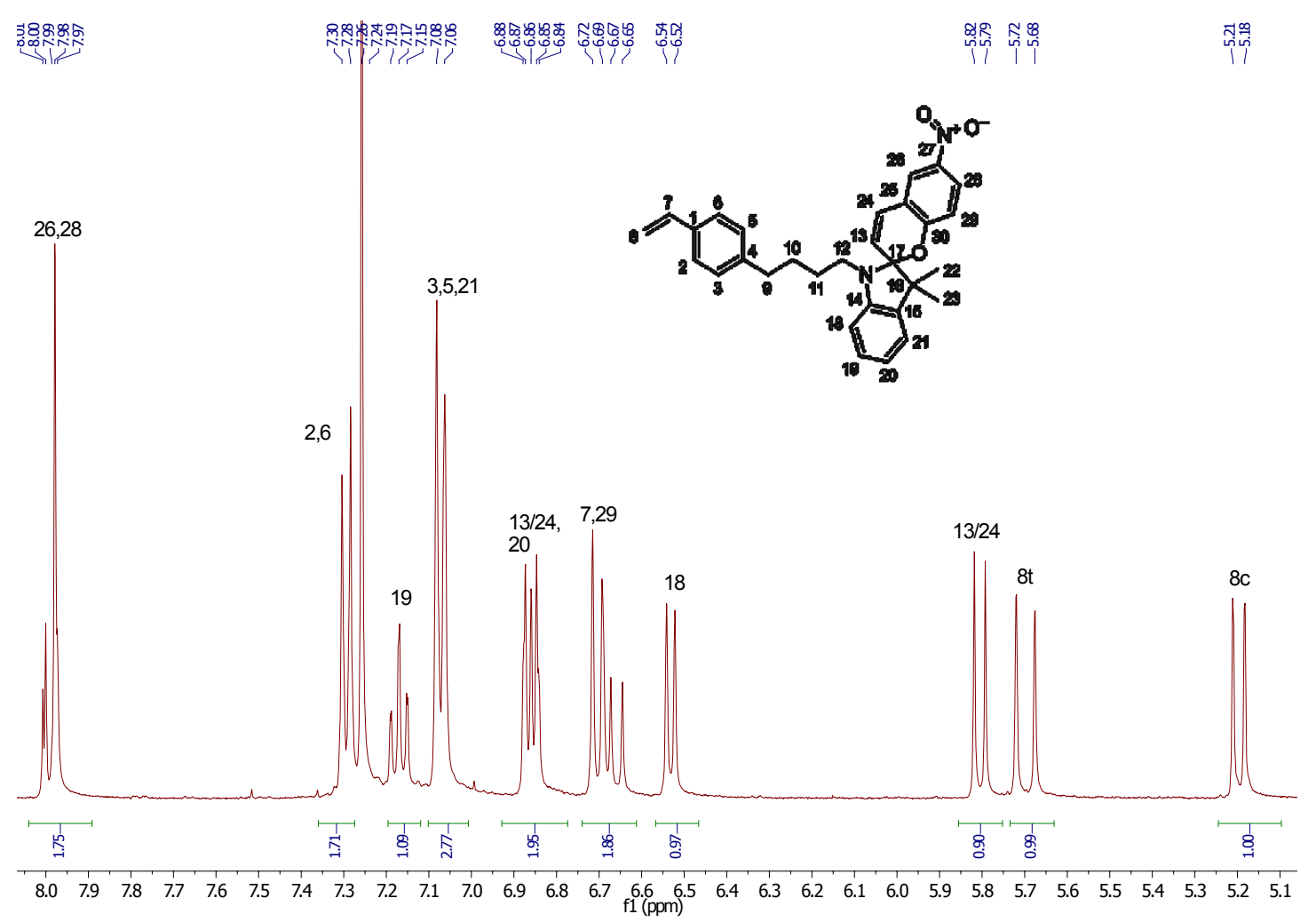

Figure 40. ${ }^{1} \mathrm{H}-\mathrm{NMR}$ spectrum of mSP-PS (7) at $400 \mathrm{MHz}$ in $\mathrm{CDCl}_{3}$ between 8.0 and 5.1 ppm 


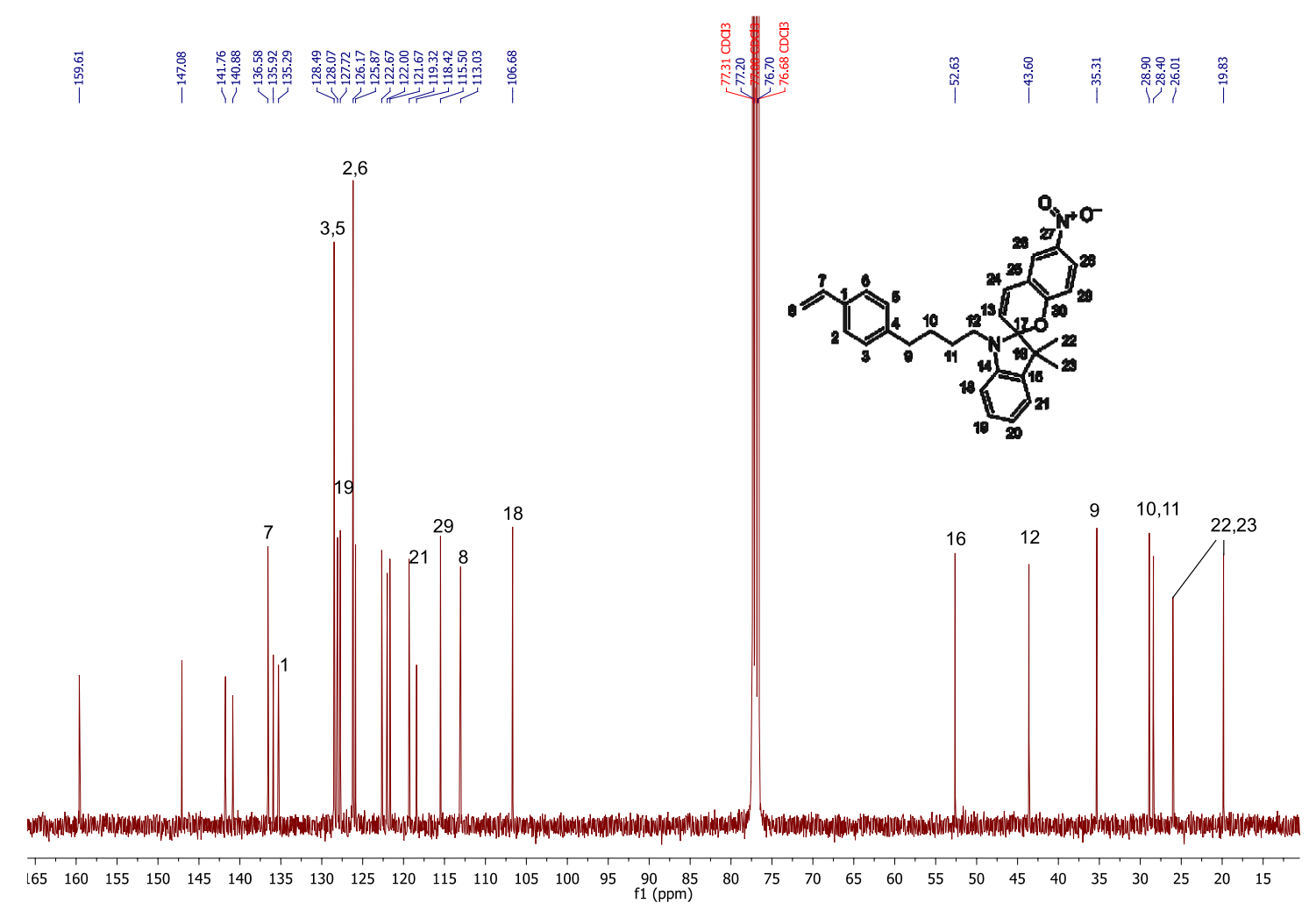

Figure $41 .{ }^{13} \mathrm{C}-\mathrm{NMR}$ spectrum of mSP-PS (7) at $100 \mathrm{MHz}$ in $\mathrm{CDCl}_{3}$ (all peaks were not assigned due to overlap in ${ }^{1} \mathrm{H}-\mathrm{NMR}$ spectrum) 


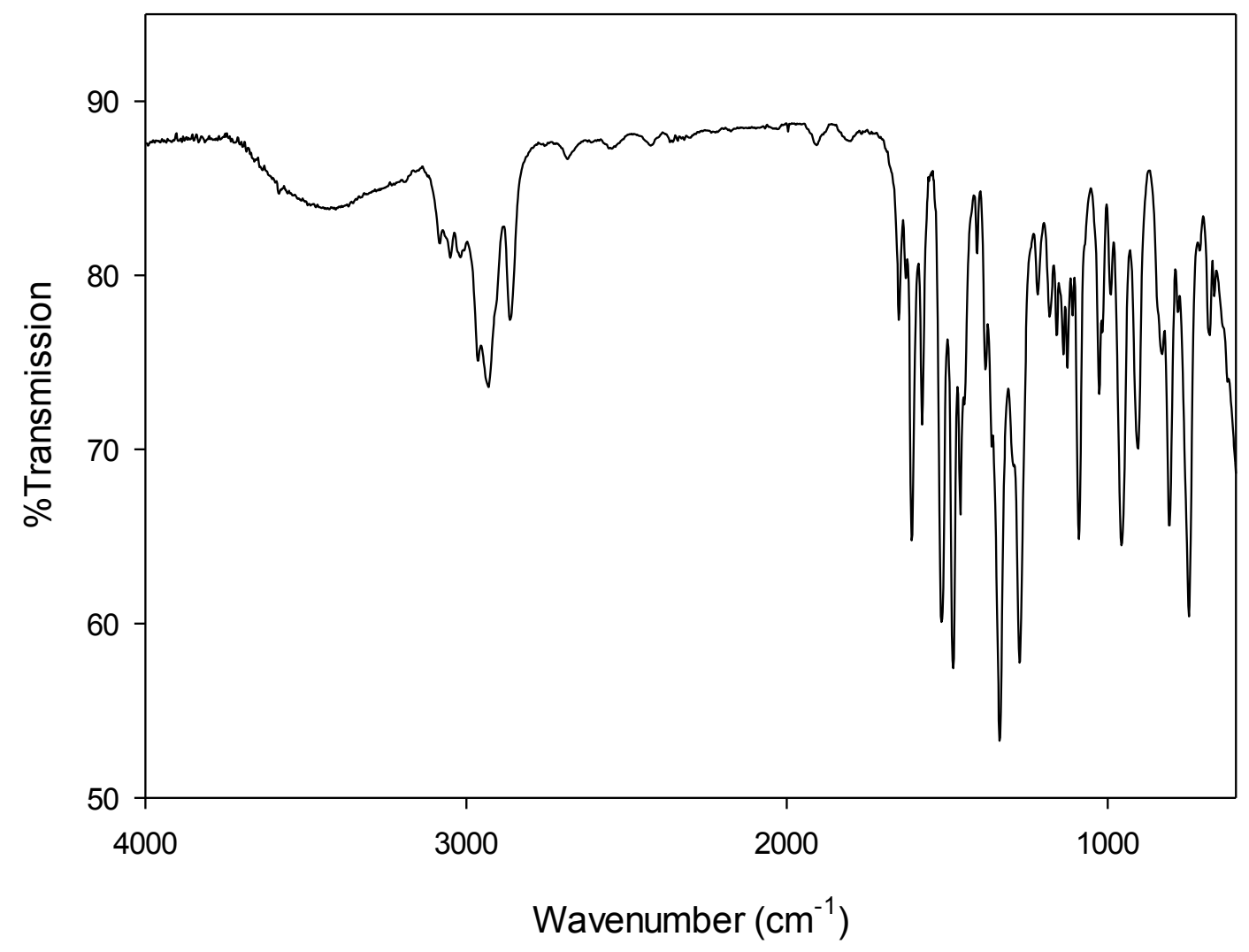

Figure 42. IR Spectrum of 7 in a $\mathrm{KBr}$ Pellet 


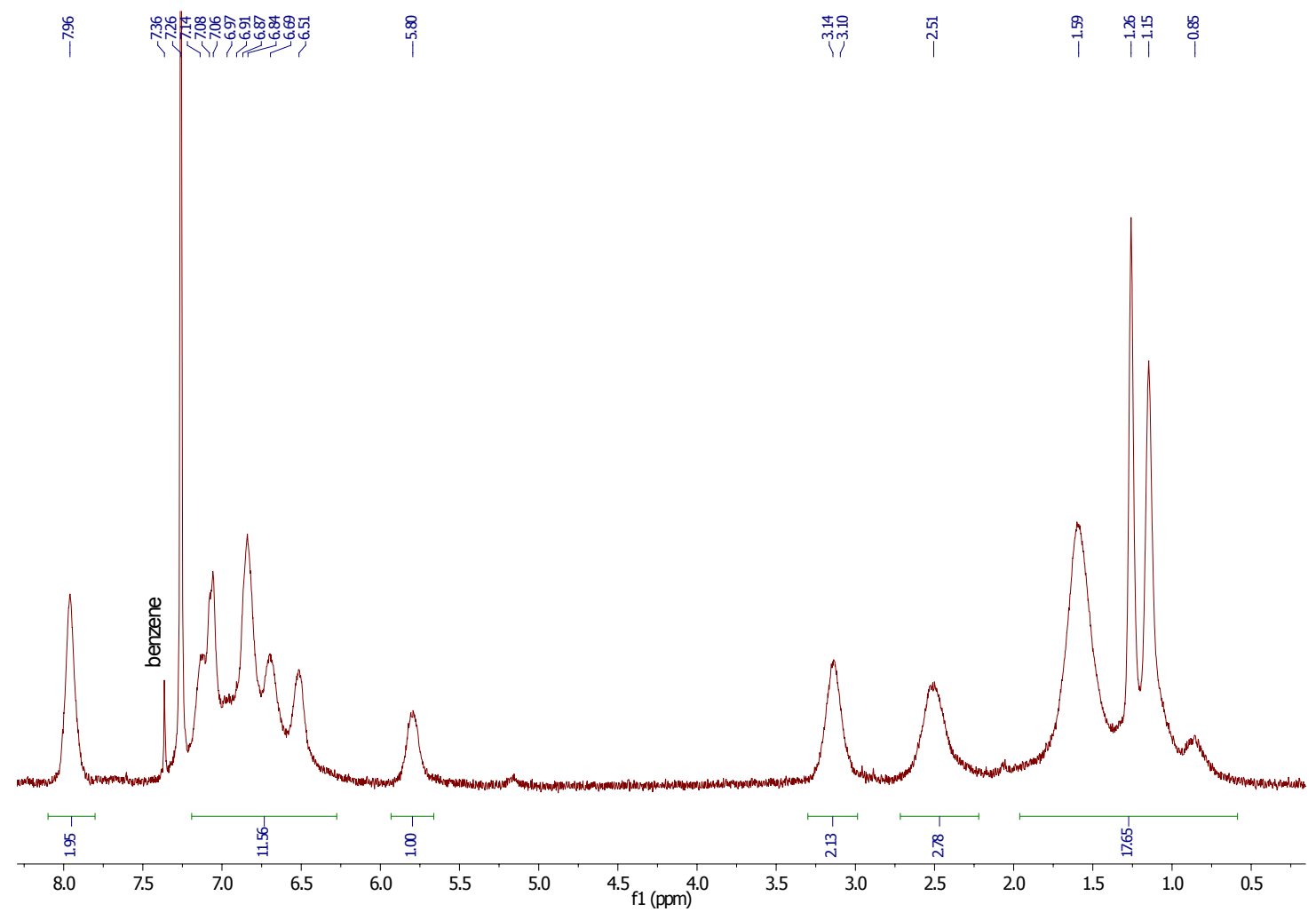

Figure $43 .{ }^{1} \mathrm{H}-\mathrm{NMR}$ spectrum of 8 at $400 \mathrm{MHz}$ in $\mathrm{CDCl}_{3}$ 


\section{Appendix 2 - Additional LED Information}

All LEDs were purchased from LED Engin and possess nominal and maximum current drives of $1000 \mathrm{~mA}$ and $1200 \mathrm{~mA}$, respectively.

Table 4. Additional LED information (*the royal blue LED was a Luxeon Rebel LED)

\begin{tabular}{c|ccc}
\hline LED Colour & $\begin{array}{c}\text { Catalog Number } \\
\text { (From LED Engin) }\end{array}$ & $\begin{array}{c}\text { Dominant } \\
\text { Wavelength } \\
\text { (nm) }\end{array}$ & $\begin{array}{c}\text { Typical Flux } \\
\text { at 1000 mA } \\
\text { (lumens) }\end{array}$ \\
\hline Ultraviolet & LZ10UV00 & 365 & 1120 \\
Royal Blue & LXML-PR01* & 447.5 & - \\
Green & LZ10G100 & 523 & 200 \\
Amber & LZ10A100 & 590 & 105 \\
\hline
\end{tabular}




\section{Appendix 3 - Statistical Analysis of Films}

The t-test results (obtained using Statplus: mac LE 2009) for comparison of reversibility rates of films with or without $\left[\left\{\mathrm{Ru}\left(\mathrm{NH}_{3}\right)_{5}\right\}_{2}(\mu \text {-dicyd)][BPh} 4]_{4}\right.$.

Table 5. T-test results of films undergoing optical reversibility

Comparing Means [ $t$-test assuming equal variances (homoscedastic)]

\begin{tabular}{|c|c|c|c|}
\hline \multicolumn{4}{|l|}{ Descriptive Statistics } \\
\hline VAR & $\begin{array}{l}\text { Sample } \\
\text { size }\end{array}$ & Mean & Variance \\
\hline & 2 & 41.76545 & 132.68694 \\
\hline & 2 & 4.98785 & 117.1108 \\
\hline \multicolumn{4}{|l|}{ Summary } \\
\hline Degrees Of Freedom & 2 & Hypothesized Mean Difference & $0 . E+0$ \\
\hline Test Statistics & 3.29082 & Pooled Variance & 124.89887 \\
\hline \multicolumn{4}{|l|}{ Two-tailed distribution } \\
\hline$p$-level & 0.08125 & t Critical Value (5\%) & 4.30265 \\
\hline \multicolumn{4}{|l|}{ One-tailed distribution } \\
\hline$p$-level & 0.04062 & t Critical Value (5\%) & 2.91999 \\
\hline
\end{tabular}

Table 6. T-test results of films undergoing thermal reversibility

Comparing Means [ $\mathrm{t}$-test assuming equal variances (homoscedastic) ]

\begin{tabular}{crrr}
\hline Descriptive Statistics & \multicolumn{3}{c}{} \\
\hline VAR & Sample & Mean & Variance \\
\hline & size & 78.05615 & 10.02669 \\
& 2 & 89.30235 & 0.05893 \\
\hline
\end{tabular}

\begin{tabular}{lrlr} 
Summary & & & \\
\hline $\begin{array}{l}\text { Degrees Of Freedom } \\
\text { Test Statistics }\end{array}$ & 2 & $\begin{array}{l}\text { Hypothesized Mean Difference } \\
\text { Pooled Variance }\end{array}$ & $0 . \mathrm{E}+0$ \\
Two-tailed distribution & 5.00806 & & 5.04281 \\
\hline$p$-level & & & 4.30265 \\
\hline & 0.03763 & $t$ Critical Value (5\%) & \\
One-tailed distribution & & & 2.91999 \\
\hline$p$-level & 0.01882 & $t$ Critical Value (5\%) & \\
\hline
\end{tabular}

